\title{
THE PERCY SLADEN TRUST EXPEDITION
}

\section{THE INDIAN OCEAN IN 1905,}

UNDER THE LEADERSHIP OF

\author{
MR. J. STANLEY GARDINER.
}

\section{No. I.-DESCRIPTION OF THE EXPEDITION. \\ By J. Stanley Gardiner, M.A., F.L.S., Fellow of Gonville and Caius College and Demonstrator of Animal Morphology in the University of Cambridge, and C. Forster Cooper, M.A., Trinity College, Cambridge.}

(Plates 1-10 and 23 Text-figures.)

Read 21st February, 1907.

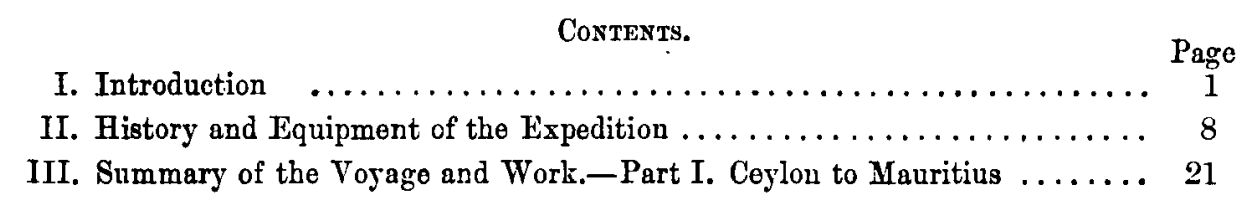

\section{IN'TRODUCTION.}

MEN of science have always been attracted by the study of the former distribution of land and water upon our globe. We see continual modifications caused by the action of large volumes of water upon its shores, also by rain and wind, by heat and frost, by subterranean explosions, and so forth. We are led, in the hope of prophesying the future, to enquire to what extent these agencies are at work in altering the face of the habitable world at the present time.

A glance around reveals to us a numerically large series of organisms, endowed with life and with powers of growth and reproduction. We require to know those changes in our world through which their ancestors have lived-changes which without doubt have largely moulded their present morphological forms. Cases are known of similar organisms occurring in strictly localised situations, often widely separated, even to the extent of having half the globe between them. Such a phenomenon at once arrests our attention, and we search for reasons for so extraordinary a distribution. Were only a few such cases to occur, we might be tempted to pass them by as a matter of chance SECOND SERIES.-ZOOLOGY, VOL. XII. 
resemblance. In reality the contrary is the case. When we examine further, we find a considerable number of sets of widely separated localities with the same or closely allied forms inliabiting them, and for this some explanatory cause must be sought out.

Each of the larger groups of animals, and in the case of vertebrates each of the subgroups, found in a locality may point to a new geographical relationship for that locality. The explanation for this must be sought not only by a careful study of the structure and bionomics of many generations of many living forms, so as to obtain a clear understanding of the modes by which they have evolved, but also by examining the past types themselves. We are compelled to believe that all existing forms have arisen by some process of evolution from primitive parents living in a past age, and we require to know its laws in order to appreciate the reason why so many living organisms have such peculiar distributions.

The question naturally arises, how many generations of a hypnthetical species, genus, or family can remain the same in any two localities-such, for instance, as Ceylon and Madagascar? Is it capable of existing in the two places for an indefinite time in the same form? Can it in the two places evolve along parallel lines so as to remain identical after the lapse of ages? Or, what is equally important in distribution, can two organisms, of different genera, families, or groups, undergo such a change, by what is termed convergent evolution, that they must be placed by systematists in the same genus, family, or group? While we can give no definite answer to these questions, our view is that both parallelism and convergence do take, and have taken, place to a far greater extent than is usually supposed. We believe that these two phenomena go far to explain many of the similarities between the organisms of different lands. For instance, does the occurrence of Epyornis in Madagascar and Dinornis in New Zealand imply a close and recent connection between these two islands, or do they represent a case of convergent or parallel evolution from different ancestors or from some older and more widely distributed Ratite or Carinate? Or, again, are we to postulate the recent union of our three southern continents in order to account for the distribution of the ostrich, rhea, and emu? We believe not. On the other hand, we do find that the resemblances between the organisms of certain localities are too close to admit of any explanation founded on convergent evolution. In these cases the previous existence of a land-connection becomes a necessary corollary. In examining a single locality we may also find that we must demand different land-connections, in order to account for the distribution of different groups of organisms, though we must aways bear in mind the fact that all groups of organisms did not appear at the same geological period. We next require the geological dates of these land-connections. In this respect isolated forms of once dominant and widespread groups are often of peculiar interest. And, lastly, we should study more particularly such deposits as form the land in order to trace out and localise the lines of connection.

The study of animal distribution postulates the existence in past times of four great land-connections. These occurred between Asia and North America, via Behring Straits (in Pliocene times), between Australia and Asia across Malaysia (Cretaceous), between South America and Africa (at the commencement of the Tertiary), and between South Africa and India by Madagascar (possibly as late as the Eocene period). With 
the first three of these we have no immediate concern, but one of the chief objects of the expedition was the investigation of the extent to which the topography of the ocean-bed supports or opposes the fourth. A glance at any chart shows a mass of islands between India and Africa, some of which (the Seychelles) may be the remnants of this ancient land-connection, while others, groups of coral islands and reefs, may be built upon foundations formed by its remains. There was no evidence from the charts, as they existed before our investigation, to prevent such views appearing quite reasonable. Except a few scanty soundings by the German 'Valdivia' expedition, nothing showed the great depths found by us between the Maldive and Chagos Archipelagoes, or between either of the latter and the Seychelles. And although on other grounds we liad reasons to expect a bank between Mauritius and the Scychelles, there were no soundings to lend support to the view that the two were connected, nor could we tell whether the latter bank was in any way joined to Madagascar. Finally, it was only by the low temperatures of the deep sea that we had any indications that the Arabian and Antarctic seas were connected anywhere by a depth of over 2000 fathoms*.

Anticipating somewhat, we may at once say that we found no trace of any bank connecting these lands. The evidence from other sources, however, is so strong that the question still remains whether the ocean-bed between India, Madagascar, and South Africa may not have attained to its present deep level in the comparatively short tertiary period $t$. Our own researches in the Maldive and Laccadive Archipelagoes, of Mr. J. Y. Buchanan and Prof. Alexander Agassiz in many seas, and of the 'Siboga' expedition in the Malay Archipelago, forbid us to accept subsidence, the simplest and most comprehensive way of accounting for the disappearance of land, without further inquiries. Although prepared to find that these connecting-banks did not exist, we thought that the western part of the Indian. Ocean would present an area singularly suited for the examination of the interaction of land and sea, especially as regards the deeper currents. This anticipation was abundantly fulfilled, and our only regret is that adverse circumstances, lack of time and gear, bad weather, and the pursuit of our other work, prevented us from making more than isolated observations in this direction.

For the consideration of questions relating to the distribution of land-organisms in general, a more accurate knowledge of the present means of dispersal of land-forms, as well as of the actual forms capable of crossing large stretches of sea, seemed desirable. It might have been anticipated that the Seychelles, situated as they are in the western part of the Indian Ocean, would give definite evidence in its land-organisms of former connections with Madagascar and India. On the other hand, other islands and groups scattered orer this area, being of coral-formation, would show only those organisms

* Vidle map, p. 14 of ' The Fuuna and Geography of the Maldive and Laccadive Archipelagoes.'

† The late Dr. W. T. Blanford in his Address at the Annircrsary Meeting of the Geological Soniety in 1890 (p. 98) said: "The evidence relating to the old land-connexion between India and South Africa has been given at greuter length than would otherwise have been necessary becuuse of its inportance, and because this is a crucial case. So fur as I am able to judge, every circumstance as to the distribution of life is consistent with the view that the connexion between India and South Africa included the Archæan masses of the Seychelles and Madagascar, that it continued throughout Upper Cretaceous times, and was broken up into islands at an early lertiary date. Great depression must have taken place, and the last remnants of the islands are now doubtless marked by the coral atolls of the Laccadives, Maldives, and Chagos, and by the Saya de Mulha bank." 
which are capable of being dispersed across the surface of the ocean. It is too early as yet to prophesy how far we shall realise the first of these anticipations, although we did find traces in the Seychelles of the existence of an infinitely larger fauna than occurs at present. The second anticipation proved true, and we hold large collections from the islands of the Chagos Archipelago, from Coetivy, and from other places, which we trust will throw light on the methods by which oceanic islands receive their population. An ideal type of locality for such a study would be an oceanic island, whose neighbouring continents have had their faunas and floras thoroughly well described. In the Atlantic such islands as exist are open to the suspicion of former connection with continents, while the organisus of the oceanic islands of the West Indies have been too much changed by man for any accurate estimate to be possible of the causes of their distribution. The Pacific is a vast ocean and the organisms of its surrounding continental lands are but little known. The Indian Ocean, therefore, seemed to be the most suitable, and it was felt that special attention should be paid to the question.

As another point bearing on the above questions, we studied the interrelations of fauna to flora, and of both to the soil, and other features of the environment. In this we were aided by our own experimental studies in the Maldives and Minikoi. Each generation of mankind may be expected to improve on the work of its predecessors, and our own studies on this, the foundation problem of distribution, must themselves be regarded as purely tentative and solely of utility in pointing out lines along which future work may proceed.

We now turn to a fresh problem in distribution, the question of the dispersal of marine organisms through the water of the globe. The factors in operation here are currents, tides, food, the possession of swimming larvæ, and the power of living at varied ranges of depth, whereby deep-living forms can ascend or descend the submarine slopes in order to migrate into new grounds. We know that the deeper seas contain animals of wide distribution and great similarity. Of these most forms are confined to deep water, though we do get striking anomalies in vertical range, such as in the genus Proneomenia found by the 'Siboga' from 18 to 3088 metres, from $27^{\circ} \mathrm{C}$. to $2.9^{\circ} \mathrm{C}$.*

When we actually come to examine the question, we find that we do not know where shallow-water faunas end and the deep begin, or whether they gradually merge into one another. In going through the work of the many expeditions since the 'Challenger,' we were struck with the relative paucity of observations under this head and by the scarcity of dredgings, from which information might be expected. Even the depth to which marine plants could live seemed uncertain. Taking these points into consideration, we decided to confine our dredging to the examination of moderate depths, especially areas from 50 to 300 fathoms. To this end we had arranged to spend at least two months in the Chagos Archipelago, a place from which especially good results were to be expected on account of its isolated situation. But to our dismay we were prevented in our designs, as our dredge-wire did not reach us till after our arrival at Mauritius. From there we still had a large stretch of ocean to traverse, and time

\footnotetext{
- 'Introduction et Description de l'Expédition,' par Max Weber, p. 120.
} 


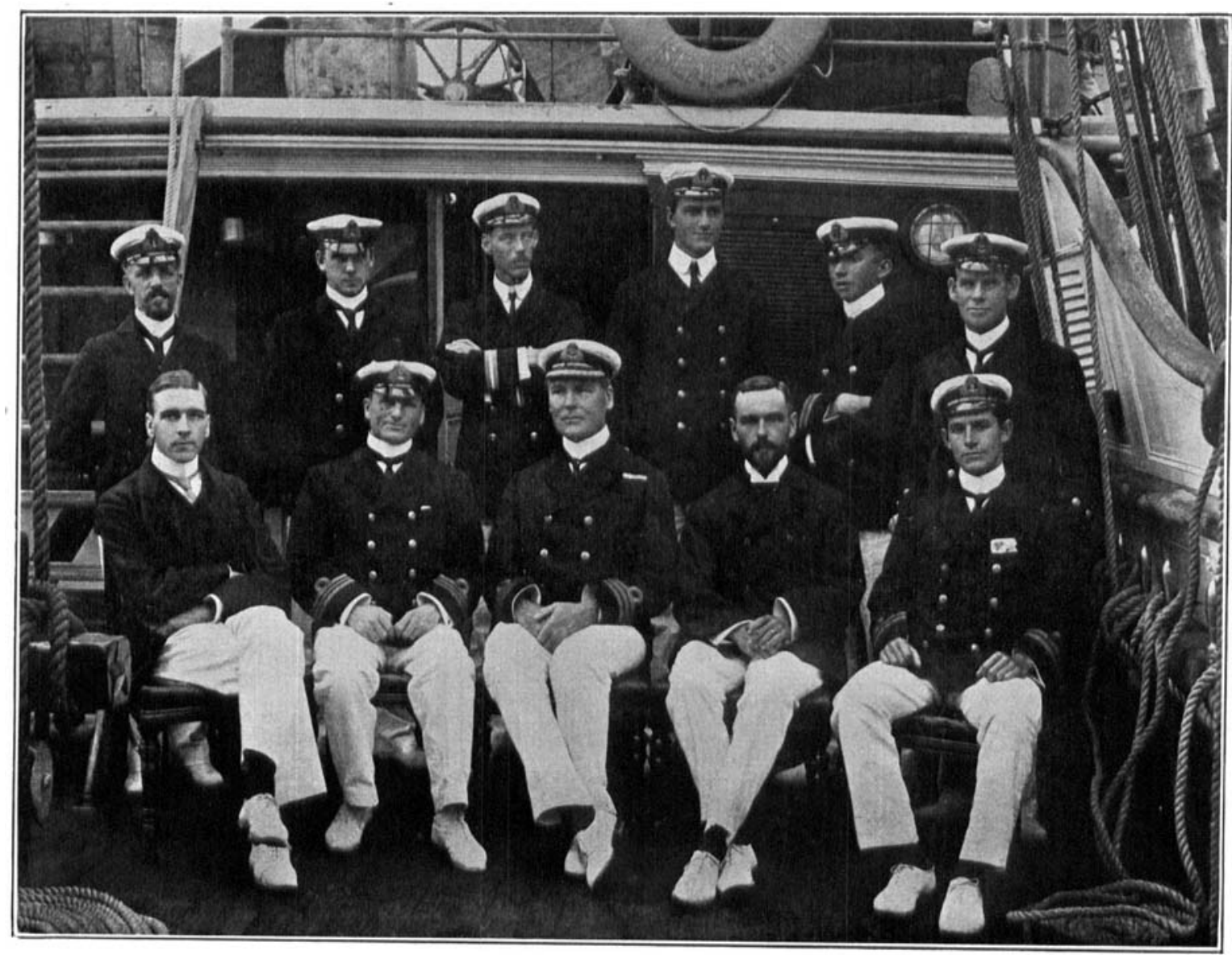

Mr. Ber Mr. Evans Mr. B. Fuetcher Lient. Craven. Sugeousimpan. Mr. Alexander (Euyineer). (Bontswnin). ('aymaster). (Surv. Bontswain).

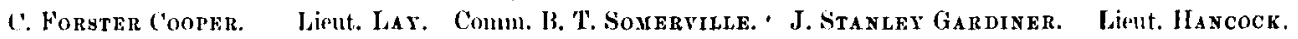

Flg. 1.-Officers and Naturalists on H.M.S. Sealark. 
and other plans would not allow us to devote as much attention to this point as we should have liked. Consequently we had to select our dredgings carefully, each for its own specific purpose-and the collections from this source are disappointing in quantity, though perhaps not in quality.

The distribution of the shallow-water organisms of marine slopes presents problems very similar to those of the land. It is complicated in many classes by the presence of pelagic larvæ*, and by forms with extraordinary powers of existence on floating weed or timber. Again, environment appears to be so much less varied than on land $†$ that, the problems of convergence and parallelism become correspondingly more acute. However, our own work at Minikoi and in the Maldives impels us to believe that though involved at every turning in numerous possibilities, some light will be thrown on the question of the pre-existence of former land-areas by the study and comparisons of littoral faunas and floras. For such work our area appeared particularly suitable, and we accordingly carefully collected the fauna and flora of each locality visited, making specialities of Salomon Atoll and Coetivy $\ddagger$.

Our own researches in previous expeditions have been largely concerned with the formation and growth of coral-reefs and the bionomics of the organisms which form them. It will be olvious to what an important extent these are related to the previous problems. All research on these questions, if rightly applied, is of practical importance, but the main scientific interest lies in the question as to whether coralislands owe their origin to subsidence or not. Granting that a land.connection once existed between India and Madagascar, we should surely expect to get an idea of its topography traced out in some degree by coral-reefs, if it fell victim to a gradual subsidence (unless, indeed, physical conditions were then vastly different-a not inpossible contingency). To elucidate this point we were careful to fill as many gaps in our knowledge of the occan-floor as possible. Particularly we aimed at getting all possible information about the topography of the Chagos Archipelago in view of its either half-drowned or upgrowing banks; and here it will be enough to state that in this group of atolls, which have been the subject of much controversy, not a single bottomsounding previously existed between any of its shallower banks. We felt, moreover, the necessity for further information of every character about the totally submerged

"Vide "Notes and Observations on the Distribution of the Larvæ of Marine Animals," by J. Stanley Gardiner, Ann. Mag. Nat. Hist. ser. 7, vol, xiv. (Dec. 1904).

† We would at once point out that the faunas found on the slopes of continental lands barred by coral-reefs, and those not so protected, are very distinct even in non-reef-building animals. The mere fuct of a slope being calcareous or siliceous appears to cause a divergence. Again, there may be differences between the animals on continental coral-slopes und the coral-island slopes in their immediate vicinity, such as actually exist on those of Ceylon and the Maldires and Iaccadives. But this instance perhaps may be really due to the inability of certain animals to cross the interrening seas. Everswhere the presence or absence and the nature of the seaweeds is a factor of primary importance to the fauna. Enough, however, has been said to show the caution requircd in dealing with the problems that arise.

\# While, on the one hand, we might hope to lay foundations (in the study of the possibilities of dispersal from the actual distribution of littorul organisms) for the more accurate delineation of land and sea in past ages, we cannot be blirs to the fact that, if a land-connection disappeared along our line by slow and long-continued subsiajence, we may have at every point remains of a littoral fauna once continuous throughout the whole line.

SECOND SERIES.-ZOOLOGY, VOL. XII. 
Saya de Malha and the partially sulmerged Nazareth, Amirante, and Seyclielles Banks. The presence of hills marked in the charts of many of the islands between the Sejchelles and Madagascar pointed to the possibility of their being in an area of elevation. And, finally, we required more definite infosmation as to the existence of raised corallimestones in Mauritius and the Serclielles. The distribution of the fringing reefs in the latter locality, as marked on the charts, secmed unusual, while in Farquhar we lioped to find a new type of shallow-lagooned atoll which would throw some light on Aldabra-an island of great interest from the presence of gigantic land-tortoises (Testudo elephantina).

Such were the chief motives which directed the course of the Expedition. How far they have been successful we must leave others to judge, when the reports are all published. In addition to these main objects much routine-work was involved, such as the taking of water-samples, temperature observations, plankton collcctions, and in noting meteorological phenomena. From the commencement of our work we recognised the necessity of restricting ourselves to limited areas, instead of spending time in making isolated observations during the long ocean-passages. Yet we now feel that our ground and work were several times too large for the time and facilities at our disposal. We cannot, we fear, do more than claim to have, in some degrec, paved the way for another expedition over the same area, and by our failures and successes to have indicated problems to be solved and their most promising methods of attack.

\section{History and Equipment of the Expedition.}

Undoubtedly the greatest biological cxpedition ever sent out by any country was that of H.M.S. ' Challenger.' It stands pre-eminent in originality and comprehensiveness of aim, in duration, and in results. It investigated every side of oceanography, lasted over four years, and extended round the whole world; in its publications, to which many of the most distinguished men in Europe contributed, it brought new facts to light bearing on every aspect of the ocean and on every group of animals and plants. 'T'ue, it was only a pioneer expedition, but the far-sightedness of its director and of the editors of its reports made it a model which has rarely bcen equalled, never surpassed, by the few expeditions which have since left European and American shores.

Only one ocean was omitted in the scheme of the 'Challenger' Expedition, the Indian, which, it was confidently believed, would be subsequently examined by the enterprise of the Indian Government-an anticipation which thirty years afterwards still awaits any attempt at verification. Meantime this ocean has become much better known in its topographical and physical features by the exertious of H.M. Surveying Vessels belonging to the Home and Indian Governments, by the soundings of 'Telegraph Companies, and a special German scientific expedition, that of the 'Valdivia.' Except for the latter, and for such observations as the naturalists on the Indian Survey-Ship 'Investigator' were permitted to undertake, its biology remained almost unknown, though the work of numerous naturalists on its continental coasts gave us a fair idea of their fauna and flora. 'The 'Valdivia' Expedition made a rapid traverse along a route 
from Kerguelen to Cocos-Keeling, Sumatra, Nicobar, Ceylon, South Maldives, Chagos, Seychelles, and Zanzibar, while the 'Investigator's' work was contined to the Indian slopes. Little, however, had become known about the geology, fauna, and flora of the islands. To the east Cocos-Keeling had been re-examined by Guppy, and Christmas Island opened up to us by the liberality of Sir John Murray. Since Moebius's and Balfour's visits, in connection with the Transit of Venus Expeditions in 1875, our knowledge of the Mascarene Islands, Mauritius, and Rodriguez and Reunion had scarcely increased. Of the remaining great mass of islands and reefs between Madagascar, South Africa, and India we knew hardly more in 1905 than we did in 1875, excepting only the Seychelles, where steady work had been done. We ourselves, in 1899 and 1900, followed by Prof. Alexander Agassiz in 1901, carried our knowledge to some degree southwards from Minikoi, the most southward of the Laccadives, to the south of the Maldives; but of the Great Chagos Archipelago, for example, we had practically no information beyond that to be found in the Admiralty Sailing Directions and a short paper by G. C. Bourne on Diego Garcia *.

Indeed, of all cceanic areas none seemed so little known in 1905 as that between India and Madagascar, while to the oceanographer and to the more specialised students of coral-reefs and of problems of distribution none seemed more urgently to demand investigation. We have his own authority for saying that over twenty-five years ago the late Dr. W. T. Blanford applied for such an investigation as that of H.M.S. Sealark in 1905 to enable him to arrive at a clearer comprehension of the various geological and biological problems which met him at every turn of his work in India. His view of the importance of such an investigation is clearly indicated later on in his Presidential Address to the Geological Society in 1890. He expected discoveries along that line which would show more definitely the former union of India and S. Africa, expectations shared by the great majority of geologists and biologists who had to deal with those lands. While Gardiner, as his chart shows + , did not expect the existence of any line of shallower water between these two lands, he required a similar investigation for the completion of his work and for the solution of many other obscure problems. It was, moreover, pointed out to him by many friends that it was clearly his duty to endeavour to carry his investigations still further to the south, and to attempt to test more fully his views on many points. A circular letter, accompanied by a scheme of a proposed expedition, met with such a flattering response that early in 1904 he decided to petition the Royal Society to take up the question of such an expedition. We were bappy in that the Royal Society endorsed the scheme, and decided to approach the Government on the matter. We had hopes that the Government of India, like the Government of the Dutch East Indies in the case of the 'Siboga' Expedition, might have seen its way to undertake to give us the assistance we required for our plans, but it was the Admivalty that finally decided to place a vessel during six months of the summer of 1905 at the disposal of the senior of us for the work. This decision we could not regard but with feelings of great satisfaction, since it was with the Admiralty

* Proc. R. S. vol. xliii. pp. 440-61 (1888).

† 'Fauna and Geography Maldives and Laccadives,' p. 14.

SECOND SERIES.-ZOOLOGY, VOL, XII. 
that practically every English marine expedition since the time of Cook had been irlentified. The Admiralty has always taken a broad and liberal interest in all matters relating to oceanographical exploration, and we venture to suggest that its officers in this field have given it glory as imperishable as that of its militant branch. Its alliance with civilians in some of its work is no new matter-and long may it continue!

We would like in this place to express our indebtedness to those gentlemen who assisted us by procuring the grant of a vessel, by aiding us in drawing up our scbeme, by allowing us to give their names as references in our petition to the Royal Society, and by practical advice in many ways, viz.: Colonel Alcock, the late Dr. W. T. Blanford, Mr. J. Y. Buchanan, Capt. Creak, the late Sir Michael Foster, Dr. Gadow, Prof. Herdman, Prof. Hickson, the late Prof. Howes, Prof. Judd, Prof. Ray Lankester, Sir John Murray, Prof. A. Newton, and Mr. Adam Sedgwick. To the expert knowledge of the late Rear-Admiral Sir W. L. Wharton, formerly Chief Hydrographer, and to Capt. Tizard, we owe a thorough overhauling of our plans and a full consideration of the methods by which they could best be fitted in with the ordinary work of a vessel. For help in the early stages of preparation, as well as throughout the whole Expedition, we owe much to the keen personal interest and goodwill of Capt. (now Rear-Admiral) Mostyn Field, the present Chief Hydrographer, under whose immediate orders the Expedition was carried out. We would also express our deep appreciation of the generous leave of absence from official positions granted to one of us (Gardiner) by the University of Cambridge and by Gonville and Caius College.

The Admiralty very generously undertook all expenditure connected with the employment of a vessel, and allowed us to use such gear as is ordinarily carried. Oceanographical research, however, at the present day requires the employment of much costly special equipment, and the expenses entailed in getting together and preserving representative collections, and subsequently in sorting and sending them out to specialists, are by no means light. Tu meet these, we were in the first place granted $\$ 150$ by the British Association towards the more geographical parts of the work. The Managers of the Fund in Cambridge founded in memory of the late Francis Maitland Balfour, as the Student of which the previous researches of one of us (Gardiner) in the Maldive and Laccadive groups had been undertaken, generously gave $£ 350$ for the further prosecution of the same work. Finally, the Trustees of the Percy Sladen Memorial Fund, the history of which is given in the first pages of this volume, undertook financial responsibility for such further expenditure as might be necessary and which we could not ourselves meet. Under these circumstances they might-and perhaps rightly-have claimed the direction of the work, but in the most generous manner they left us an absolutely free hand. To one of their number (Prof. Herdman) we owe many acts of kindness and much valuable criticism and advice.

The vessel placed at our disposal was the most recent addition to the surveying-fleet of the Admiralty. Built in 1880, and christened the 'Wanderer,' she was bought into the Service in 1904, specially refitted at Southampton for surveying, and renamed the 'Sealark.' Originally a square-rigged vessel, she was to some degree remasted and 
fitted with fore and aft sails. She had already auxiliary steam, with a two-bladed propeller. Her tonnage is 900 tons and coal-capacity 95 tons in the bunkers and, on emergency, 30 tons on deck. Her economical consumption is 9 tons per diem at 8 knots, this giving her a steaming-range under very favourable conditions of about 2500 miles. Of her sailing-capacity we had little experience, winds being generally contrary. She had a ligh forecastle, bridge forward, a deep waist, and a high poop. Unfortunately there was really no accommodation beyond what was required for her own officers and crew. Her deck-space was limited, but the poop was most generously given up to us as far as possible for our gear. Her boats consisted of two steamboats, two whaleboats, two skiffs, and a dinghy. Her complement was 100 officers and crew (Pl.2).

We were singularly fortunate in that the Sealark was entirely officered from the Surveying Branch of the Navy, so that we were able to resign all topographical, meteorological, and indeed most oceanographical work of a physical character into other hands. She was under the command of Cornm. Boyle T. Somerville-a most skilful hydrographer and a most charming man,--who took the keenest interest throughout and who assisted in every part of the work. In particular, he took all the observations for magnetic variation, and undertook the examination of the bottom-samples as they came up, a proceeding necessary for getting indications of shallow banks in the vicinity. To his unfailing interest, courtesy, and kindness any geographical success that the Expedition may have met with must be largely ascribed, as must all the pleasant relations which throughout existed on board. The other officers of the ship were Lieut. Lay (Navigator and Senior Surveyor), Lieut. Hancock (1st Lieutenant), Lieut. Craven, Mr. Alexander (Boatswain on Special Service and 2nd Class Surveyor), Mr. Beer (Engineer), Mr. Evans (Boatswain), Paymaster Bainbrigge T. Fletcher, and the late Surgeon Simpson, each of whom most cheerfully assisted us in every way in his power.

Detailed description of the equipment of a vessel for such work as we were undertaking is unnecessary. For sounding there were on either side of the forecastle Lucas machines, each holding 5000 fathoms of wire. The position was an especially good one, because the officer on duty could watch the sounding and communicate with the engineroom when necessary. Each machine was provided with a large driving-wheel, which could be instantaneously connected to the winch, situated at the base of the mainmast, by leads attached to the rigging. A Lucas machine consists of a large drum carrying piano-wire, with a flattened rim to which brakes can be instantaneously applied. From this the wire is led over a guiding-wheel of known circumference (generally half a fathom), which is carefully adjusted so as to revolve absolutely freely. On one side of the frame which supports this is an indicator, on which the number of fathoms can be read off as the wire runs out. The movements of the ship when sounding are remarkably simple, being only such as are required to keep the wire vertical, the ship being laid at starting with the wind about one point off the starboard or port bow in accordance with which machine is being used. The machine is very accurate, and each sounding is to a certain degree checked, since, in "heaving in," the indicator registers the backward revolutions of the wheel and should return to zero; if it does not, a fresh sounding is at once taken on the same spot. The rate at which the wire runs out depends upon the 


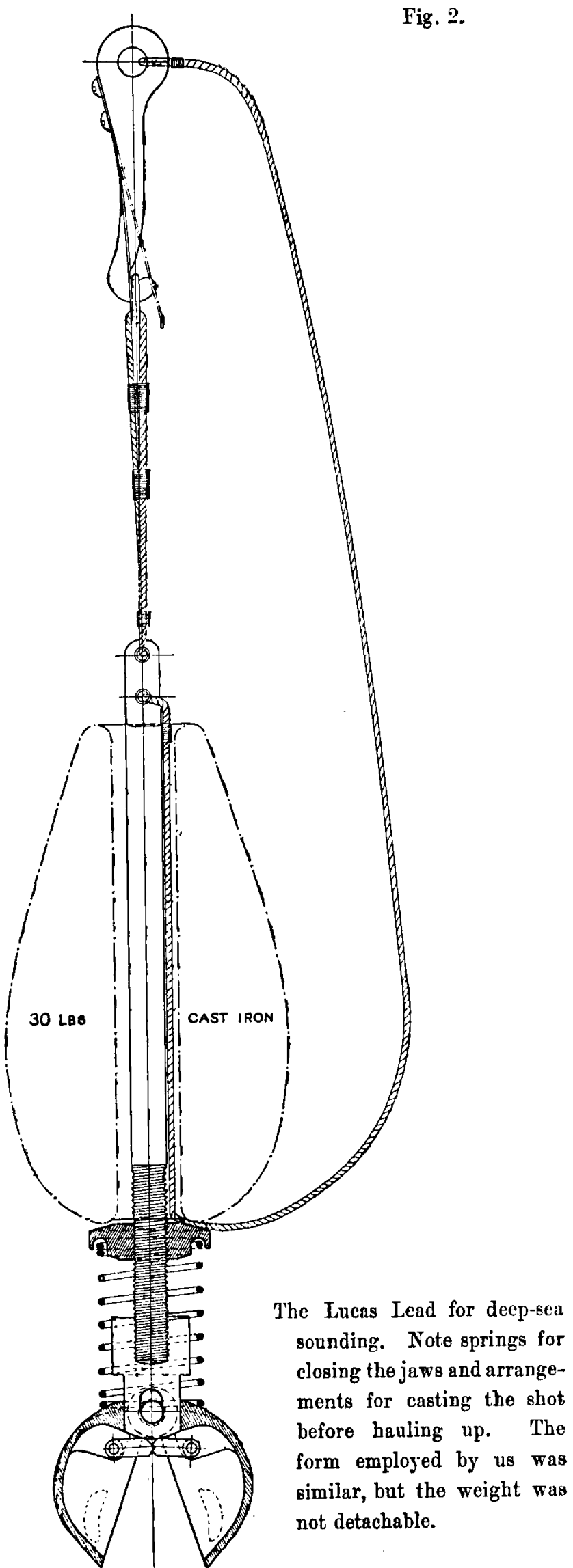


amount of brake placed on the drum. A sounding of 2000 fathoms, from the time that the order is given until the ship proceeds again upon her course, does not generally take more than an hour (Pl. 4).

The weights are connected with the sounding-wire by stout pieces of hemp about 3 fathoms long, so that an indication of the bottom having been reached is received at the machine before the wire can itself touch the bottom. The leads employed by us were three in number-the old valved lead so often described; the modification of the last regularly employed for deep-sea sounding, which consists of a tube with valves running into the middle of the weights, the latter being mechanically detached as soon as the bottom is touched; and, lastly, the Snapper Lead, invented by Mr. Lucas. For most of our work we found the latter by far the best lead for procuring samples of the bottom, particularly for soundings below 1000 fathoms and on more or less hard bottom. The form that we employed unfortunately had no detachable weights, and the whole of its 28 or $30 \mathrm{lbs}$. had to be heaved in by the machine, this weight in a seaway sometimes throwing an undue strain on the sounding-wire. 'The apparatus itself consists of a steel shaft (ending in a ring for attachment) extending through the centre of a conical lead. At its lower end the latter is hollowed out so that a spiral steel spring can be inserted around the shaft; this acts upon two brass spoons, which are hinged on to the end of the shaft, and which, when closed, fit tightly upon one another. The box so formed is kept open by a sear while the lead is sent down, but its sides at once snap up tightly when it strikes anything. It seldom fails to bring up a sample of the bottom-a small handful of sand, a few pieces of rubble, or fragments detached from the rock beneath (see fig. 2).

The thermometers employed for the ship's use were of the usual old maximum and minimum type, as supplied by Cary, and Negretti and Zambra. When sounding in the deep sea, one is attached to the sounding-wire just above the lead. In addition we employed them in series at every 50 or 100 fathoms down to 800 fathoms, attaching them to a wire of a smaller Lucas machine fixed on a platform on the port side of the poop, lowering slowly, and heaving in by hand. Their readings may be relied on to a quarter of a degree. In addition, we ourselves employed, generally in pairs, Richter's reversingthermometers, as approved by the International Bureau for the Exploration of the Sea. They reverse by messenger or by propeller. Careful tests showed that the latter, after we had readjusted it, released the frame so that it swung over after passing through about 7 fathoms of water, and although not so reliable as the messenger form, the error of its thermometers from every cause did not, we think, exceed one-tenth of a degree. The propeller form has the inestimable advantage that several thermometers may be attached as the wire runs out so as to reach different depths. The temperature of the surface-water of the sea was taken in a narrow canvas bucket by a specially tested thermometer. This receptacle was very satisfactory, as we found by experiment that its contents, even if hung up in a strong sun, do not vary by a tenth of a degree for the first two minutes, long before which the temperature would have been read.

For the reversing instruments we employed a steel rope half an inch in circumference, consisting of six cords each containing nineteen strands. To prevent kinks and to keep 


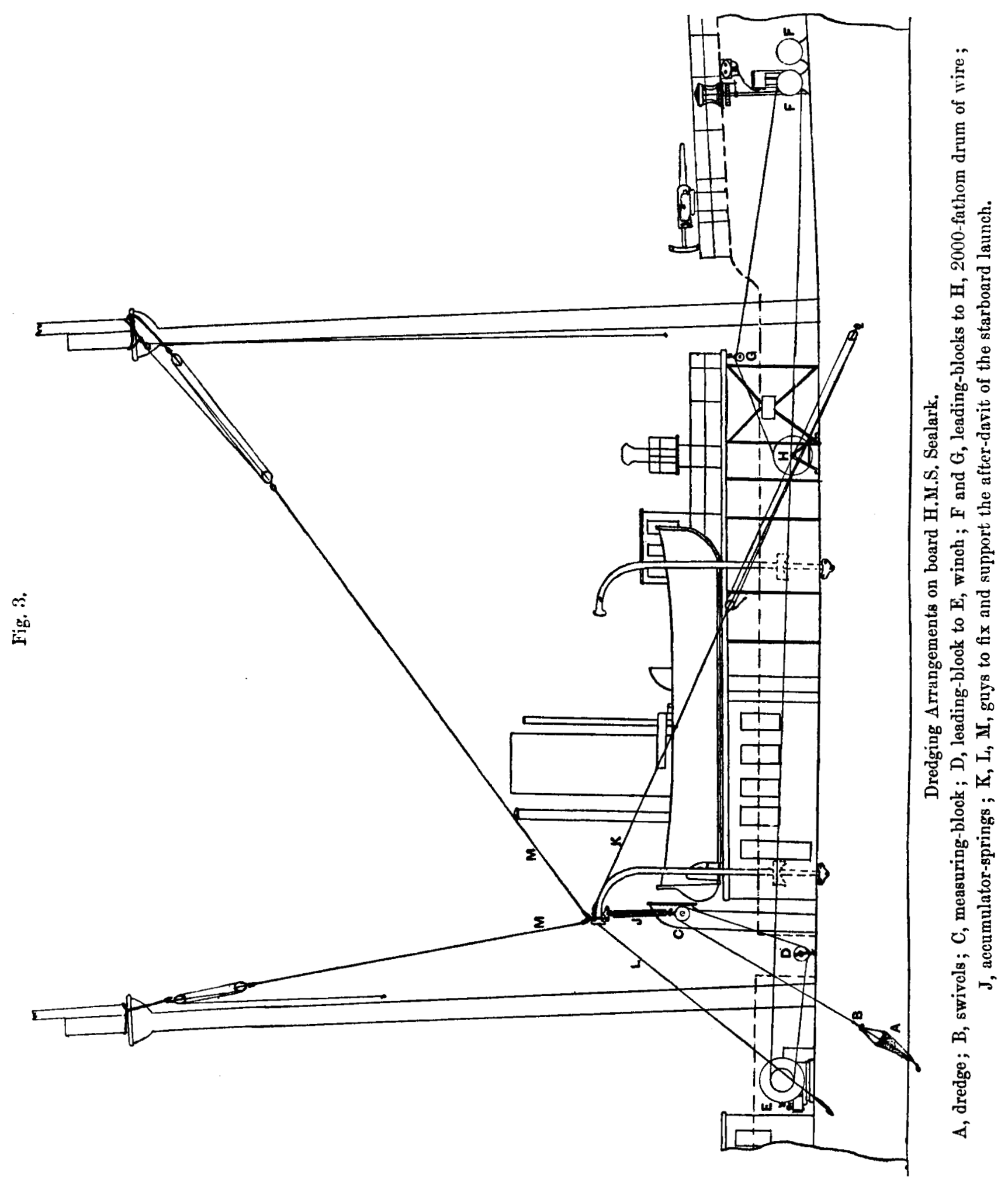


the wire thoroughly taut we used an 80-lb. lead at the tail and hauled in by the winch over a specially made $\frac{1}{2}$-fathom Lucas block attached to the steamboat's after-davit swung outwards. The water-bottles employed were of the reversing type, as recommended to us by Mr. D. Matthews and used by the International Bureau, fitted some for messengers and others with propellers. Attached to each were frames for two reversing thermometers. To store the water for analysis from the above, and also from our daily samples, we used specially blown bottles of green insoluble glass with china patent clip stoppers and rubber rings. They were fitted into felt-lined cases properly partitioned up, each containing 42 bottles and their requisite printed labels.

In dredging we used a steel rope, 1 inch circumference, 114 strands in six cords, a pattern regularly made by Messrs. Bullivant \& Co. The breaking-strain was supposed to be $4 \frac{1}{2}$ tons, but, as tested by us, it proved well able to take any load up to 6 tons. It was placed beneath the bridge on its drum, which took 2000 fathoms (fig. 3). From there the rope was led through a block under the forecastle down the starboard side to the winch, around which three or four turns were taken, thence through a lead up to the measuring-block attached to the steamboat's after-davit, the latter being especially guyed to the fore- and main-masts to stand the strain. Previous to leaving England we had obtained four spiral steel springs, each 15 inches long, with a total of 12 inches compression under a strain of 5 tons. We had intended to have a frame made for them in Ceylon, but, owing to a series of errors preventing our dredging-wire from reaching us before we got to Mauritius, we did not have them fitted up until we arrived at that island. As the distance from the top of the davit to the water was small, we placed only three in series in the accumulator, thus getting for a strain of 5 tons a compression of 9 inches, or 1.8 inches for 1 ton. To hold the wire we used a hemp stopper, which on occasions of severe strain allowed the rope to pay out somewhat, and undoubtedly saved us on many occasions. On the whole these arrangements worked admirably, but the drum for the wire should be part of the winch, or itself be capable of being wound up by steam. Such an arrangement was impossible on the Sealark, so that four hands were commonly placed on the drum to wind up the rope, but the labour was very severe. The dredges should be heaved in fairly rapidly and without stopping (which is disastrous), or the greater part of the swimming and crawling forms may be lost. One of the causes of our failures in dredging in the Chagos was undoubtedly the absence of any accumulator to show us the strain. Subsequently, after some experience, we were enabled, by watching the contraction of the accumulator, to see whether the dredge or trawl was passing over the bottom properly. Further, we were enabled in some degree to estimate the character of the ground over which we were working. We could see when we were caught up, and so could stop the ship, and by going astern trip the net if necessary. The arrangement was awkward, in that the whole of the starboard gangway had to be kept clear in case of accidents. Few of our nets could be swung clear of the water, and the delay in getting them on board by hand often caused us the loss of valuable specimens. In manœuvring tue ship during dredging our chief concern was to keep the wire rope clear of the ship and of her propeller. We would be inclined to recommend any future expedition to employ a boom from the mast, taking the strain 
on accumulators attached to the deck at the base of the mast. This method was impossible on board the Sealark, but by constant care we managed to get through fairly successfully between Mauritius and Seychelles (Pl. 4).

The dredges employed by us were of two shapes only, triangular and rectangular. The blades of the former varied from 2 to 5 feet in length, and of the latter from 1 to 6 feet. The blades of the triangular dredges were set at equal angles to one another, some bent together round their ends and others bolted through. The former generally broke at the angles, and the latter straightened and drew in the same positions. We would ourselves recommend bolts and nuts of one pattern only, and a fair supply of spare blades and handles. The same applies also to the rectangular dredges. We found it to be almost immaterial at what angle the blade is set, so long as the dredge-rope can be easily let out and hauled in. Our dredges were set at different angles, and our experience was that, steaming at about $1 \frac{1}{2}$ knots, the amount of warp to be let out varied from one and a half times the depth for a dredge with its blade at $35^{\circ}$ to four times for one with a horizontal blade. We recommend a blade set at about $20^{\circ}$, when the warp required would be about twice the depth. All dredges of a pattern should have their blades set at the same angle so as to give the best comparative results. A sharp blade on hard ground bites into the bottom better, digs up growing organisms, and chips off pieces of the rock. Unfortunately it tends to bite so deeply into masses of the relatively soft limestone-rock around coral-reefs that it is unable to break them off, with the result that in spite of all manœuvring the dredge must be broken or lost. Probably over such ground as large a number of organisms would be secured with blunt blades, and much less damage would be done. Sharp blades, however, were generally adopted by us, because they give positive information of the nature of the bottom, which can be obtained by no other means. The weight of the dredge should lie in its frame; some of our rectangular ones were not heavy enough, so that we had to lash fire-bars on to them, sometimes with not very successful results, as the extra weight must be nicely adjusted. Our best triangular dredge, with 4-foot blades, weighed about $75 \mathrm{lbs}$., and for steamship-work we would not recommend a lighter form whatever size it might be. Next we found by experience that at least two strong swivels should be placed between the warp and the dredge to prevent twisting, and that preferably they sbould be separated by a thin lead weight of about $30 \mathrm{lbs}$. Should the dredge be too light, it would be probably best to increase the weight in this position.

The nets generally employed were made of thick Manila cord and of 1- to 2-inch mesh; canvas bags were also used for obtaining large bottom samples of mud and soft ground. The nets were made fairly voluminous and attached by wire to holes bored in the backs of the blades. Those actually employed by us varied greatly in length, but for a triangular dredge should not be less than four times the length of its blades, and for a rectangular three times; all should taper, and open at the bottom. A 20-lb. shot may occasionally be attached with advantage to the cord which binds up the end of the net, as a means of preventing the net fouling the frame when descending; it also keeps it fairly taut, so that the smaller organisms cannot escape through its meshes. For rough ground we recommend spare nets for all dredges, and also spare pieces of netting. We ourselves 
used nineteen dredges, and, in spite of the constant exertions of the blacksmith, had on arrival in the Seychelles only four fit for use; but then, as already mentioned, our aim was rather to ascertain the nature of the bottom around coral-reef's than to preserve our instruments. Under no circumstances can we recommend the galvanized frames, as the process weakens the steel and flaws are less apparent.

The trawls employed were of one pattern only, a modification of the well-known Agassiz trawl, used for the first time, we believe, by ourselves. The Agassiz trawl is derived from the beam and consists of two stirrups joined together, top and bottom, by

Fig. 4.

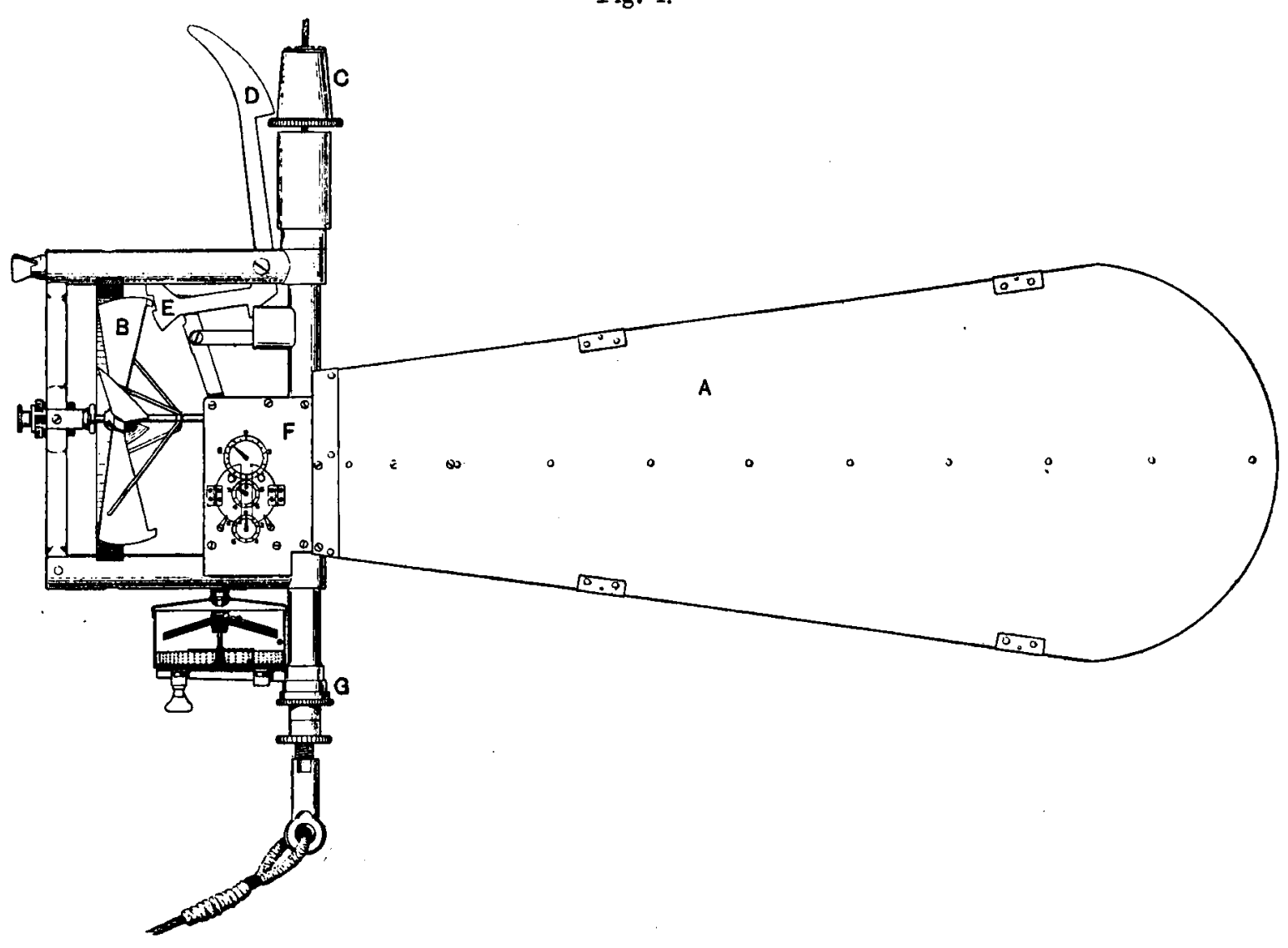

Ekhman Current Meter.

A, double vane; $B$, propeller; $C$, first messenger, which has pushed out $D$ so that $E$ no longer catches the propeller; F, measuring-dials over the compass; G, ball-and-socket joint on which the meter swings freely.

bars. Its particular merit lies in the fact that it is immaterial upon which side it falls. It is also particularly convenient for transport, since all its parts, being bolted, can readily be taken asunder and put together. Its weakness lies in the bars joining the stirrups, which readily become bent or broken. Our modification consisted in attaching the bag on either side not to the bottom angles of the stirrups, but two-thirds up their sides. We then made the ground-ropes considerably longer, and to prevent the upper falling on the lower and closing the bag coarse netting was stretched between the upper and lower bars joining the stirrups. This also served in some degree to prevent strong swimming forms from getting out of the mouth of the net as its upper half was closed. It will be SECOND SERIES.-ZOOLOGY, VOL. XII. 
obvious that with the slacker ground-ropes a much greater grip of the bottom is obtained. The sizes employed by us were 9,6 , and $4 \cdot 5$ feet, the bags three or four times these lengths and made of twine, 1-2-inch mesh. To give weight we had to lash old firebars on to the stirrups, but it would have been far better to have made all the parts much stronger and heavier. A lead must always be attached to the bag, or in letting out quickly it will often be caught up over the mouth of the trawl. These trawls tend to twist up to a lesser degree than the dredges, and the arrangement of swivels, mentioned before, on the end of the warp is less necessary. Their bridles are of considerable length, and hence it is difficult in any vessel to swing their bags clear of the water, unless they can pass through the block together with the swivels. We experienced considerable inconvenience at first, since we hung our indicator-block on the end of the davit. It ougint to have been a suatch-block that would open on one side; we could have then removed the warp from it and taken the strain on a second larger block, which up to that time would lave been hanging from the same davit.

Another instrument with which we had provided ourselves-and the use of which we strongly recommend-was the Ekhman Current Meter. It consists of a frame through the centre of which a wire cord can be passed, having a heavy weight at its end. A screw and indicator on one side are balanced by a large vane on the other to keep the screw in position facing the current. Messengers start and stop the meter. There is a compass in a box open to the water below the meter, and as the screw revolves, shot are dropped on to the top of the compass itself. This has the north point deeply grooved, so that the shot are bound to run down it. They then fall into the box, which is divided up into compartments. By examining the position of the shot in the box in relation to that of the screw the direction of the current is clearly shown. For use the ship should be anchored, but it would be possible to rest the lower weight on the bottom and buoy the wire. The meter requires to be nicely adjusted and continually tested, but for direction the arrangement is a great advance on the compass clamped by a messenger, which one of us (Gardiner) used in tho Maldives and Laccadives in 1899-1900 (fig. 4).

For the plankton or pelagic-fauna work we used the same wire and arrangements as we employed for reversing thermometers and water-bottles. In the collecting-gear. cmployed we (having little experience of our own) in the main followed the directions of Dr. G. H. Fowler, who most kindly gave us every assistance in his power. For ordinary purposes we employed two kinds of nets-iron rings of 13 and 7 inches in diameter, nets of silk bolting-cloth, 6 and 3 feet in length and of 60 and 180 meshes to the inch. Most of the rings were fitted with a pair of clamps with butterfly-nuts, which came unscrewed in a few turns, so that they might be readily affixed to a vertical wire. For the sinallei nets we used 4-oz. bottles, while for the larger we intro!luced a modification in the shape of vessels made of aluminium. These tended to float upside down, unless filled with water before being lowered into the sea, but they undoubtedly by their lightness allow the hag of the net to float out more horizontally, so that the organisms caught are less damaged and probully more numerous. We also used a large net, 4 feet in dianeter at the mouth, with long bridles and a 2-gallon tin at its end. Its net was made of the best mosquito-cloth 8 meshes to an inch and 16 yards in length, so as to allow the water 
to pass with as much ease as possible. The smaller nets were for use while the ship was drifting, the larger net while steaming at 2-4 knots, an $80-1 b$. weight being generally placed between two swivels at the end of the warp to sink it. At 3 knots the wire then ran out from the ship at an angle of about $45^{\circ}$, while the net itself beyond the lead would be streaming out horizontally.

To some degree we used the above nets for collecting the plankton at different depths, but we were provided also with the Wolfenden and Fowler closing-nets. The former was lent to us by its inventor, Dr. Norris Wolfenden, and the latter was a net which had been for two winters in the Antaretic Regions in the 'Discovery,' cleaned and repaired for us under the direction of Dr. Fowler (fig. 5). They differ in principle, the Wolfenden being opened by a messenger and closed at the same depth after a certain interval of

Fig. 5.
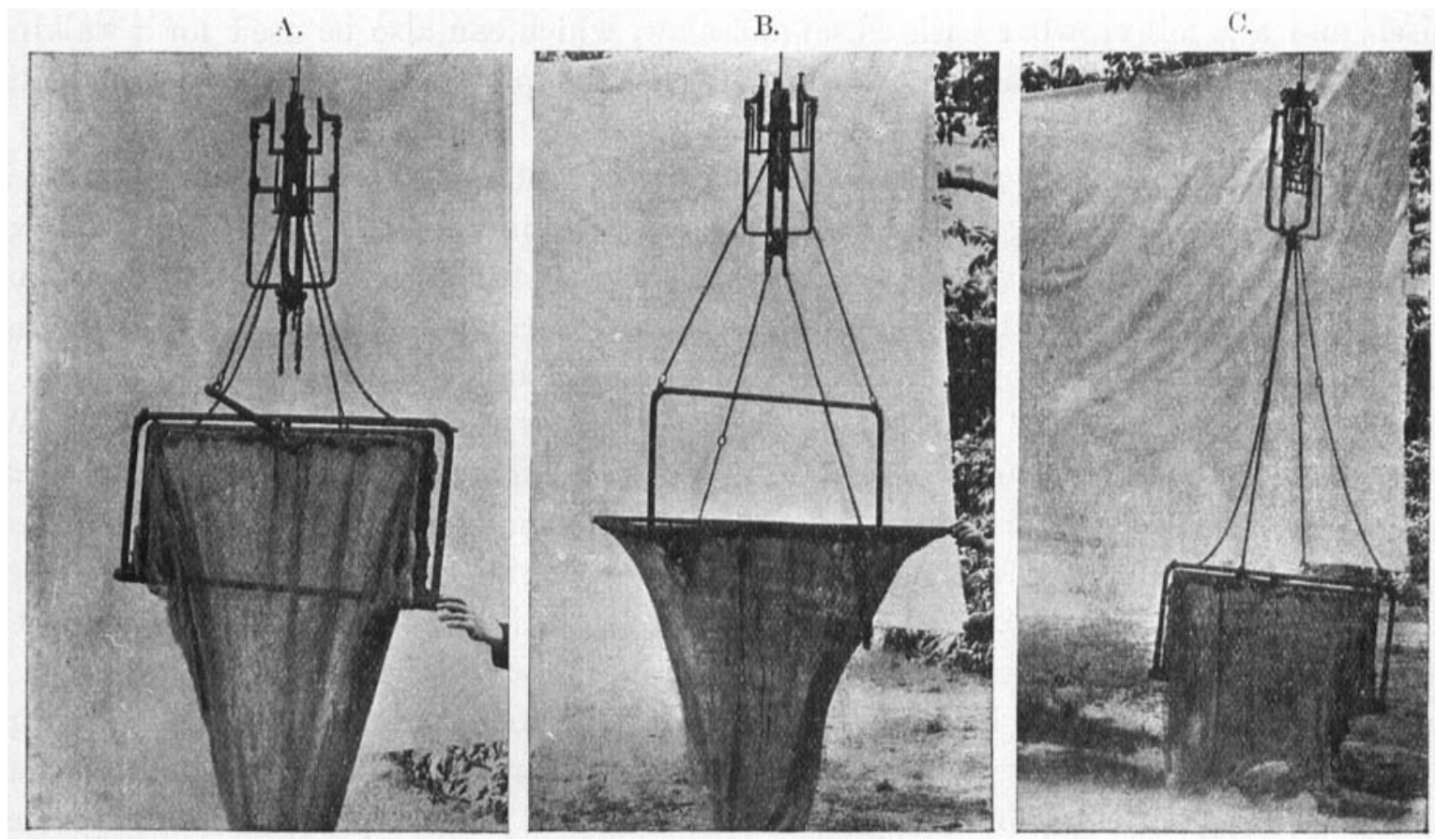

The Fowler Vertical Plankton Net.

$A$, closed ready to descend; 13 , opened by first inessenger; C, closed by second messenger.

time by a second messenger, and the Fowler being opened at a certain depth, hauled up vertically through the water to a lesser depth, and then closed. Our experience is that they both give the depth of their organisms quite reliably, and that they are both casy of manipulation and so simple in construction that they cannot go wrong. With either, the manipulator is able to see when the messengers strike and when the nets are working. In the weather we experienced, almost constantly heary winds and seas in relation to the work we were doing, the Fowler net proved the most successful, perhaps because of its larger size and weight. For the Wolfenden type of net heary messengers are essential, and the not should be of considerable length, since the longer it is the more rapidly will the water pass through it. 
The boxes and gear used by any individual collector are largely the product of his own fancy. We ourselves used flat-topped, patent bottles with india-rubber rings, placed in cases lined and divided by partitions cut out of mill-board. Our tubes were especially made for us in various sizes with rounded ends. For plankton we had corked bottles holding 4 and 8 ounces. The tubes were generally placed in larger vessels, but all bottles whether clamped or stoppered had their ends dipped into melted paraffin to prevent evaporation and the action of the air on the corks and rubber rings. The result was actually less than 1 per cent. of losses by breakage or drying up. We also used various kinds of tanks, some copper and some common tin, which could be soldered up. The preserving-fluids were alcohol (pure spirit diluted as required) and the ordinary formic aldehyde manufactured in this country, which we have found always to be more reliable, being less likely to acidify, than the much more expensive patented formalin. For reefcollecting *-and for land-collecting also-hammers with pointed and chisel-shaped ends, chisels and a small crowbar with chisel and claw, which can also be used for a walkingstick, are useful. The entomologist will do well to employ white nets in such localities as we visited.

Mr. Bainbrigge Fletcher set our Lepidoptera as we obtained them and pinned out some of the Neuroptera and dragon-flies. For the rest we followed the advice of Dr. David Sharp and placed them to dry in sawdust, from which the finer particles of wood had been well sifted, subsequently setting them on our return to England. With the plants we had great difficulty, owing to the damp. The land plants, too, in such regions tend to be more succulent than the same plants in larger islands where the soil is less salt. We found that the only thing to do was to use plenty of paper and to change them at least daily. Fermentation set in at once, when we tried placing our press, which consisted of two flat boards with canvas straps, in the sun or engine-room. The limited success which we obtained was mainly due to Mr. Beer, who daily dried our paper for us in the latter room. The last stages were to paint the plants with corrosive sullimate, and to put them up in newspaper, labelling the packets with their different localities. Larger specimens, such as the flowers and leaves of trees and shrubs, we often in the first place killed in boiling water. The latter was used for all the marine plants that we pressed, but otherwise the treatment was the same.

* It is scarcely necessary to point out that the reef-collector should under no circumstances, particularly at night, go into the water with any part of his body except head and arms exposed. To obtain a really representative collection from any locality, he must be prepared to work for hours with the water up to his waist or neck, and he must occasionally go out by night as well as by day. He will find at times that he is the object of considerable curiosity to small sharks and the deadly, though small, sea-snake (Hydrus platurus), while occasionally sharp-jawed fish will, perhaps frightened by his companion, dash against him. Again, many fish have poisonous spines and Siphonophora have batteries of stings, while abrasions of the skin on corals usually lead to sores which can only be cured if salt water be avoided-in fact, by giving up reef-collecting for a time. We ourselves, after considerable experience, recommend, for cornl-reef collecting-work, a shirt and khaki coat (the sun on the spine should be aroided), khaki breeches moderately tight and closing up at the knee, putties, and hobnailed boots. 


\section{Summary OF the Voyage aNd Work.}

Part I.-Ceylon to Mauritius.

According to the arrangements which had been made, we were to leave Ceylon for our cruise about the middle of April, 1905. We ourselves arrived in Ceylon early in April in anticipation of leaving about that date, but unfortunately we found that the Sealark had damaged her forefoot on a coral-reef, while surveying the waters around Port Sudân, then a mere waste of sand, broken only by the holy tomb of the Mirza Sheikh-el-Bardd. This was at first thought to be of little importance, but in any case it necessitated her being drawn up on the slip at Colombo. The repairs, which were at first to have taken a fortnight, were protracted day by day to five weeks. In the meantime we got together the cases of bottles and gear which we intended for use between Ceylon and Mauritius. We also procured from the Customs our barrels of alcohol, which we had especially ordered from Sydney, N.S.W., on account of its greater purity. Supplies, too, for camping in the Chagos were obtained, as well as a limited number of articles as presents for traders, \&c.

We found that the Sealark's starboard steamboat had been so disabled that we should have been compelled to proceed on our cruise with only one boat. Anyone, who has been on a surveying-cruise through island groups, knows well how much steamboats are in request. One with a skiff in tow can, in many classes of work, do about four times as much as a single whaleboat. The employment, moreover, of mechanical means of progression is very desirable in the tropics. Under the circumstances we deemed it desirable to substitute a boat of our own, and purchased the 'Xanthus.' She was a square-sterned boat, 22 feet in length, with vertical boiler, engines by Simpson, Strickland, \& Co. She had originally been built as a yacht's launch for work in more or less protected waters, so that to make her serviceable for work in the open seas we had to have her bows decked in and her gunwale raised. We also had to alter her to fit the slings of the Sealark, and to give her more water-tanks and coal-bunkers. She could be stopped or turned in her own length, so that she was particularly suitable for work among coral-reefs, while her speed, 8 to 9 knots as against the 5 to 6 knots of the other steamboat, caused her to be constantly in request. Although largely used for survey-work, she was kept particularly at our disposal and enabled us to see considerably more of the reefs and islands than we should otherwise have been enabled to do.

We finally cleared Colombo Harbour at 5.30 P.M. on the evening of May 9 in a heavy rain-squall, the forerunner of the south-west monsoon. A course was set west-south-west right into the teeth of the wind, which increased on the second day to a moderate gale. We crossed the Fquator on May 13, passing two days later into more genial weather. During all this time we had been having a heavy swell, continued rain-squalls, and dark cloudy nights, and as we were heavily laden with 30 tons of coal on deck we were uncomfortable in the extreme. From lat. $2^{\circ} \mathrm{N}$. to $3^{\circ} \mathrm{S}$. we experienced each day currents of over 40 miles in 24 hours setting almost due E., the maximum being 59 miles between lats. $1^{\circ} 47^{\prime} \mathrm{N}$. and $0^{\circ} 04^{\prime} \mathrm{N}$. It was interesting to us to note that 
during these nights the sea never showed even a spark of phosphorescence, because in similar weather in the south-west monsoon off Minikoi, in June and July of 1899, Gardiner and Borradaile had frequently noticed a particular brilliancy, evidently produced by a large variety of forms. The time, however, was more than a month later, and, of course, by then there would have been a very considerable drift of the sea from west to east. It might, too, have been a breeding-time for the pelagic organisms, as it certainly was for the reef-living forms.

During this time we busied ourselves in getting our gear into order and opening cases ready for work. Corp. Cronk, in charge of the small detachment of Royal Marines on board, who had been told off to assist us, was instructed in keeping the meteorological log, in which he became extraordinarily proficient. We also for a week continuously checked the four quartermasters in reading the various instruments. These consisted of barometer with thermometer attached, wet- and dry-bulb thermometers, and thernometer for sea-water temperature, which were all regularly read six times a day, just before the watches were changed. At the sume times or at noon particulars of the course, distance by $\log$, direction and force of winds, clouds, weather, and state of the sea-surface (waves and swell), the position of the ship, and currents experienced in the previous 24 hours as well as the compass-error were entered. Similar logs are kept by most large passenger-liners, and are forwarded, when convenient, to the Meteorological Office, from which it is enabled to draw up and correct its charts.

We put down our first sounding on the early morning of May 14, obtaining 2121 fathoms. Unfortunately the wire parted, and, as we did not know our position, we lay-to until the evening, when we managed to get sights. We then sounded again, 2135 fathoms, about 80 miles to the east-south-east of Addu Atoll, finding a hard bottom. Doubt is always cast on the statement that the bottom is hard when deep soundings are concerned, as it rests generally on negative evidence, no sample having been obtained with the lead. However, in this case there was no evidence that the valves failed to act, and likewise in three soundings further east of 1600,1596 , and 2100 fathoms no bottom-sample was obtained. If the bottom is really hard, it can only be explained by the existence of a deep current sweeping round the south of the Maldives, diverted partially no doubt by the ridge on which they are situated.

Thence we ran down to lat. $2^{\circ} 45^{\prime} \mathrm{S}$, where we ran a series of soundings across the direct line between the Maldive and Clagos Archipelagoes, obtaining depths of 2129 , 2078, 2008, 2062, and 2082 fathoms. These showed us that the ridge on which the Maldives are situated, which in its southern part lies at a depth of about 1000 fathums, tails off to the south of Addu in about 75 miles to roughly 2000 fathoms, at which depth it continues until the Chagos Bank commences to rise. The distance from Addu to the north end of the Chagos (i.e. Speakers Bank) is 240 miles, and the approximate depth is not more than 2300 fathoms on either side of what is evidently a low ridue connecting the two groups. These are the first soundings which have been put down across the line between the two groups, the 'Valdivia' Expedition having unaccountably omitted this important work. If the Maldive and Chagos atolls are taken to indicate the sites of lands which have disappeared owing to subsidence, some more definite 
connection would certainly have been expected, especially if they are both considered to be remnants of a large continental mass which once connected S. India to Madagascar. At the same time it must be remembered that, as far as the then existing soundings are concerned, it was still possible that a ridge or broad bank at a depth of 1500 or 1000 fathoms might connect the $\mathrm{S}$. Maldives to the line of shallower banks between the Seychelles and Mauritius.

We lay-to from the afternoon of May 17 for 24 hours to try our plankton nets and gear, which by that time we had got into order. We were in a belt of calm which apparently extended from lat. $3^{\circ} \mathrm{S}$. to lat. $5^{\circ} \mathrm{S}$., so as to separate the northern monsoon from the southern trade-wind, the former with westerly winds and the latter with easterly. This weather, being particularly favourable, the ship was swung for the compass-error due to the iron gear on board and for the natural variation of the compass from true $N$. and $S$. in position. The latter alters from time to time in all parts of the world, and it is essential to the navigator that he should accurately know the variation along his course, that he may be the better enabled to set a compass-course equivalent to the true course which he desires to steer. The operation requires as clear a day as possible, and, as the

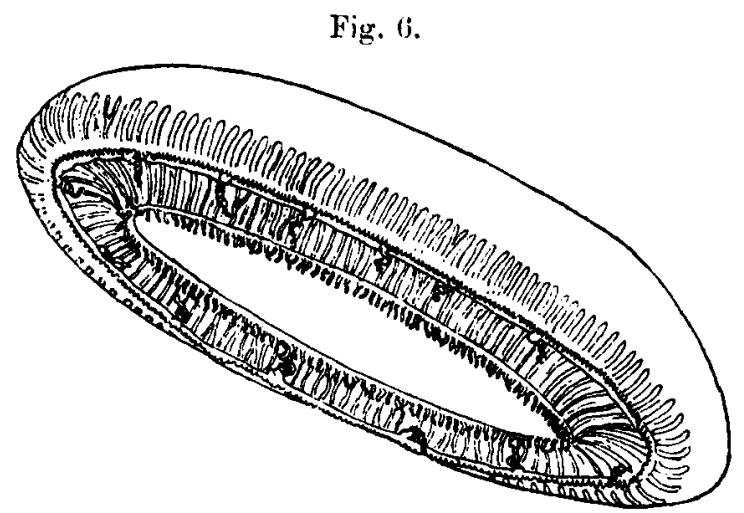

1 Medusa with widely open mouth from a deep plankton haul (Mesonema). $\times 1 \frac{1}{4}$.

sun must not be at a high altitude, in the tropics is performed generally in the morning or evening. On the Sealark it was always carried out by Comm. Somerville himself, assisted by Lieut. Lay, his next in command. It consists in laying the ship's head on each point of the compass in rotation and, when she is steady on each, in reading off the then directions of the sun in relation to the same on the ship's compass; the operation is finally repeated in a reverse direction. The variation found here in lat. $4^{\circ} 16^{\prime} \mathrm{S}$. was $3^{\circ} 41^{\prime} \mathrm{W}^{\prime}$., and as subsequently in lat. $10^{\circ} 58^{\prime} \mathrm{S}$. to the north of Madagascar, less than $7^{\circ}$ of lat. further south, we found a variation of $8^{\circ} 38^{\prime} \mathrm{W}$., the value of such work to practical navigation will be at once apparent.

One of the objects of the series of plankton observations taken on this occasion was to ascertain the pelagic organisms found at different depths by night and day. In connection with the same we desired to find the depth to which the zoo-and phytoplankton organisms extend. On account of their remarkably minute size we used the smaller nets with silk bags of 180 meshes to the inch for the latter, while for the animals we employed the larger nets throughout, 60 meshes to the inch. We had nets 
streaming out from the ship's side for the surface-animals, and for the deeper waters we attached a 100-lb. lead to our wire cord and, standing in the open starboard gangway, clamped on our nets in series as the requisite lengths ran out, in the present case attaching them at each 25 fathoms down to 150 fathoms. When the nets reach their depths, the ship is allowed to drift for whatever time it is considered desirable to leave them downwith us, generally half an hour. The nets being ready and their aluminium cans filled with strained water, the operation of clamping each one on and letting it down into the sea does not take more than 30 seconds in calm weather. They are then lowered rapidly and go down streaming straight up against the wire with their tins reversed; the latter are so light that it generally takes subsequently about 2 minutes before the net streams out at right angles to the wire, as it should do. In hauling in the nets, they are of course reversed, and, if it be started rapidly for the first 10 fathoms, will all coil

Fig. 7 .

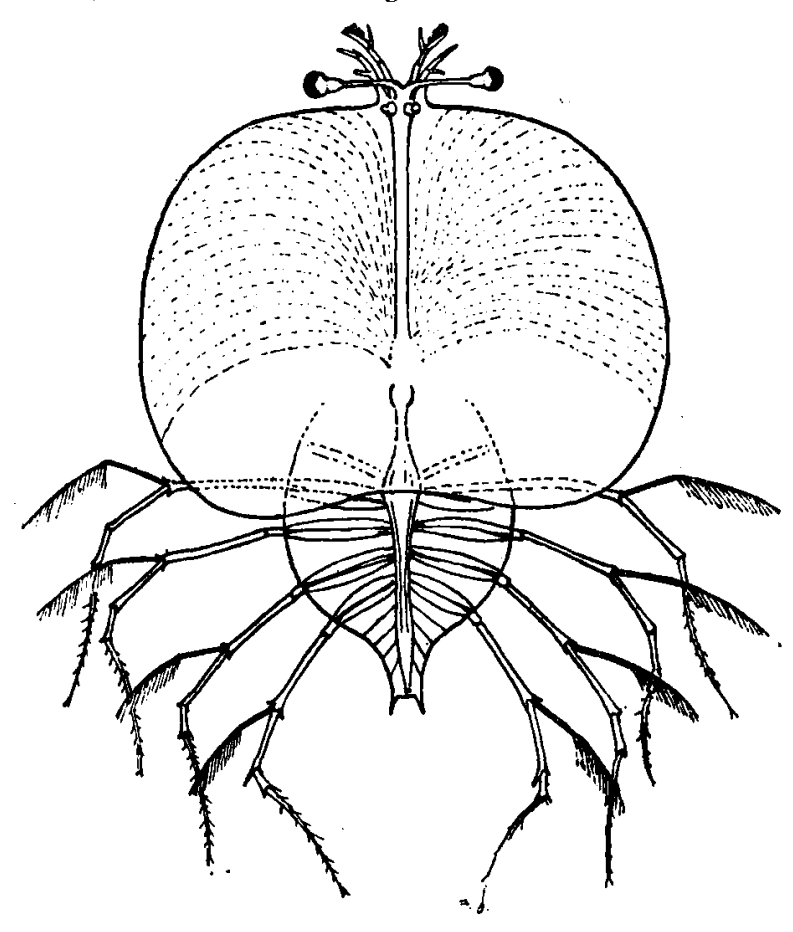

A Phyllosoma larva from deep water. $\times 1 \frac{1}{2}$.

themselves round the wire, so that no organisms can pass into them during their upward course, and the several nets may be removed at leisure as they come up. Of course, the method is open to the objection that the bags are not closed on their downward course, and that the catches, though mainly from some particular depth, may include some additional organisms caught while passing from the surface down to that depth. The method of clamping the rings of the nets to the wire instead of attaching them by a bridle to a large degree obviates this objection, as the ring and net-opening cut the column of water at right angles during their journey downwards. Thus in practice the actual number of organisms caught from lesser depths is infinitesimal, and all, except the rarer animals (from which no deductions are in any case possible), can be eliminated by comparison with the contents of other nets. 
Subsequently, in the same position, we took a series of observations with the Wolfenden and Fowler closing-nets down to 1000 fathoms. Both acted satisfactorily, and the wire showed no tendency to kink in any way. We next determined to try our large net with 8 meshes to the inch. Steaming very slowly ahead we let out some 1400 fathoms of wire, while the net sank rapidly, the wire making an angle of about 60 degrees with the surface. We then commenced to haul in slowly and got up about half the wire with comparative ease. Unfortunately it had unravelled somewhat during its two years' rest in the Antarctic Regions-it had never been used before-and no doubt had twisted a good deal in going down. As we had unfortunately placed no swivels upon the wire to counteract this, for the next four hours we were hard at work with the whole watch on deck and most of the officers to assist us in trying to unravel its large kinks under the beams of the electric lights. Finally we got the net itself on board, but the whole starboard gangway was blocked up with a mass of wire, from which we had to cut about 250 fathoms before we could finally get clear for the next haul, an important one for the comparison of the depths at which different animals float by day and night. Of course it was anticipated that the greater part of our catch was lost, but evidently in our first manœuvres, when about 750 fathoms were out, its tin had fouled the mouth and so had been absolutely closed. On examining it in the shade we could see only a mass of bright specks with larger spots of red, white, and blue light. However, when we had poured the catch into a series of bottles and they had been passed round, it was apparent to all that we had had an extraordinary haul, and that our labours had not been in vain. The catch included, among many others, a curious gelatinous cuttle-fish (Eledonella) set with minute black specks, each giving a tiny spark of rather blue phosphorescent light; a large vermilion prawn-a peculiar position for what are usually bottom-living animals; Mesonema, a Leptomedusan, with an enormous open mouth, two-thirds of its diameter across ; the pteropod molluscs Cavolinea and Desmopteris ; numerous Crustacean larvæ, Erichtheus and Phyllosomas an inch across; and Phronima, a large-eyed Amphipod. Tunicata such as Salpa and Pyrosoma were abundant, as also were Siphonophora-nearly all adding their green, red, and blue lights to the general illumination. (Figs. 6-8.)

On the morning of May 19 we sighted land, first a few specks on the horizon, giving place to low domes, the tops of banyan-trees; then a ragged line of coconut-trees and Casuarinas; and, finally, a vivid line of green, the white strand with the variegated reef-flat outside, edged by its line of brilliant white foam. It was île Diamant, the most north-westerly island of Peros Banhos. As the atoll had not been resurveyed since 1837 , and we did not as yet know the value of that survey, we were naturally careful; the 'Xanthus' was accordingly lowered, Mr. Alexander going ahead and sounding the channel, while we followed in his wake, anchoring shortly after mid-day about a mile off Diamant. Our object was to see the Manager of the oil-settlement so as to glean some information about the atoll, as we had an idea of making a careful examination of it, in respect particularly to the formation of the Chagos reefs. It was also desired to take sights, since Moresby had run down to the same island for longitude when he was preparing the charts of the group in 1837. We had expected, in accordance with the SECOND SERIES.-ZOOLOGY, VOL. XII. 
Sailing Directions, to find the chief settlement on this island, but although we could see huts no boat came off to us. Accordingly we determined to find a passage for ourselves over the reef-flat which extended for a breadth of $1 \frac{1}{2}$ to 2 cables out from the land. The tide being nearly high, as many as possible got into the 'Xanthus' and by shooting over the edge of the reef in parties in one of the skiffs landed ashore. The inhabitants consisted of two pensioners of the "Société de Huilière de Peros et Diego," which, with its headquarters in Mauritius, owns the islands: the one was a Malagasy coast negro and the other a quarter-cast European Creole from Mauritius. Both had their wives on shore with them and both had been in the group for over 50 years without leaving it. From them we learnt that the settlement had been moved to Ille du Coin on account of there being some small protection there from the heavy seas of the south-east trades, which at Diamant, being absolutely unchecked by the comparatively shallow rim of the

Fin. 8.

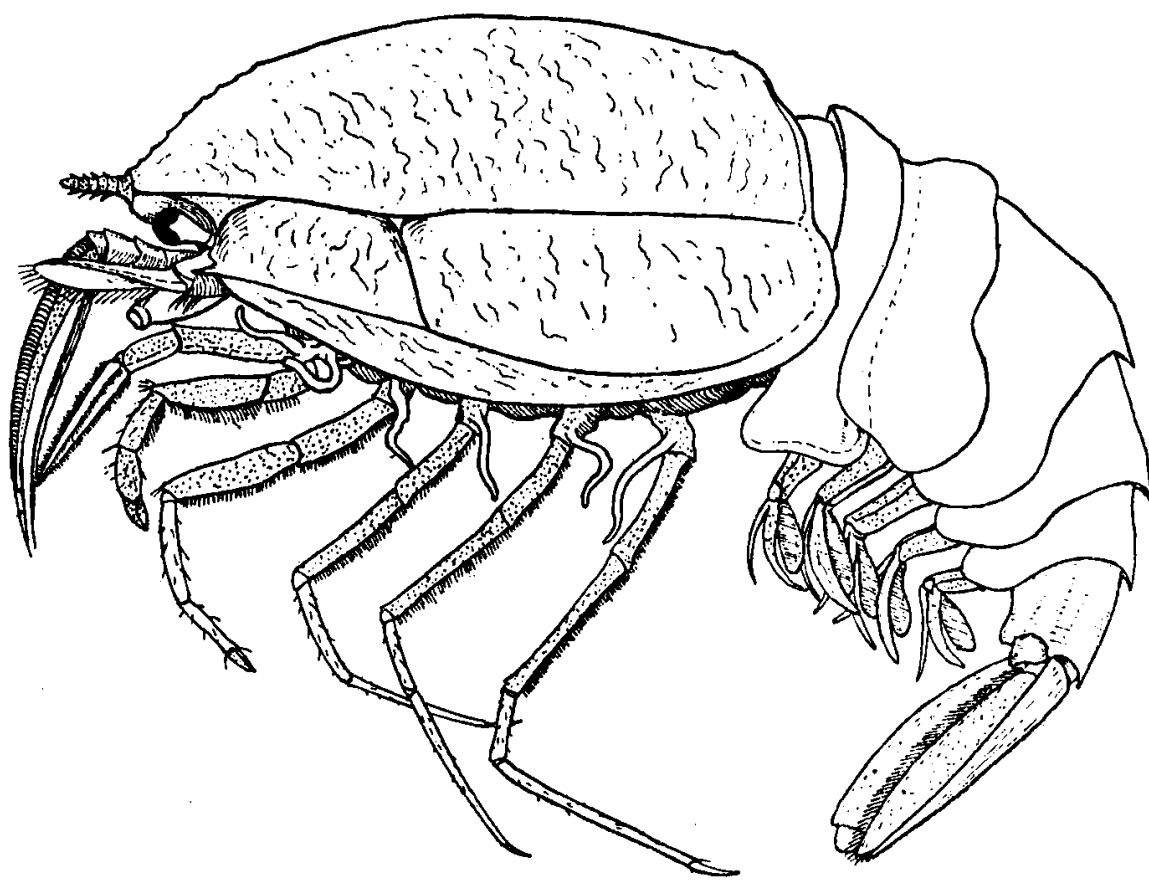

A Gnathophausid-like Prawn from deep water. About nat. sizo.

atoll to the south-east, are said to break with terrific force on the lagoon-reef. We also obtained a considerable amount of information about the whole atoll, which scarcely seemed favourable for the extended investigation we had intended.

We then separated, one of us taking the north, the other the south half of the island, Capt. Somerville examining the former settlement, Fletcher entomologising, Simpson commencing the botanical collecting which he had volunteered to undertake, while Mr. Alexander set out to inspect certain special points which we had observed from the ship. This island is about 2 miles long by 600 yards in greatest breadth and tapers at either end. It passes off to the east into a series of sand-banks, continuing up to the channel through which we entered the atoll, and to the south into a chain of islands on the atoll-rim, which is unbroken on its west side save by a single passage. The seaward 
and lagoon reefs average in breadth about 100 and 300 yards respectively. Their shores behind are rocky, or covered with stones and sand, their character varying in accordance with the breadth of their fringing reefs. The reef-flats of each are very similar in appearance, being ordinary coral-flats, but the outer is evidently very largely built up by calcareous plants and the inner by animals. The former settlement was situated on the middle of the lagoon side and consisted of the regular buildings required for the preparation of oil from coconuts, together with a large number of houses, some built of coral-concrete, others of wood, but all raised to a height of 4 or 5 feet on built-up foundations, of which we counted about thirty *.

On either side of Diamant the shore is raised by the piling up of sand by wind and waves, but nowhere does it attain a greater height than 8 feet above high-tide level. The centre part is lower, and in parts forms swamps, into which the sea has broken from the outer (i.e. north-west) side of the island, in places forming small backwaters, or, as they would be termed in Mauritius, barachois. One of these is barred up for fishing purposes, but the rest seem to be encroaching upon the land, as evidenced by fallen timber, \&c. At the south-west end the island extends out into two points, with a bay between, while Grand Mapous, the next island to the south, likewise shows two points as if extending along to meet those of Diamant. Connecting the two seaward or outer points are two lines of rock on the reef, which are exposed at low tide, while the large pool between the inner and outer points of each island has apparently about 6 feet of water. It was at once quite evident that the two islands had been connected along the reef, but that the sea had broken through into the centre lower-lying land and formed a barachois such as those which occur in Île Diamant itself. 'The seaward points and the adjacent shores are now markedly washing away, as evidenced by undercut rocks, but it was uncertain whether the islands are not gradually becoming joined together again by sand being piled up along their lagoon or inner side.

The whole island is now devoted to the cultivation of the coconut, but its central part was evidently at one time a large garden for taro (Creole "songe," Colocasia antiquorum), cassava, arrowroot, marrows, gourds, bananas, and papayas, while there were several breadfruit trees. No indigenous jungle is left, and the whole surface of the ground in the swamps is covered by a creeper (like a wild bryony) known as " pocpoc," while the dried shore-ridges had coarse grass, with bushes of manioc (Sccevola Koenigii) and veloutier tabac (Tournefortia argentea) next the sea. Only about 45 plants in all were observed, and no cultivated plant beyond those mentioned, an extraordinary fact considering the large settlement formerly on the island, and one in striking contrast to the Maldives. True land-animals of all sorts were scarce, even in comparison with the other islands of the Chagos-not only in species, but in actual number of forms. This fact we are inclined to attribute to the vast numbers of mosquitoes, which breed in the swamps among the rotten and stinking coconut-husks. According to our observations they

* Commander R. Moresby in his 'Nautical Directions for the Maldive Islands and the Chagos Archipelago, 1839 , states that the principal establishment was on Diamond Island, and that the group produced abont 34,000 gallons of oil yearly, being worked by an overseer and about 90 negro apprentices. He adds that plenty of poultry and pigs were obtainable, also fruit and vegetables at 6 Spanish dollars per cwt. 
attack not only mammals and birds but on occasions lizards, spiders, and other insects as well, while they will feed voraciously on any dead animal matter. Indeed only landcrabs were much in evidence, the enormous red Cardiosoma staring at us from every quarter of the swamp and affording much amusement to Bruce, the captain's Irish terrier, who developed a penchant for all crabs, which often materially assisted our collections.

We remained at anchor at Île Diamant over Sunday, May 21. On the Saturday the wind increased from the south-east to a strong breeze with rain-the commencement of the trade-wind, as we subsequently found. One of us went off to further examine the island, while the other remained on board to sort out the plankton previously collected. Additional hauls of the same organisms were taken while at anchor, and a series of

Fig. 9.

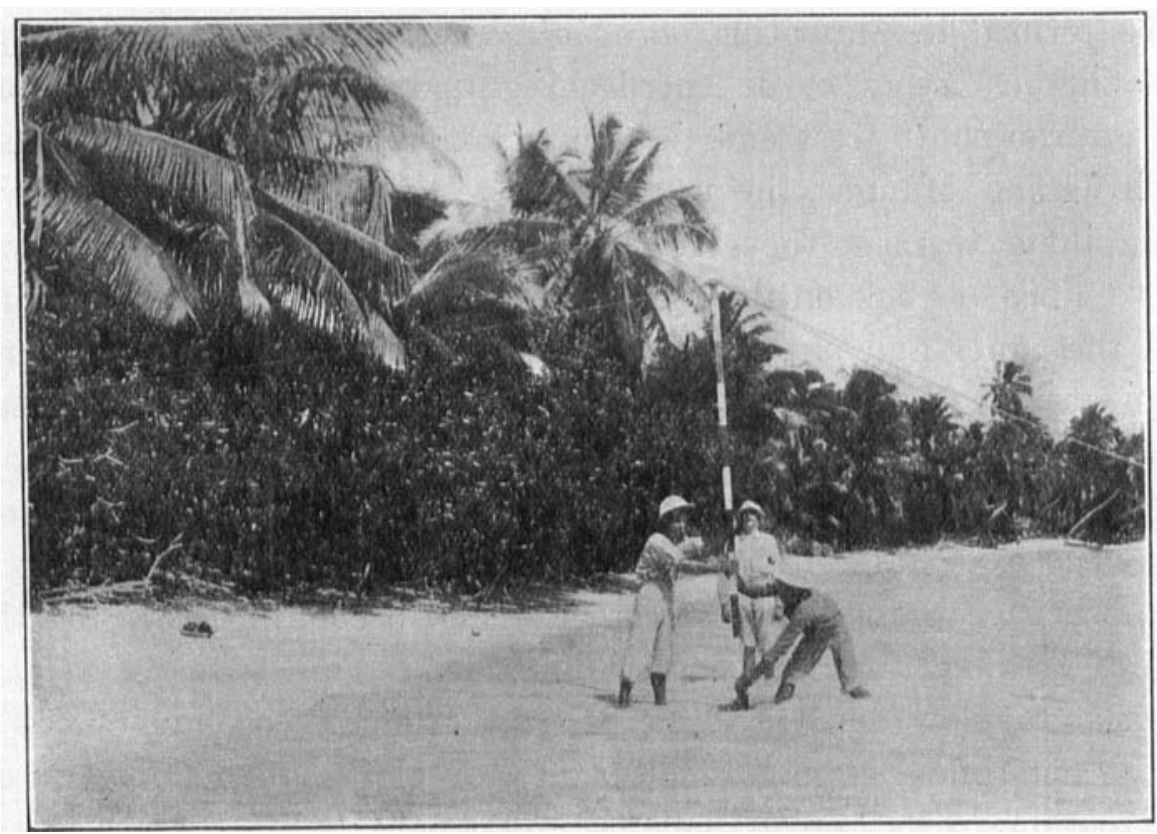

Tide-party erecting their pole in Salomon lagoon.

experiments were made in preserving them, the method finally adopted being to kill them in bulk with a few drops of formic aldehyde. When the organisms had settled, we decanted the clear fluid, finally pouring the residue into as many 4- and 8-oz. corked bottles as might be necessary, and adding more formic aldehyde to make up to a strength of $2 \frac{1}{2}$ per cent. The solution, as bought, is generally an aqueous solution of 40 per cent. strength. The bottles after being corked and thoroughly sealed with melted paraffin are then ready to be sent home without further examination. We also placed out swabs, made of old hempen rope unravelled, such as is used for mopping up water on the deck. These swept over the bottom with the swinging of the ship and brought up from 15 fathoms several large masses of a slate-coloured Alveopora, and many reefcorals of the genera Euphyllia, Orbicella, Prionastrea, Mussa, and others. Some of these were preserved, while others were broken up with the hammer and chisel, yielding 
a variety of Mollusca, Crustacea, Gephyrea, and Chætopods, one of the latter with a brilliantly phosphorescent spot at the base of each parapodium.

On Sunday no one was able to land on account of the weather, and we decided to transfer and make in the first instance an examination of Salomon Atoll, into the lagoon of which it seemed that the Sealark might be able to enter. In Peros it was clearly apparent that it would be necessary to keep steam up in the ship and fires banked; and coal, on account of the heavy weather we had met with, was getting very short. On Monday morning, passing out of the same passage, we skirted along the north side of the atoll, observing the different islands as we passed. We noticed the rocky outer shores of Moresby Island and the absence of broad reef-flats as off some parts of Minikoi, indicating either a washing away of both land and reef or perhaps an outgrowth of land by the piling up of rocks by the waves*.

The bare sandbank marked next in Moresby's chart on the rim had evidently become an island covered with coconuts; it is termed St. Brandon, as we found subsequently. In the next five islands we observed little change, save in their vegetation; all appeared to have generally a narrow reef-flat to the north skirting a rocky shore, broken through in places and with sand exposed. In Yëyë we observed such marked changes that subsequently we were led to camp on that island. Arriving off the entrance of Salomon the 'Xanthus' was sent in to sound, but on the arrival of Mr. Sauvage, the Administrator, we anchored in the entrance, at once going off to inspect 'Takamaka, which we thought might be the most suitable centre for our examination of the atoll. Finding a good entrance through the lagoon-reef, suitable coconut-leaved houses ushore, a good spot for tidal observations, and comparative absence of mosquitoes, we landed with our gear the following morning, May 23, with three Indian seedee-boys as servants--Daniell, Sam, and Joseph. The tide-party, consisting of Corporal Cronk and two hands, also pitched their camp, got their tide-poles erected, and commenced a series of half-hour observations, one of them being always on watch, for the next six weeks (fig. 9). On the same day the Sealark having buoyed a passage canie to anchor in the lagoon about a quarter of a mile from our settlement and drew her fires.

It would be tedious to attempt a precise chronological account of the work undertaken in Salomon Atoll. We were camped together at Takamaka until June 5, when one of us (Forster Cooper) re-embarked. The ship then proceeded to Diego Garcia to await the arrival of one of the British India vessels, which, it had been arranged, should stop on her course between Colombo and Mauritius to bring us coal. The other, with Mr. Alexander, remained on Takamaka with the 'Xanthus,' a skiff, and their crews until June 16, when the camp was finally struck. Commander Somerville and his officers were very fully occupied during this time in making a fresh chart of the atoll. In the other branches

\footnotetext{
* Moresby represents a broad reef-flat on his chart. His charts of the Chagos generally show the position of either end of the island of the atolls accurately, and his notes as to their character were carefully compiled. Their lagoon-sides are glso often fairly correct, but their ends in the direction of the atoll-rims and their seaward sides are merely sketched in. The position of shoals in the lagoons and all soundings seem to us to have been carefully fixed and plotted. Indeed we could rely on Moresby's work wherever there might be any question of the safety of a ressel.
} 
of work Fletcher undertook charge of the entomology, we handing over our collections to him from time to time. Simpson made a careful collection of the plants of Boddam, while we made independent collections from other islands both from land and sea. Mr. Alexander ran sections for us with the theodolite across three of the islands, and one or the other of us visited and thoroughly examined every island and every mile of the reef. We also dredged the lagoon, examined a large number of its shoals, collected the

Fig. 10.

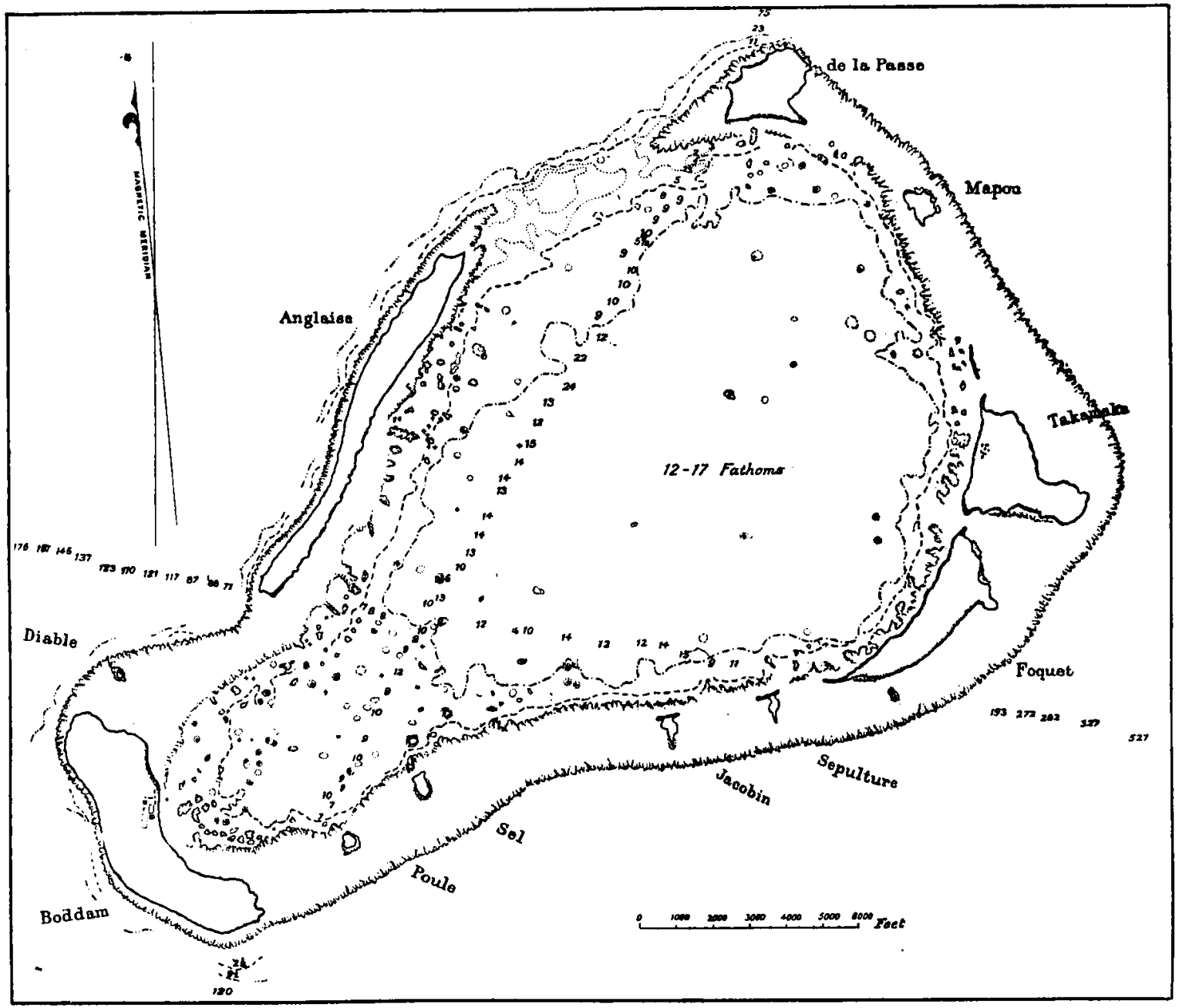

Chart of Salomon Atoll (after the survey by Comm. B. T. Somerville and the officers of H.M.S. Sealark).

plankton inside and outside the atoll, measured the currents in the passage, and getting two fine days examined the outer edge of the reef and its slope. The preparation and storing of the collections, too, was no light labour.

In the plan of the survey the triangulation had to be drawn out, a base-line measured, flag-posts erected on every island, and bearings taken from each. The outline of each island had then to be carefully placed in, and the reef outside accurately measured. After this the lagoon had to be closely sounded, so that not even the smallest rock should 
escape observation. And, finally, the latitude, longitude, and variation had to be accurately observed. All this, of course, had to be carried out upon or inside the reefs, but later on there were sections of soundings to be run outside so as to put in the 100fathom line accurately. The resulting chart (fig. 10), on the scale of 6 inches to the mile, is wonderfully accurate, and is the largest chart of any atoll yet made. Charts on a lesser scale are almost too small to enable anyone to ascertain by accurate comparison the changes in the progress of atolls within any reasonable period of time, and we have no hesitation in declaring that the preparation of this chart is a work of the highest scientific

Fig. 11.

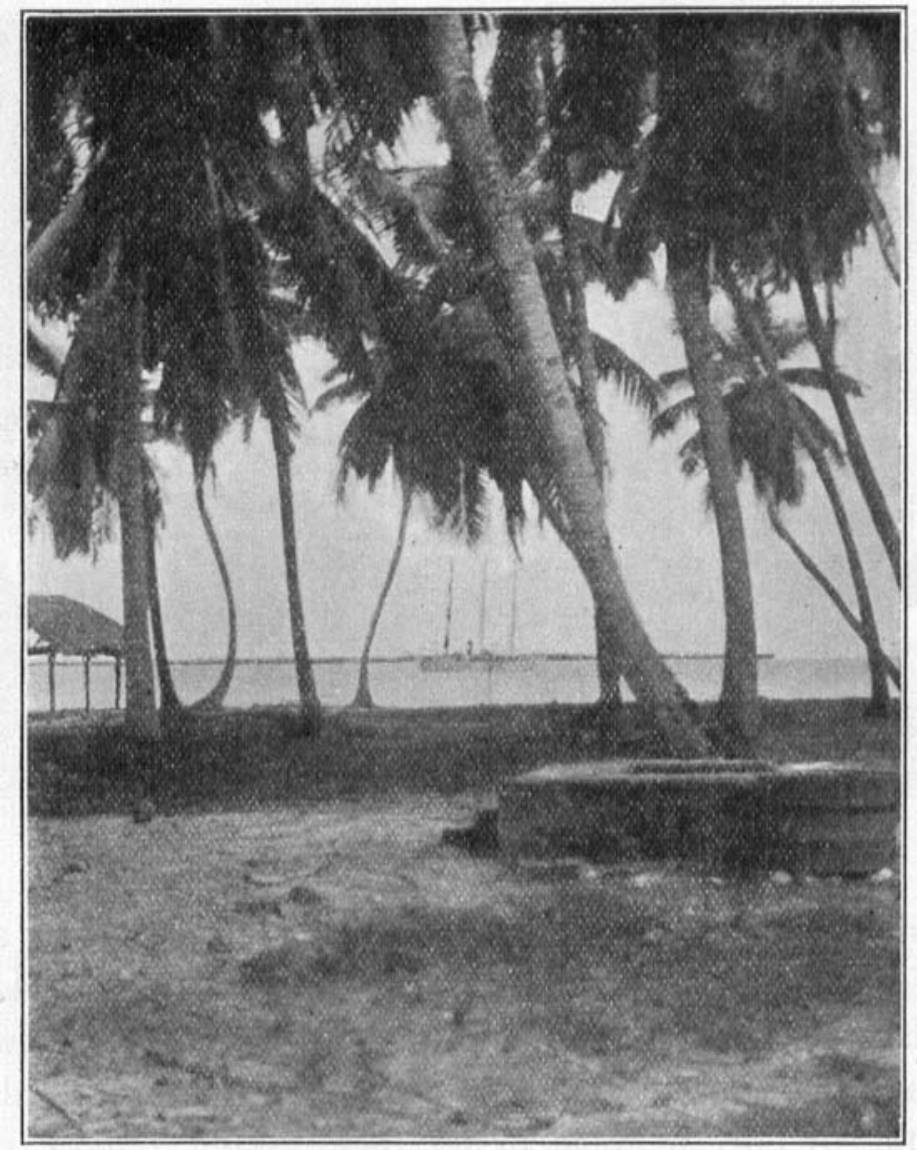

View from Takamaka over the Lagoon of Salomon Atoll, showing

H.M.S. Sealark and Île Anglaise in the distance.

importance. Commander Somerville and his officers have denoted an atoll for all time, so that by a re-survey at any future date its changes in progress may be ascertained and many points in the interaction of land and sea, and in the formation and growth of coralreefs, may be accurately estimated. Their chart may not be of much economic value, since few ships visit the Salomons, but it will be of great importance to a knowledge of coralreefs, such as will enable an estimate to be made of their probable growth and potential dangers to navigation in other places.

The Salomon Atoll consists of eleven islands on a surface-reef, which surrounds the 
lagoon in a ring unbroken save to the north by a single passage with 3 fathoms of water. It lies 13 miles to the east of Peros, and it is $5 \frac{1}{2}$ miles in a south-west and north-east direction by 3 miles broad; its lagoon is relatively large and varies in depth up to a maximum of 17 fathoms. All the islands are fully planted with coconuts, except lle Diable, which is a mere rocky and bush-covered patch of land. The islands belong to the "Société Huilière de Salomon et Trois Frères," a company with its headquarters at Mauritius. The produce amounts to about $1,800,000$ coconuts a year*, Takamaka yielding 17,000 a month and Boddam about 60,000.

Fig. 12.

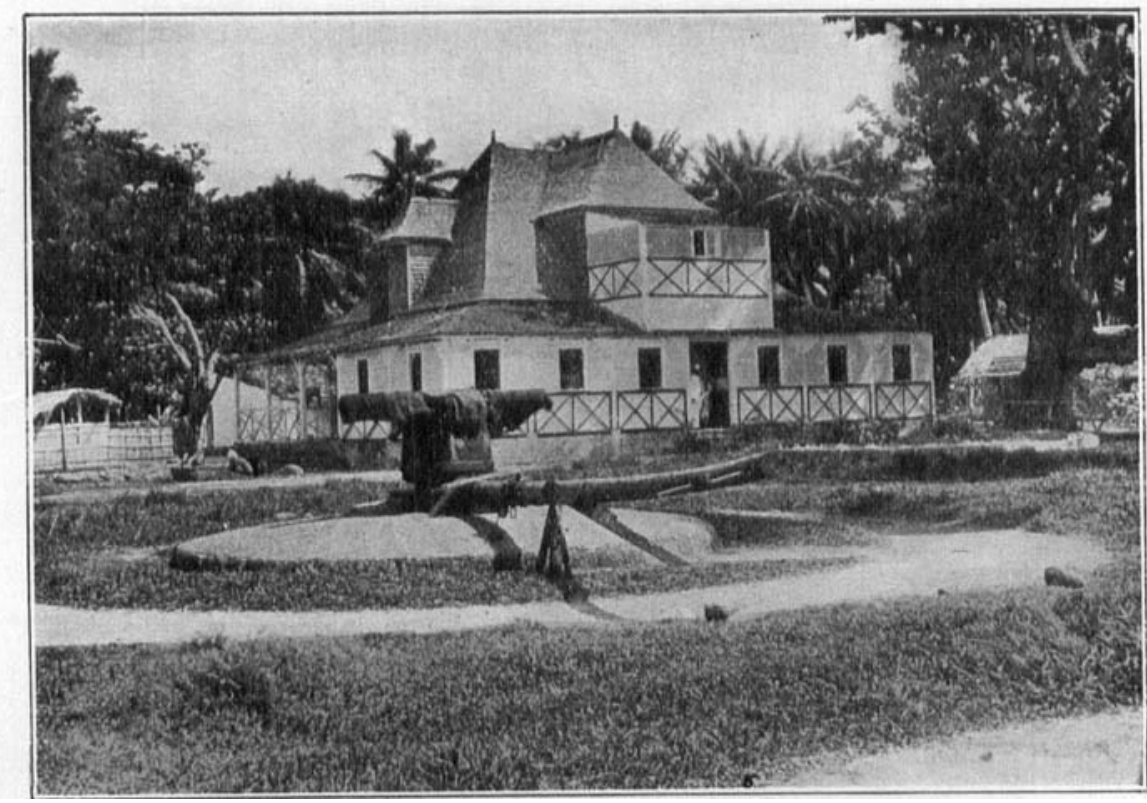

Coconut Mill and Manager's House at Île Boddam, Salomon.

The establishment was on the latter island, which is named after a former governor of Mauritius, and consisted of Mr. Sauvage (Administrator) and M. Des Marest (SubAdministrator) with their families, and about 30 coolies with their wives and children. The islands, however, were greatly undermanned, owing to a sad fatality which occurred to the atoll in 1904. A boat manned by ten men, taking 7 days' provisions, went off on January 25 of that year to Nelson Island, 21 miles to the south, the only island on the north side of the great Chagos Bank, to take the eggs and young of the frigate-

* Moresby, in 1837 (loc. cit.), states that the vield of oil was 6000 gallons per annum, and that pigs and poultry conld be obtained in abundance. He did not himself visit the group, his second in command, Lieut. F. F. Powell, a much inferior surveyor, making the chart.

The first chart was derived from a survey by Capt. Blair, of the Hon. East India Company's Marine, in 1786. His account of the islands is given in James Horsburgh's 'Directions for Sailing to aud from the East Indies,' 1809, p. 135. According to this work they were named after the French ship 'Salomon,' Capt. Bourde, who saw them in 1776, but Capt. Blair called them Governor Boddam's islands. "From Nov. 21st to the 25th he (Capt. Blair) remained there taking in wood and water." "They caught 20 turtle, and a sufflcient supply of fish, but the latter were not, so plentiful as at Diego Garcia, probably occasioned by the number of seals." 
bird, which breeds there in immense numbers. As they did not return, the Administrator, on Feb. 11, sent off a second boat with 8 men, and himself sailed thither on Feb. 20. He found traces of the first boat, but none of the second, and it must be presumed that both were lost, with all hands, in the heavy westerly weather which occurred at that time. Both were large boats, which could scarcely have been swamped, so that it must be concluded that they were either broken up on the submerged Victory bank, 10 miles to the south, or, more probably, unable to make head against the strong easterly currents between the atolls.

The establishments on all these oil-islands are very similar and will be treated of later ,on. The Salomon Islands differ little from the rest, save perhaps in their greater richness and in having returned in places to some degree of wild jungle. The islands were noted originally for their "gayac"-trees (Afzelic bijuga), which seem to have been found nowhere else in the Chagos. These trees, admirably adapted to the calcareous soil, appear to have attained an immense size, often 3-4 feet in diameter at 6 feet above the ground, being supported in the comparatively shallow soil by massive buttresses * The largest living trees now exist on Ille Fouquet, but the stumps of the trees which have been cut down for boat-building and export-the wood being a beautiful rich red and taking a high polish-are numerous in Boddam as well. The "bois blanc" (Hernandia peltata), likewise buttressed, contended with the gayac, while a grove of immense "takamaka" (Calophyllum Inophyllum) have given their name to the island on which we camped. The three trees differ in that the "gayac" prefers the hard sandy land in the centre of the islands and is killed by the near approach of the sea, while the "bois blanc" lives best in a mixture of rock and sand and is not killed, though it becomes stunted, if bathed in sea-water; and the "takamaka," trailing its great roots over the ground, loves to cling round rocks among which the sea can freely percolate. In past time, indeed, they formed probably the most characteristic plants in three zones extending inland parallel to the coast. Of course most of the large trees had long ago been cut down, but the shrubs and herbaceous plants served by their appearance to divide up the islands into regions corresponding to the nature of the subsoil-rocky, loose sand, or, finally, hard sandstone or "tuffe." Coconuts flourish best on the coral-rock, and often have an extraordinary undergrowth of immense "langue de bœuf" (Asplenium) and other ferns. They grow but slowly on the tuffe, which is generally rather open land with a small rush ("herbe mosambique") and a few succulents.

The land-animals of Salomon are few in numbers, rats being the only mainmals. The most interesting animal is the "sipaille" (Birgus latro), the well-known coconut- or robber-crab (fig. 13). It abounds in Takamaka, and is caught by baiting places with pooniac (the pressed remains of the coconut from the oil-mills) or roasted coconut. It lives

* Horsburgh refers to these trees in the following terms:- "If a judgment may be formed from the soil and productions these islands," Capt. Blair remarks, "may be supposed much older than any we have visited; the soil is tolerable and much deeper than at Diego Garcia or Peros Banhos, consequently the trees take much deeper root and grow to a greater size. One sort, peculiar to these islands, which appears to be very good timber, grows to the height of 130 feet, many very straight, some 4 feet in diameter, and 40 feet from the ground to the branches. The young timber is white, but the old decajed trees are of a deep chocolate-colonr, and the timber perfectily sound." SECOND SERIES.-ZOOLOGY, VOL. XII. 
in burrows in the daytime, sometimes ejecting the large Cardiosoma for the purpose, and comes out at night. It is then a striking object, standing up on its claws several inches above the ground, with its back dark purple and body white beneath, its long antennæ waving in every direction, its brilliant eyes following our every movement and its great chelæ ready for any attack. The beast is interesting, as it is entirely an air-breathing land form, which nevertheless goes down to the sea to breed and possesses a zoæa-larva. For food it prefers a coconut which has fallen, but will eat any vegetable or fruit. On occasions it ascends the coco-trees, a process rendered easy by the enormous stretch of its limbs, which can clasp round their trunks, and undoubtedly nips off the nuts, subsequently descending to its feast. It opens the coconut with the great chelre. To do this it secures itself by its hinder legs to some rock beneath, and holding the nut

Fig. 13.

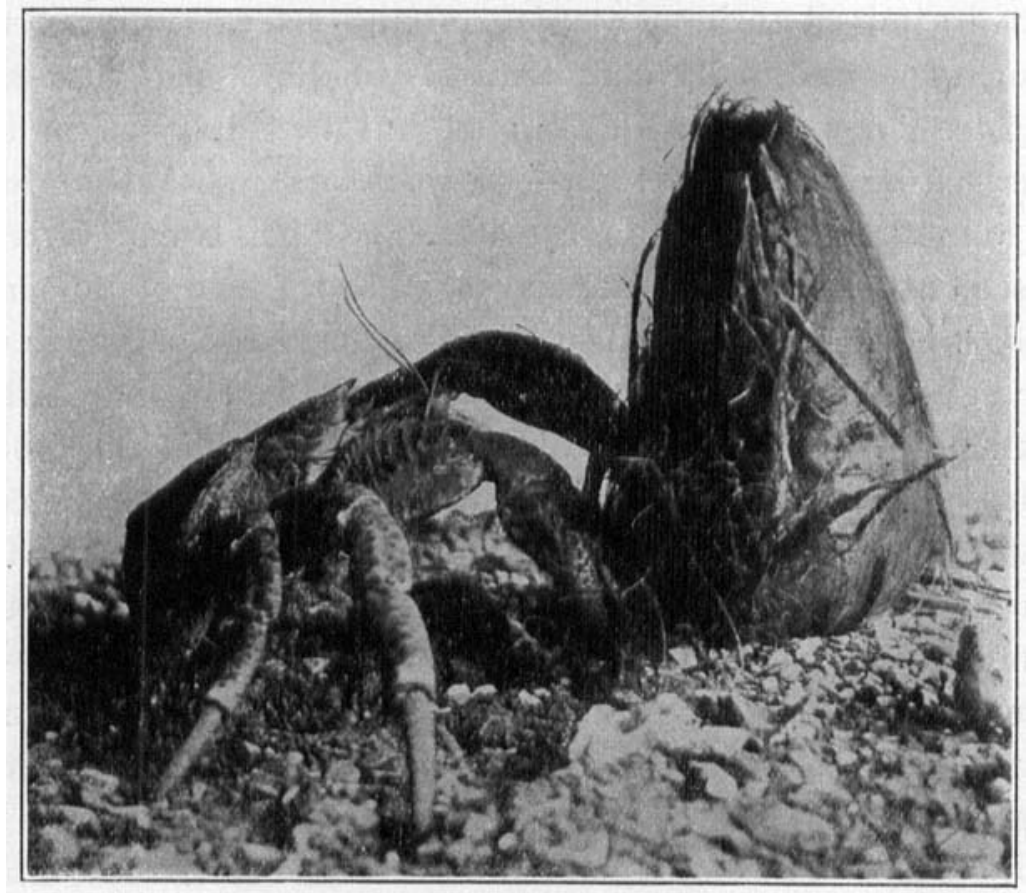

Birgus latro attacking a coconut.

firmly by one claw, it strips off the husk with the other. Next it keeps biting at the shell in one spot until it breaks through, and then chip by chip enlarges the aperture to the requisite size. As each large Birgus consumes probably at least 250 nuts a year, the damage it does causes it to be carefully sought after, and it is, moreover, of most delicate flavour. Of other land-crustacea there is the yellow Geocarcinus under every heap of coconut-husks, the hermit Coenobita, the burrowing Ocypode of the beach, and a few Isopods near the settlements. Earthworms are scarce, save in the regular planted land, and of Land-Mollusca we found not a single species. The only reptiles are Geckos, which are preyed upon by a few of the spiders, the latter taken together being neither abundant in actual numbers nor in variety. Scorpions, centipedes, and millipedes are represented by one or two species of each. The inscets generally are 
much of the same facies as those we found in the Maldives, but not half so numerous in species. Indeed only the strongest of fliers occurred, together with such as might have been brought by human agencies. The only land-birds are the little grey bittern (Butorides atricapilla) and sparrows, the latter introduced from Mauritius, but curlews, whimbrels, sandpipers, and plovers appear to be regular visitants from a distance, and we saw a martin on one occasion. Of sea-birds there are terns, noddies, and gulls, and frigate-birds constantly made their appearance. Guinea-fowl were introduced many years ago and a few still exist in a wild state on Takamaka, Foquet, and Anglaise.

The encircling reef of Salomon Atoll* does not materially differ from those of the Maldives. It consists of the same parts, but is in no wise hollowed out in the centre. Its one peculiar feature lies in the fact that in places its surface close to the lagoon-edge is covered by dead masses of coral-rock, almost like the "pinnacles" which are such a

Fig. 14 .

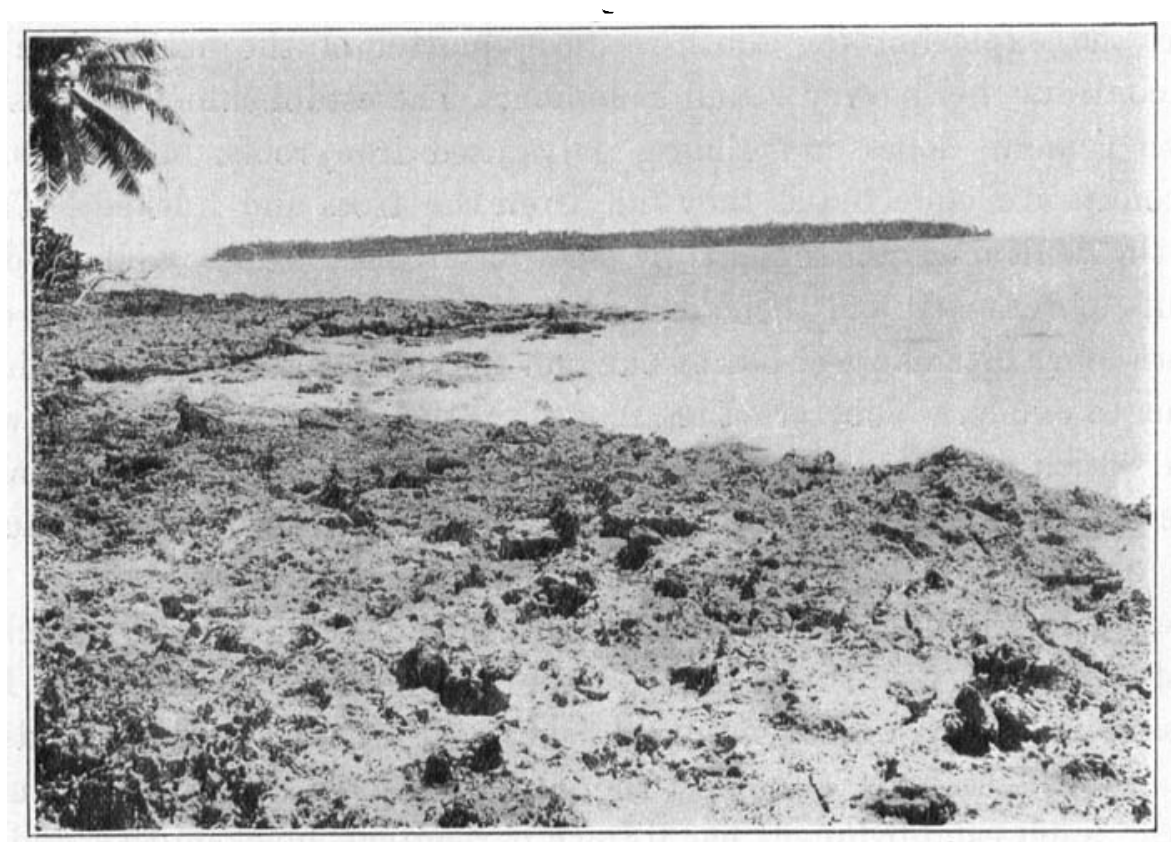

View along seaward side of île Mapou, Salomon, showing coral-rock and lle de la Passe.

marked feature on the seaward sides of so many reefs. Probably, like the latter, they point to the previous existence of land; and, if so, the form of the land and reef must have been very different in the past. The outer edge of the reef is everywhere remarkable in being almost completely covered by Lithothamnia (calcareous algx), which in this position are solely responsible for its growth. 'The lagoon is, of course, of the most enclosed type; it is studded with shoals formed entirely of massive coral-heads, but otherwise is singularly barren of life (even as compared with Diego Garcia, which we subsequently dredged as well). The reef-animals in their general facies had the same appearance as those on other similar reefs in the Pacific and Indian Oceans, but it

* Salomon Atoll with its reefs will be the subject of a special detailed report and examination in connection with the formation of the coral-reefs visited by us. 
became obvious after a week's collection that the variety of species was much less. The corals, among which so many of the free-living animals dwell, were the same, but the branching Stylophora was unusually common. Echiuroidea were not found, and in turning over and breaking up coral-masses, Crustacea, worms, and molluses were comparatively scarce, and only a few specimens of Ptychodera were secured. To a certain degree this lack of variety was made up, it is true, by an increased abundance of certain forms, but it is obvious that the greater the variety of forms, the larger the number of sites that can be filled and the greater the total number of animals. We shall, however, only be able to see as publication proceeds how far there was really a lack of variety, and to what extent the Chagos Archipelago is of value in considering the distribution of marine animals.

On June 17 we re-embarked on the Sealark, and the same day came to anchor off the settlement on Île du Coin, at the south-west corner of Peros Banhos. Here we were welcomed by Mr. Leal and his amiable wife, with whom we stayed until the 25th, collecting in and exploring the south-western quarter of the atoll, while the Sealark returned to continue her survey round Salomon. The establishment consists of dryinggrounds with cement floors and sliding galvanised iron roofs, oil-presses, stores, \&c. The ripe coconuts are collected as they fall from the trees and husked. They are then brought to the central establishment by hoat, or in the islund itself by donkey-carts. Next, the nuts are cracked and their kernels removed; sometimes they are damped with water, but are more often spread out at once on the drying-ground, where in 4 to 6 days the oil begins to exude. They are then placed in the mills, large iron or wooden pots, with a beam, which is caused to revolve by mules or donkeys harnessed to a shaft. The oil is drawn off from time to time and allowed to settle, when it is placed in tanks, ready to fill up the barrels brought three times yearly from Mauritius by the brig 'Wm. Turner.' In the best mills about 64 per cent. of weight of the kernel is extracted as oil against 75 per cent. in steam mills; the remainder forms pooniac (in Europe when further pressed known as one form of oil-cake). It is used in the islands for feeding the donkeys, mules, chickens, and pigs, the latter regularly being killed and sold to the black labour. Each establishment has its own carpenter's, blacksmith's, and shipwright's shops; its. own soap-boiling. house-a coarse soap being manufactured from oil and carbonate of soda, obtained by burning the coconut-husks,-its piggeries and its donkeyyards. There is also a " boutique" opened every evening, where ordinary negro goods can be bought, an office, and a small jail, the Administrator necessarily having some of the powers of a magistrate.

The produce of Peros consists of about $2,800,000$ nuts per annum, producing 65,000 gallons of oil. About 120 green turtle (Chelone mydas) are caught annually for food, when they land to lay their eggs at night during the south-east monsoon. In addition about 35 shell-turtle ( $C$. imbricata), worth over 2000 rupees, are obtained in the northwest monsoon; they differ from the last in always depositing their eggs in the daytime.

The establishment on Peros is a large one, having, in addition to Mr. Leal, a SubAdministrator (M. Vendries) and an Accountant, each provided with a good bungalow, with their families 13 persons in all. The labour consists of 85 men, 51 women, with 
between them 30 boys and 36 girls. They are of two classes, imported negro labour from Mauritius and "enfants des iles," mostly of mixed negro and Indian blood, many the descendants of negro slaves at the time when the oil-mills were turned by manual labour. We saw one old women who had herself been so employed at Diamant; she was, according to the hooks, 103 years old and remembered Moresby quite well in 1837 . The "enfants des iles" make far the best workers, being accustomed to the sea from childhood, and, as they increase, will do away with the necessity for importing labour; when young they wander from place to place in the Chagos, perhaps making a voyage to Mauritius for a wife, but almost invariably return to the land of their birth. Each has a separate house of wood and coconut-leaves for himself and family and often a small

Fig. 15.

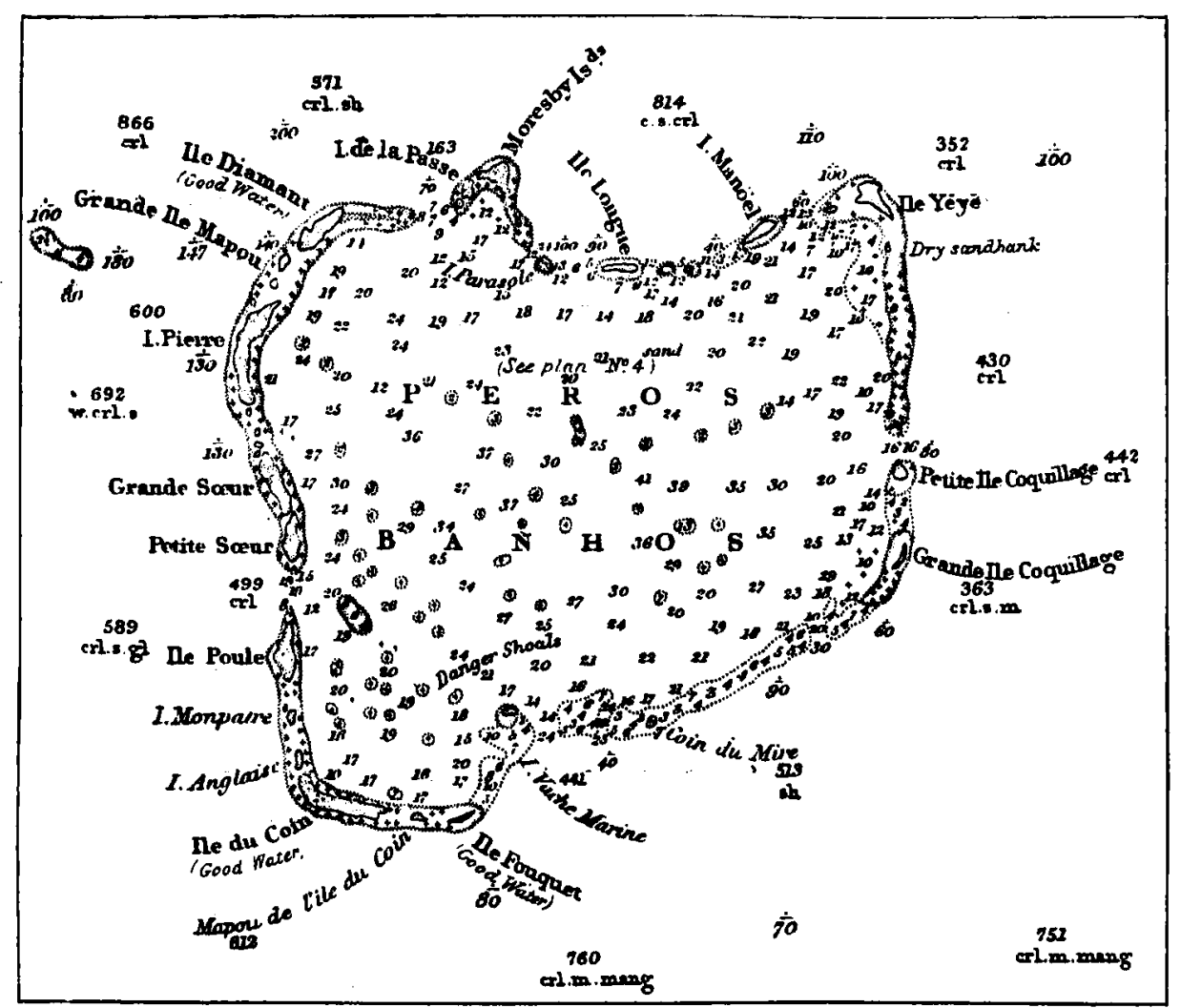

Peros Banhos Atoll (from the Admiralty Chart, with large corrections by H.M.S. Sealark).

enclosure for bananas, marrows, papayas, \&c. All are nominally Roman Catholic, and there is a small shrine dedicated to St. Joseph cut in the base of a bois blanc, before which candles are burnt. Their pay varies from 8 to 35 rupees a month, and is entirely for piecework. Women and children can earn 4 to 12 rupees by splitting open coconuts and cleaning the ground underneath the trees. Generally the task is completed by midday, but the people are too lazy ever to undertake a second on the same day. In addition each individual gets weekly $12 \mathrm{lbs}$. of rice, a little dall, curry stuff, oil, and salt, in addition to some vegetables and such fish as he or she likes to catch. A certain amount of the strong wine of Provence is kept in the store, one bottle being allowed to be bought daily. There is no crime, only a little drunkenness and a 
certain amount of quarrelling about domestic relations, which are decidedly mixed. The islands are singularly healthy, though the manager keeps a good supply of medicines and acts as doctor in cases of necessity.

Our time was very fully occupied while we were at $\hat{I} l e ~ d u$ Coin, as we examined and collected practically in every part of the 8 miles of continuous reef, on which it forms the central island. We devoted this special attention to it because, being largely open to the south and swept by strong currents, it might differ in some of its characters from the reefs of Salomon, Diego, and Egmont, and resemble the isolated reefs of the Great Chagos bank. In this we were not disappointed, since the reef appeared to be extending on either side at the expense of both ocean and lagoon. Its outer (seaward) edge consists of buttresses, 2-8 yards broad, covered with Lithothamnia, and divided one from the other by deep fissures 20 to 40 yards long, which gradually lessen in width and depth as they penetrate into the reef-flat. The inner (lagoonward) edge is less irregular in outline and to a large extent is composed of massive coral-heads which have grown up and fused with the adjacent reef-edge, the interstices between them becoming filled up with sand and rubble. Off Mapous de l'île du Coin the inner edge is more or less consolidated by encrusting Lithothamnia, which are not present off Île du Coin itself or further north. Indeed, the lagoon-slope there is quite irregular and supports corals of many kinds, such as Mussa, Madrepora, Stylophora, and Pocillopora, at depths of 5 to 10 fathoms; while in the shallower waters down to 4 fathoms dominate the massive corals Siderastrea, Orbicella, Goniastrea, Prionastrea, and above all Porites with its broad heads, 20 feet in diameter, decayed in the centre, and spreading outwards on all sides. The well-defined edge of the reef is formed by the growing together of these corals, the spaces left between them being filled up by various smaller species of reef-corals together with Millepora, Alcyonacea, and, further in, with Heliopora and Tubipora.

On either side of the islands the reef-flats, each in accordance with its mode of formation, are outside a flat of solid rock and inside a conglomerate of huge blocks of decaying coral with patches of soft discoloured sand between. The reef-edges on the two sides show their different composition, for while the outer, covered with hardy surfloving Lithothamnia, steadily presses its way seawards against the mighty rollers which crash upon it, the inner with its corals does little more than hold its own against the far lighter waves which rise up in the shallow lagoon. A further difference exists in the complete continuity of the outer reef as against the numerous boat-channels and lesser passages on the lagoon-sides of most of the islands. It is through these passages that the tidal water rushes, bearing with it sand and mud from the reef in sufficient quantities to prevent any corals taking root.

No definite boulder-zone exists on the lagoon side, though there are patches of corals thrown up off Mapous de l' $\hat{I} l e ~ d u$ Coin and again further to the east. It is, however, well marked along the whole length of the reef to seaward, and generally runs into the shores of the islands, or at least is connected with them by ridges and masses of rocks showing where the islands have once extended outwards. The south part of Monpatre has been washed back, but the north part still extends out to the boulder-zone. Within the last 20 jears, however, the sea has cut a passage lehind the latter diagonally through 
the island, separating off a part now termed Gabrielle. The actual land of Mapous de l'Île du Coin and of Fouquet lies 150 yards behind the boulder-zone, as do Coin and Poule in certain positions. The north end of the latter island is being washed away by the tremendous current which rushes round it; its reef, too, in this position is narrow and certainly is not growing out to close up the passage to the north-in fact, the latter, if anything, appears to be widening. The islands between Coin and Poule are hollowed out against each other-in fact, are double-ended. From each end either a rocky point passes on to or behind the boulder-zone; or a sandy point 200 to 300 yards in length runs on to the reef parallel to the lagoon-edge. The outer points, too, are joined along the reef by conspicuous masses of rock, so that there is no doubt but that at one time Coin and Poule, at least, formed part of one elongated island (Pl. 6).

Passing to the lagoon ward points, they are perhaps as extensive now as they have ever been. Probably the islands, as a whole, are growing towards the lagoon by piling up of sand *; and if this continues some may be reunited by banks of sand on the inner parts of the reef. The islands themselves are generally formed of coral-rock towards the outside, solid in some places, loose in others, tuffe or consolidated sand-rock in the centre, and loose sand towards the lagoon. Where masses of rock exist in and behind the boulderzone of the outer reef, they indicate that the island is being washed away, additions from the reef being quite negligible. The boulder-zone, too, is largely formed by the aggregation of loose fragments of coral-rock from the islands. This gradual washing away raises the question of the formation of the islands, but from the area investigated it is not one to which we can give any decided answer. The greatest height of rock above high-tide level we found to be 8 feet, and it was quite uncertain whether its corals were really in situ or not. On the whole, we incline to think that the islands were originally formed by the elevation of a continuous reef extending from Fouquet to Poule and conceivably bridging the northern passage and joining up to the reef, of which Diamant forms the northern island.

The marine animals were strikingly similar to those at Salomon, but the stinging-ray (Tiygon sp.?) is more common. We saw porpoises daily in the lagoon and whales were stated to enter it not infrequently. The marine plants were similar to those which live round most oceanic coral-islands, such as the encrusting Lithothamnia, bunches of the calcareous-leaved Halimeda, and a small variety of the more insignificant forms towards the outer edge of the reef. Between Monpatre and Gabrielle was a considerable growth of a grass-like cotyledonous plant (Cymodocea ciliata), a form which we never met with elsewhere in the Chagos and which we never saw again on the reefs until our arrival at Cargados. Even in Peros it has not spread from this single locality, a relatively still backwater between these two islands, and more probably its absence elsewhere in the Chagos is due to its inability to find suitable surroundings, perhaps proper rootingground, rather than to the improbability of its seeds being. floated over from the Seychelles region where it abounds.

* There is such considerable change and movement of the sand in the two monsoons that we cannot make the statement on our own evidence alone. However, all the older inhabitants are agreed on the subject, and certainly the regetation seemed to bear them out. 
The land fauna and flora are likewise similar to Salomon, but the Casuarina equisetifolia has been introduced and is contesting with the indigenous flora such waste spaces as are left. At the south of Île du Coin there is a large Mapou tree (Pisonia Calpidia), which is about 130 feet high, quite 40 feet higher than the surrounding vegetation and so a conspicuous mark for any approaching vessels. To support its enormous bulk in the comparatively shallow soil it possesses both large and adventitious roots and buttresses,

Fig. 16.

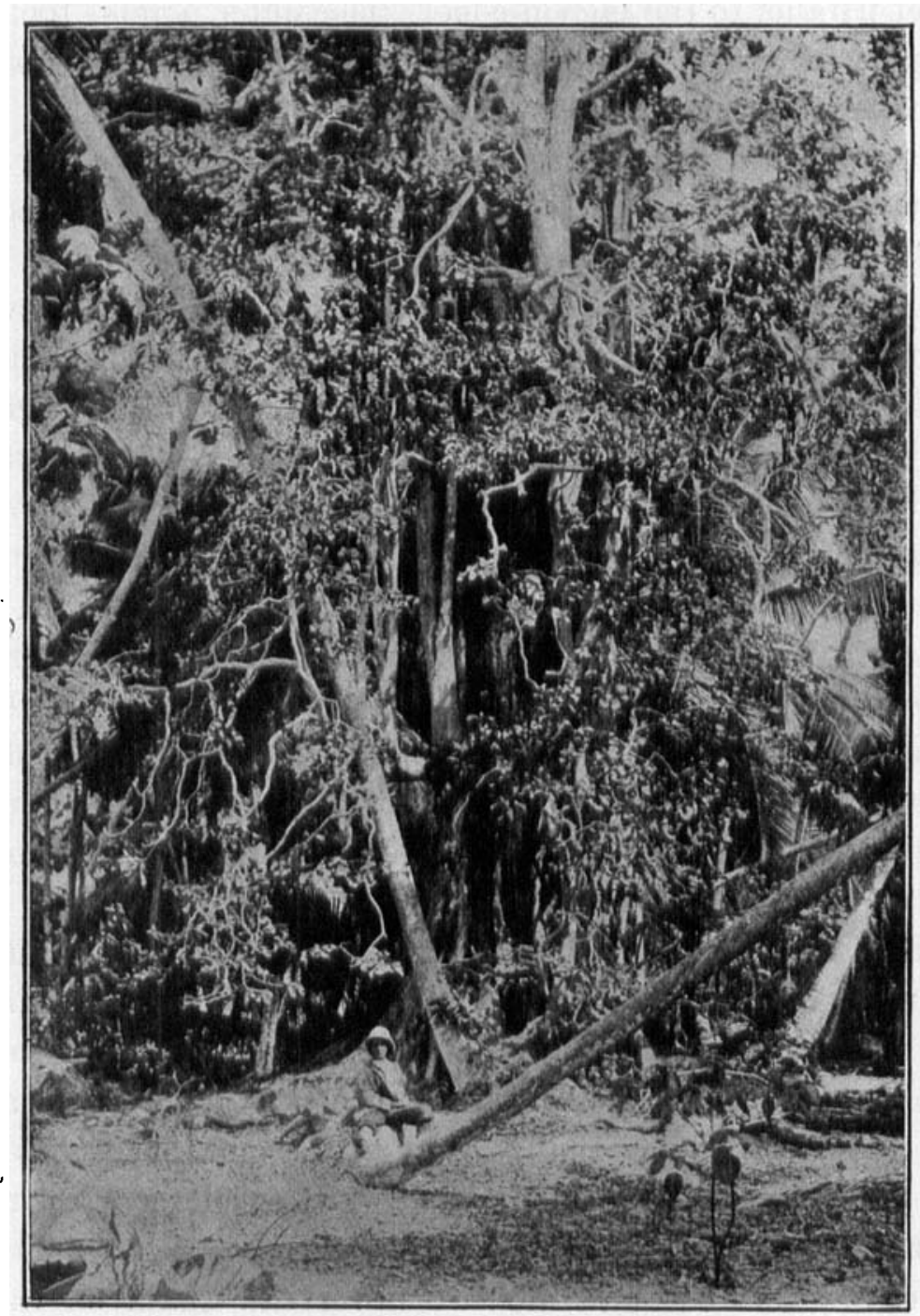

Basc of large Mapou trce about 130 feet high, on Ile du Coin, Peros Banhos.

on the top of one of which we found the letters "R. M.," Moresby's initials cut by his orders in 1837 (fig. 16). As far as possible we collected both the fauna and flora, obtaining about 88 species of plants with the Creole names and uses of most of them, about two-thirds being reputed to have some medicinal properties. Probably about the same number are really indigenous.

We left Coin on June 26 and passed by Ille Vache Marine, a growing coconut-covered 
sandbank and a great resort for turtle, to Coin du Mire, the only land and surface reef on the south rim of the atoll for 8 miles. We were unable to land upon it, but we steamed as close to it as we dared and examined it from the rigging. Moresby found it grown over with bushes, but now it consists of a small flat about 10 feet above the sea-level covered with some clinging green halophilous plant. Around it is a ring of rocks evidently broken off a ragged cliff outside, 4 to 6 feet in height. Below this, about 5 feet above the sea, it appears to rest upon a red-looking terrace, 20 yards in breadth, continuous all round except one little patch of sand to the north-west. This again ends in a cliff which is undermined in places. There is no trace of any surface-reef nor, indeed, of any upgrowth in the vicinity, the bottom beneath us in 5 to 10 fathoms appearing very bare and dead. The rock of the island appears to be sand with a certain admixture of coral, perhaps tuffe, a slight horizontal stratification being visible in the upper cliff and the broken-off masses being more or less squared. The island has without doubt washed away materially since Moresby's survey, and is now evidently occasionally completely washed by the spray. ' In another 60 years it will probably disappear if the same process continues, and in yet another 60 no trace of its former existence will remain. It suggested itself to us at once as being perchance the remains of a former great series of islands and surface-reefs extending between Fouquet and Grande Coquillage. If this be so, it follows that Peros is gradually being submerged or destroyed, but this is a matter which demands more careful examination later on.

We reached Yëyë the same evening, and, finding some huts there, decided to camp and examine it and its reefs, particularly in connection with the formation of the coralreefs of Peros. Lieut. Hancock was with us, devoting himself to a survey and section of the island, and we also had the 'Xanthus,' as we intended, if the weather moderated, to visit some of the other islands. Our first object was the examination of Petite Ile de Yëyë, a small rocky islet which had been washed up on the reef to the west. It was just commencing to show its first vegetation in the shape of three coconuts, which after being washed up had germinated (Pl. 7). There were also a few seedlings of manioc (Scavola); and its shores were strewn with the nuts of takamaka (Calophyllum), and we observed those of five other plants as well. Yëyë itself was singularly barren, the greater part of its surface being a great tuffe-flat, studded with clumps of Scavola and Tournefortia, looking like laurels with aged rhododendrons pushing out of the same. On one part of its shore were growing two bushes of Pemphis acidula, the only place where we found it in the Chagos, though in the Maldives it is certainly the most important and widely distributed plant of the shores-especially where they are washing away.

Taking advantage of a fine day we started at dawn for Petite Coquillage, where we spent the whole day examining the island, while Hancock did his best to secure us a representative collection of its birds. It is an oval-shaped island about 11 feet above the high-tide level, or 16 feet above the reef-flat, with a lower belt of loose sandy land. applied to its western side. The higher land is bare, save for one clump mostly formed of papayas and a few small mapou, but its surface is covered with a close matted tangle several inches thick of the "liane sans feuilles" (Cassytha). It was strewn with the eggs of grey-headed terns (Anous stolidus), at least one to every square yard, some

SECONJ SERIES.-ZOOLOGY, VOL. XII. 
broken by the young emerging, but others pierced by the sharp beak of the little green heron (Butorides atricapilla) which abounds everywhere. We found two young terns and some young herons, but it was evidently not the season. In the breeding-time it could not have been unlike the islets of Cargados which we saw two months later covered with sitting birds. On the shores were whimbrel, curlew, plover, dotterel, and sandpipers. Overhead a few terns were flying, and soon a great flock of frigate-birds came to add their noise. Crab-plovers (Dromas ardeola), interesting on account of their isolated position in the bird-kingdom, occupied each coign of vantage as the tide receded. According to the natives a fow breed in the group, but their eggs are hard to obtain, as they are generally placed in a burrow some feet beneath the ground, perhaps that of a Cardiosoma. In the coconut-clumps we found a flock of sparrows, but there were no other land-birds, though the group is stated to be inhabited during the north-west monsoon by buzzards, crows, and martins. In one place we found a pool of slightly brackish water, which had been cut off from the sea, containing a few fish which appear to feed on the stinking mud that covers its bottom to a depth of 8 or 10 inches. The island is only visited occasionally for the coconuts on its lower lands, and boats seldom or never remain for the night, the swarms of ticks and mosquitoes forming a very efficient protection to the birds.

On June 30 the Sealark, which had been sounding round Peros and to the north, picked us up and returned to Salomon. For the next five days we employed ourselves in finishing off certain work suggested by our stay in Peros, in preserving our collections and in sounding and dredging. Besides a series of plankton hauls of different sorts, we put down ten dredgings on the slopes of Salomon Atoll at depths greater than 50 fathoms; but we could not hope to do much, having but 200 fathoms of coarse 1-inch wire with a breaking-strain of only $1 \frac{1}{2}$ tons, though to the end of this we added one of the ship's cables. The whole arrangement was awkward, and occupied too much time in letting out and taking in. Our whole record was one of disaster, as we completely lost 180 fathoms of 1-inch rope and three dredges and broke up four others, though fortunately their bags came up intact. In every case the wire was found to be attached to one arm of the dredge only, the stopping having broken. Our catch included among living objects a number of Alcyonaceans (particularly Gorgonians), Antipatharia, a few solitary corals, some sponges and Polyzoa, as well as a few molluscs, Crustacea, worms, \&c. In addition we brought up many hundredweight of dead corals and Lithothamnia, such as can only grow on the reef above, thus clearly proving that it was a talus-slope, and that in fact the atoll was extending outwards on its own débris from the reef above.

We next moved further out, making four hauls to the north, using our $\frac{1}{2}$-inch plankton rope, in 350 to 600 fathoms. Our object was to ascertain for certain the nature of the bottom, which soundings had shown to be generally hard rock. We therefore used sharp-sworded dredges with bags, and in the end abundantly confirmed the soundings, the dredges drawing very evenly over the bottom and only bringing up a few dead leaves of Halimeda and some rounded fragments of corals with a Bathyactis and a small piece of Amphihelia, both corals. From the existence of this hard bottom between all the Chagos banks we are bound to deduce the existence of strong currents 
which sweep the bottom clean between them and which are worthy of careful consideration in respect to their action in fashioning the group. While taking one dredging in 430 fathoms, the ship drifting slightly to the north-west and the dredge going down almost straight, rather underneath the ship, we observed between 150 and 200 fathoms a sudden drawing out of the wire to the east. This seemed so conspicuous that we in the next haul placed on a light trawl with long net and no weights, and paying out slowly we found it sank almost straight to 150 fathoms, but at 180 fathoms was streaming out to east by north. Letting out more wire it streamed out still more and we only got it on the bottom at all by steaming east. There would accordingly seem to have been a surface-current setting west down to about 160 fathoms, passing over a current streaming almost in the opposite direction underneath it and extending to the bottom. We were subsequently to see other and better evidence of sea-currents in relatively deep water, but this was the only case where we found a current underneath moving apparently in an opposite direction to the surface-current. It only remains to say that this last trawl was a singularly fortunate one, as we obtained in it a fish, 2 feet long, not unlike a fishing-frog, with a gape of mouth large enough to easily take a man's head; it is, we are informed by Mr. Regan, the type of a new genus.

We had intended, according to our programme before leaving England, to have gone over the Great Chagos and run a line of soundings across. But the non-arrival of our dredging-wire at Colombo caused us to alter all our plans in the group; and in the months of June and July the weather was so bad that even if we had succeeded in landing on any of the islands of Great Chagos it would have been doubtful when we could have got off again. Besides Nelson Island to the north there are seven islands to the west which are worked for oil by the same company that owns Salomon. Mr. Sauvage had been manager for some years, so that we were able to get some general information about them. The chief settlement is on Eagle Island, consisting of about 65 people with a white manager. It has a reef, apparently very similar to that off Coin (Peros), on the two sides, as also to the south of it has Cow Island, which is stated to be twice as high as any island of Salomon. Of the Three Brothers, the most eastern, Land and Middle Islands, have reefs with flats, but Devil Island between the last two and North Island have practically no reefs. They consist of sandy rock, and appear to be precisely similar to Coin du Mire in Peros and to be suffering the same fate. Danger Island to the south consists of rock and tuffe and has a reef to the north-west; generally boats run directly on to the shore to the east and are quickly hauled up out of danger. The plants are very similar to those of Salomon, but Danger Island is fringed with Pemphis (Bois la Mare). When Mr. Sauvage as a retired ship's captain makes the statement that the reefs round Great Chagos are mostly flat and devoid of life, and that they are generally too bare for the anchor to catch properly, we feel a deep regret that we were unable to examine them, as these facts, if correct, can only mean that Great Chagos is an atoll in process of destruction.

On July 7 we anchored at Diego Garcia to meet a second British India ship with coal, remaining there until the 13th. We waited until the 11th, when Capt. Brown arrived with a much welcome mail and came alongside about noon. They had sighted the atoll 
the previous night, but had not sufficient light to enter. Lying-to the ship had been drifted during the night about 20 miles to the eastward by a current from the west, while actually a stiff wind from east-south-east was blowing. Going on board we found one of our boxes for water-samples, which was being filled by the captain during his run

Fig. 17.

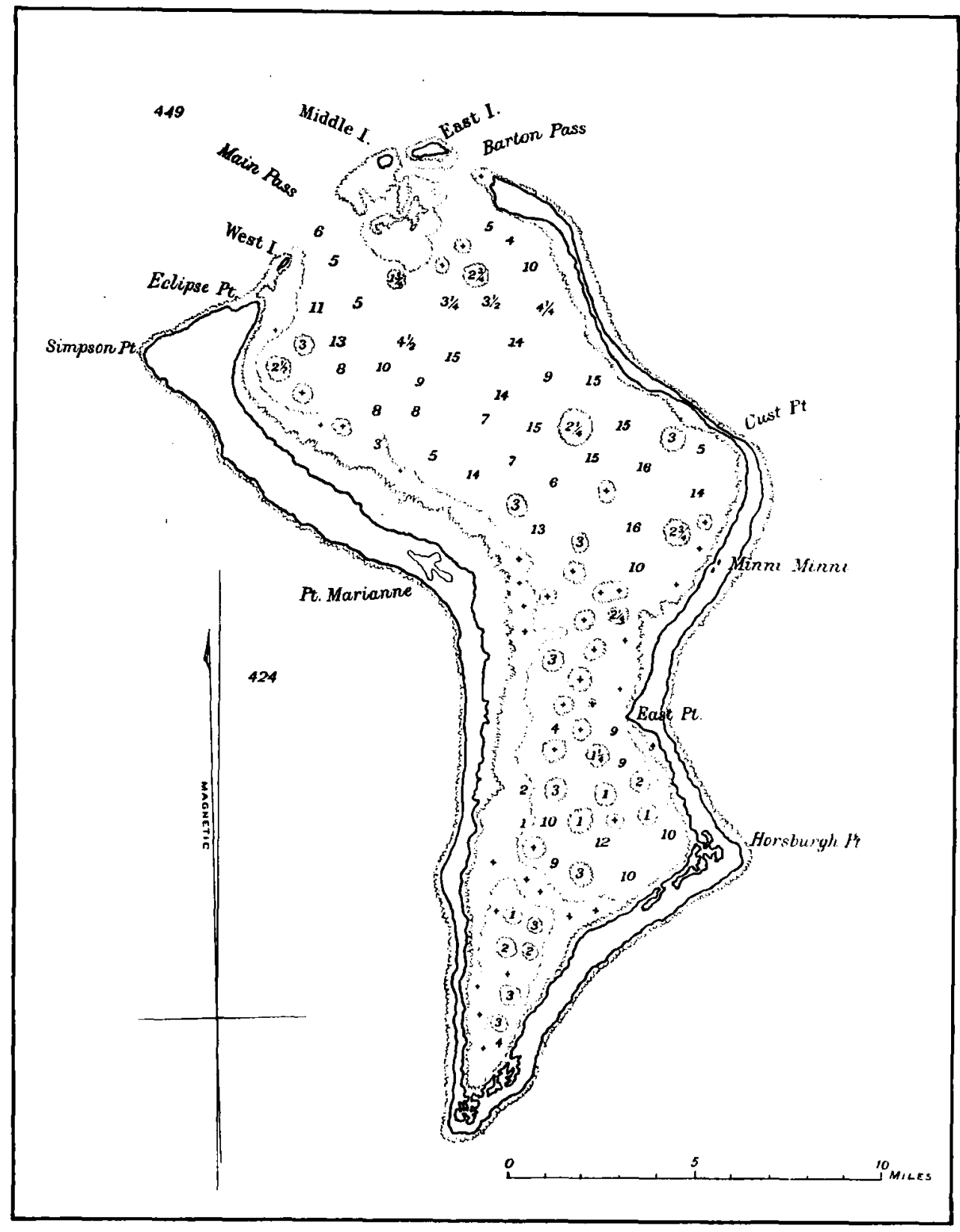

Diego Garcia Atoll (after Admiralty charts).

between Ceylon and Mauritius, this being a line which was regularly worked for us during the year by the British India Steam Navigation Company.

Diego Garcia was first surveyed by Capt. Blair, of the Hon. East India Company's Marine, in 1786, and subsequently by Capt. Moresby, of the same service, in 1837. It was for some time adopted by the Orient Line as a coaling-station between the Red Sea 
and Australia, its northern half during this period, in 1885, being surveved for the third time by Commander the Hon. F. C. P. Vereker, in H.M.S. 'Rambler.' We can give no better description perhaps than that of James Horsburgh in $1809^{*}$ :-- "Capt. Blair states that this Island is one of the most wonderful phenomena of the globe. Its length from north to south is about 14 or 15 miles, and the general breadth 3 to 4 iniles, having the form of a crescent, with the convex side to the eastward. But it may be considered as a steep coral wall standing in the ocean, for the whole interior of the island is a lagoon or natural harbour, which is nearly of the same length and breacth as the island itself, ns there is no part of the circumjacent wall above $\frac{1}{2}$ a mile broad, and the

\section{Fig. 18.}

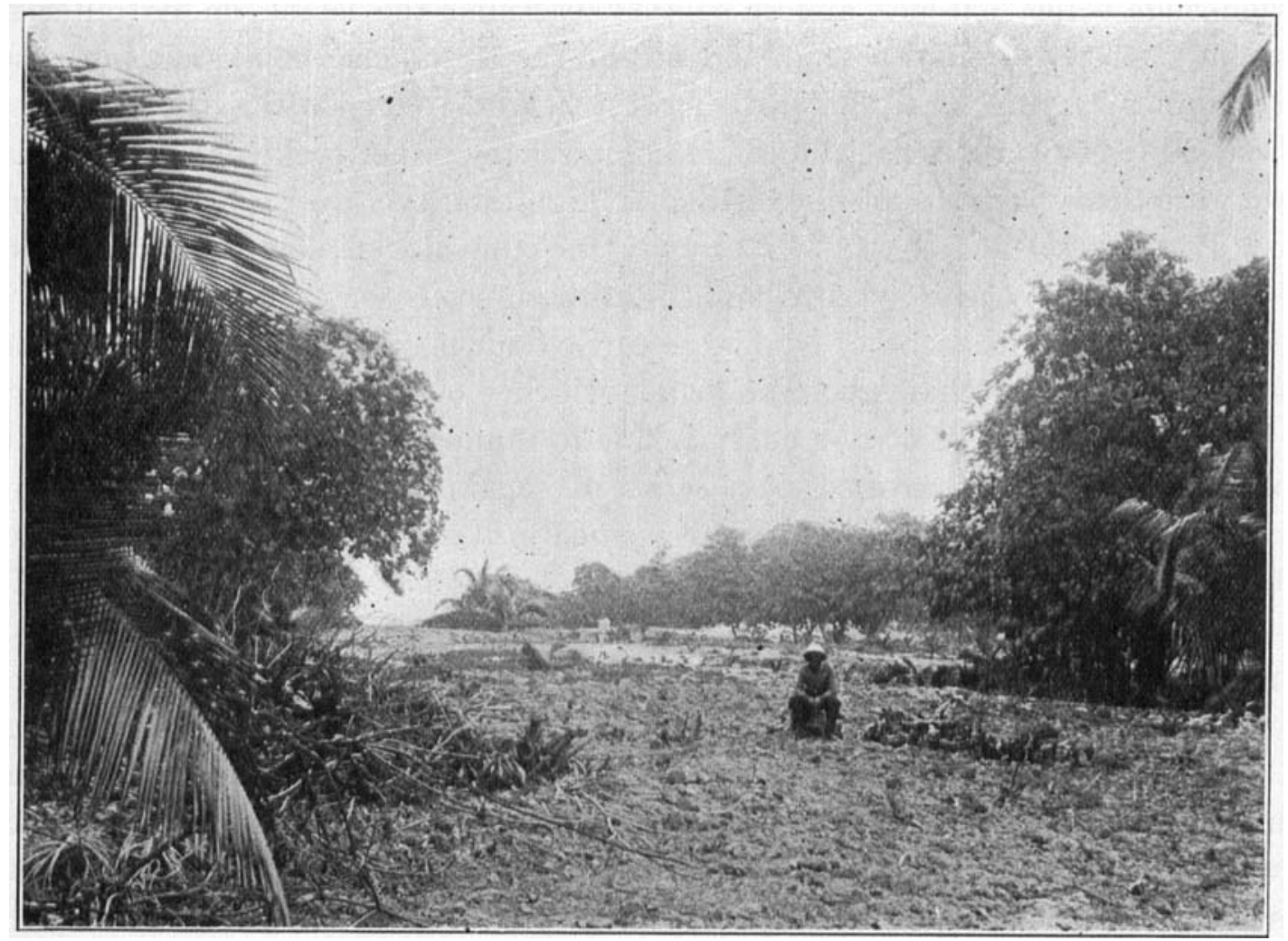

Vegetation on the sandy land of Diego Garciu.

greater part of the eastern side is only about $-\frac{1}{10}$ of a mile in breadth. This Island or contour of an Island is low, generally 8 or 10 feet elevated above the sea at high tides, but inundations of the sea appear to have pervaded the wall in some places, and imparted their waters to those in the harbour. Although low the island is covered with tall cocoa-trees, which makes it visible $5 \frac{1}{2}$ or 6 leagues to sea. A steep coral-reef fronts the sea all round, on which it breaks very high and renders the landing on the exterior impracticable. This reef is steep, too, in most places, there being no anchorage for a ship on the outside of the island except in the entrance of the harbour at the 
N.W. end. The points which form the entrance are called by Capt. Blair the E. and W. points, between them three islands are situated."

This atoll, the position of which was first definitely fixed by the Abbe Rochon in 1769, is, as the above description implies, a typical atoll of great size with its lagoon extraordinarily closed in by land. We anchored opposite Minni-Minni, and from that centre explored the whole atoll, one of us (Cooper) taking the lagoon, which was thoroughly dredged, and the smaller islands, while the other (Gardiner) zigzagged round the whole island from the north-east point round the south end to about 2 miles above Pt. Marianne. We both visited the barachois or backwaters of the lagoon, of which there are seven on the south-east side, extending into the land. Horsburgh's description, which we had not then seen, is wonderfully accurate, but he neglects to mention the great sand-ridge which extends almost completely round the island on its outer side; it is evidently formed by blown sand, and at the north-east end breaks up into a series of barren dunes varying up to 30 or 40 feet in height. Outside this the reef forms a typical flat 80 to 150 yards broad, the shore behind being either rocky or sandy, the latter when we were there having a piled-up ridge at high-tide level over a foot broad, formed of dead "Portuguese men-of-war" (Physalia) and the blue-shelled Ianthina, which is floated over the whole ocean by air-chambers in the mucous secretion of the foot.

Our observations on the rim of land were carried out mainly in view of its formation and its present and past changes. We found evidence of the land having been divided by sea in places. These we do not consider due to inundations of the sea, but rather to the atoll rim having been covered by a series of separate islands, which subsequently became united together. To seaward there seemed to be but little loss going on, though undoubtedly the island formerly extended out for some distance on the reef-flat. Against the lagoon, however, it was very different, the shore often ending in small cliffs or being strewn with fallen timber, evidence of rapid encroachment from the sea. It has no reef-flat, but either tails off gradually or has a sandy flat. In the lagoon, which has a maximum depth of 17 fathoms, one would not perhaps expect to find much life, but so far from this being the case its dredging turned out to be singularly rich in every way as compared to Salomon. Porites and a few other corals occur even at its southern extremity, where the change of water produced by the tides is but slight* Algæ, too, with the exception of the massive Lithothamnia, are more abundant here than anywhere else in the Chagos, and it is evident that the conditions are very suitable for their growth. Perhaps the dead matter carried from the land into the lagoon produces here a sufficiency of carbonic acid for both algæ and corals (which feed on commensal algæ). These would then in their turn liberate enough free oxygen for themselves and for a rich variety of animal life as well.

The present settlements are at East Point and at Point Marianne on the middle of the east and west sides of the island respectively. Everywhere coconuts are planted, and there are from each settlement cart-tracks running north and south, boats being used only for the south end of the atoll. The island belongs to the same company as Peros,

- There is about two hours' difference between the tides of the outer and inner sides of the island at its south end. 
but there is fortunately a small Government Reserve at the north-east end, where the Orient Line formerly had its coaling-sheds. Previously it consisted of about half a dozen properties, the central stations of most of which are only marked now by clumps of "bonnet carre" (Barringtonia speciosa), the large square seeds of which are used for burning and for salad. Its population numbers about six hundred, and there are enough "enfants des iles" to make the importation of labour unnecessary. The latter are a fine sturdy race, but they have only recently been attaining to ideas of western decency, and we met a party working in the bush in puris naturalibus, who had apparently as yet little idea as to civilised requirements.

Collections from the barachois were the objects of our special attention, the fauna and

Fig. 19.

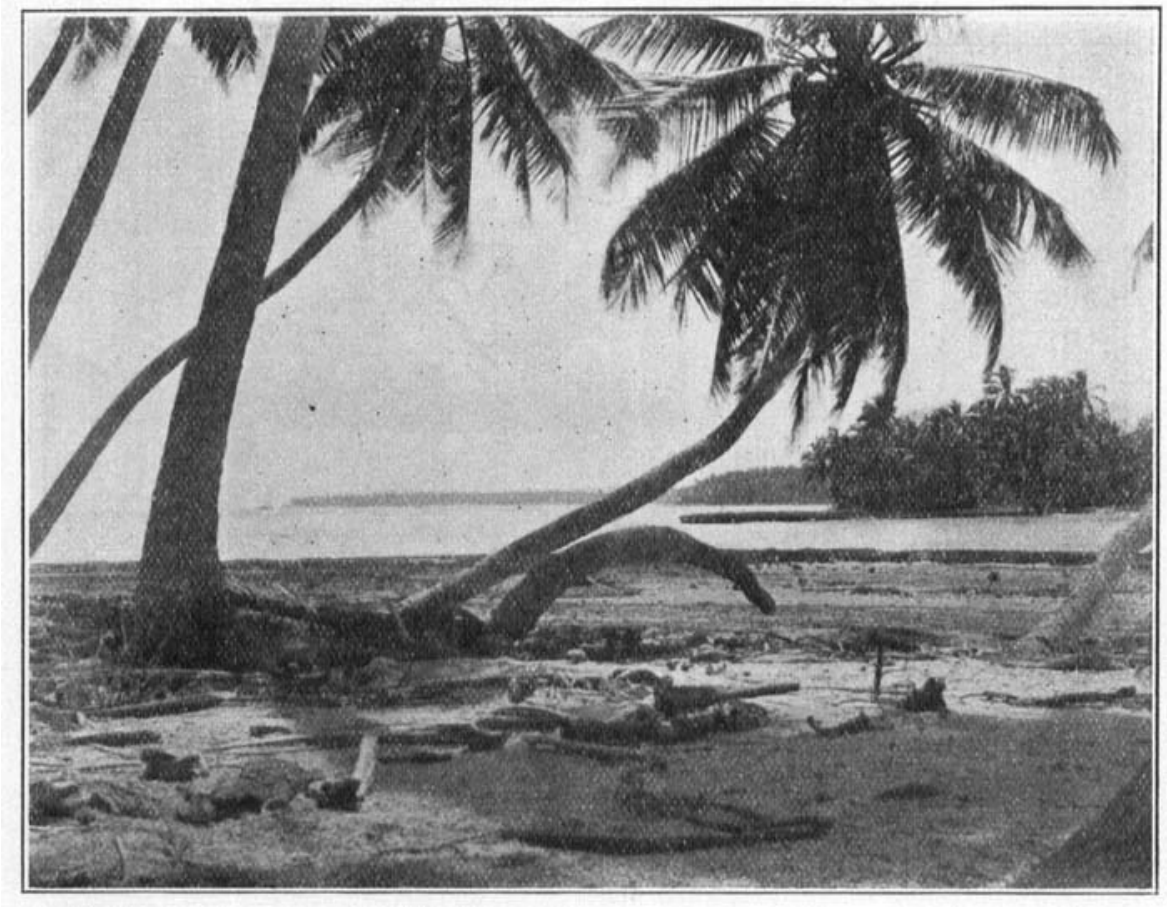

Entrance of Barachois Silvain near Horsburgh Point, and lagoon of Diego Garcia.

flora elsewhere being very similar to those of the other Chagos atolls. One we found to be barred up and used as a pond for fish, being full of mullet, but the rest were open to the lagoon. Their entrances are all relatively small, but inside they open out with horns branching off in every direction; the whole is fringed with tall coco-palms. At high water all parts are covered, but at low tide they form vast expanses of glaring white sand or mud, with perhaps shallow streams in their centres. They are evidently growing, dead and fallen coconuts fringing their sides, soon to be buried by the Cardiosoma crabs, whose immense holes and heaps of soil give a rough appearance to the ground. On the flats, too, which are regularly covered by the tide, any coral-mass or stone is as quickly buried by Uca. These interesting crabs burrow as near to each other as worms in our 
meadows, and perhaps as deep. Each hole is iniabited by a male and female, which differ in that the great chelæ of the female are equal-sized and small, while that of the right side of the male is as big as its body and of a brilliant pink colour. They come out freely at night, but never wabder from their holes in the daytime, the males often resting in their entrances with their eyes just above the ground and their great claws standing up straight into the air. Preyed on to a large degree by the crab-plover, they have become extraordinarily quick, and the least shadow, that of a stone thrown from under the coconut-trees over them, will cause all those for 2 or 3 yards on either side of its line to disappear. Of the birds, gulls, terns, dotterel, and herons abounded, and we saw also a few snipe, preying for the most part on worms of various sorts. In the wetter parts a bivalve, like an Orca, was very common in the mud. It must also have been

Fir. 20 .

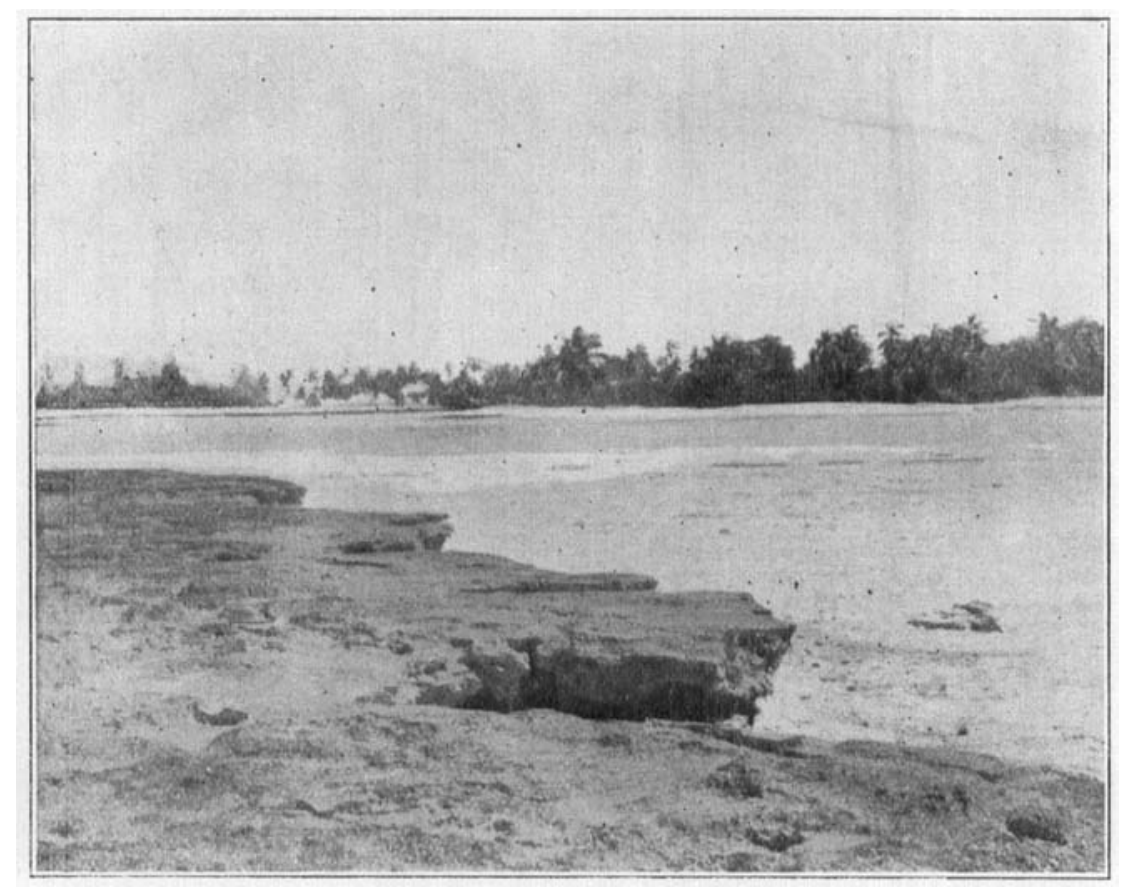

Low cliffs fringing Barachois Maurice, to the south of Diego Garcia, at low tide.

often pecked at by birds, for it appeared to have acquired a definite habit of nipping off the end of its foot and of disappearing into the mud when disturbed, the small masses of tissue, the size of a hazel-nut, which we picked up causing us at first considerable perplexity. Here and there might be found, at the tops of the barachois, pools of water to which the sea at springs alone had access. In them were invariably a few fish and often prawns, neither of which seemed to have been in any way affected by the brackish nature of their water. Again, in others containing still fresher water were dragon-fly larvæ and beetles, though no weed was able to grow. In one swamp near East Point were tortoises, doubtless introduced many years ago from Zanzibar or Madagascar by the natives. In such positions, too, in the decaying wood, were multitudes of Isopods, 
with an equal number of spiders which preyed upon them, as well as earwigs, cockroacbes, and an occasional scorpion and centipede. Rats abounded, scavenging the barachois-flats at low tide for anything that might be left behind.

On the morning of July 13 at 6 A.M. we weighed anchor for Egmont, intending to sound round Diego Garcia and between the two atolls. At different depths off the north of Diego Garcia we took water-samples for the gases and salts in solution. The former were taken in vacuum-tubes of about 300 c.c. capacity drawn out to fine points at either end. The finer end being inserted into the tap of the water-bottle, the cock was turned so that the point was broken and the tube was filled from its contents, the broken end being subsequently resealed. The soundings taken showed that Diego Garcia is rather steeper in its slopes than any of the atolls to the north of Great Chagos, and also

Fig. 21.

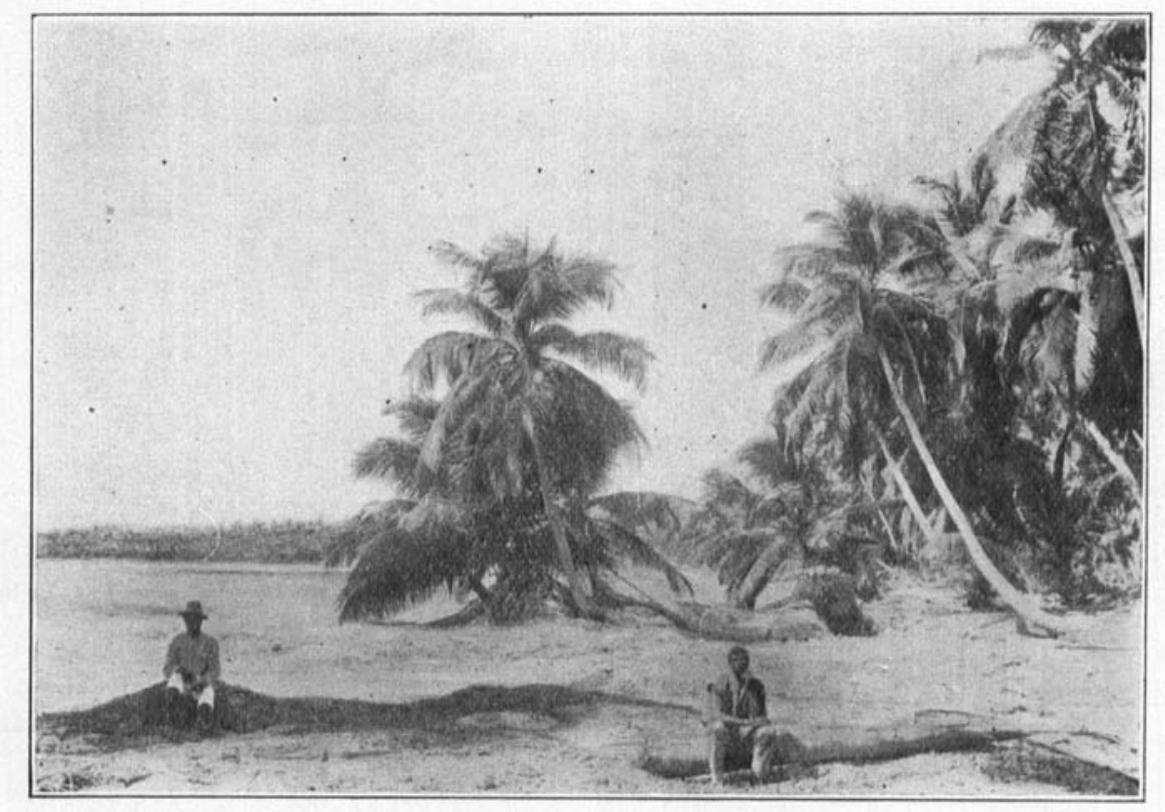

View in Barachois Silvain, Diego Garcia.

that the general depth of the whole Chagos bank is apparently rather greater in its southern half.

On the following morning we anchored off the entrance to the north of Egmont Atoll, with a heavy swell running and a strong wind from the south-east. To secure good anchorage on the outer slope of an atoll is always a difficult matter, as the shore-platform may be so smooth as to afford no holding ground or so rough that the anchor fouls and is lost. A ship should never anchor to windward, but to leeward no danger need be apprehended, as she would only drift into deeper water. This is what happened to us, and we soon found ourselves a mile to the north with the anchor and 60 fathoms of cable over the bows. Steaming up we re-anchored about 120 yards from the reef, and at once lowered the ' Xanthus' to explore the passage and find a suitable camping-ground. As the court-house and estate-office on Ile Sudest were offered to us by M. de Comarmond, SECOND SERIES,-ZOOLOGY, VOL. XII. 
the manager, we returned immediately for our gear and finally got settled ashore by midday, the Sealark at once weighing anchor to continue her soundings round Great Chagos. We retained our native servants, together with the 'Xanthus,' a skiff, and their crews, consisting of 1st Class Petty Officer Titcombe, Leading-Stoker Carter, and A.B.s Bridgeman and Greenslade, the latter a native of Jersey and quite at home with the Creole French spoken by the people.

Egmont Atoll * is slightly smaller than Salomon, and consists of six islands situated on an oval-shaped reef, extending west by north and east by south. It has only a single boat passage into its lagoon situated very near its most northerly part and consisting of a dipping of its reef down to a maximum depth of $2 \frac{1}{2}$ fathoms below the surface for a

Fig. 22.

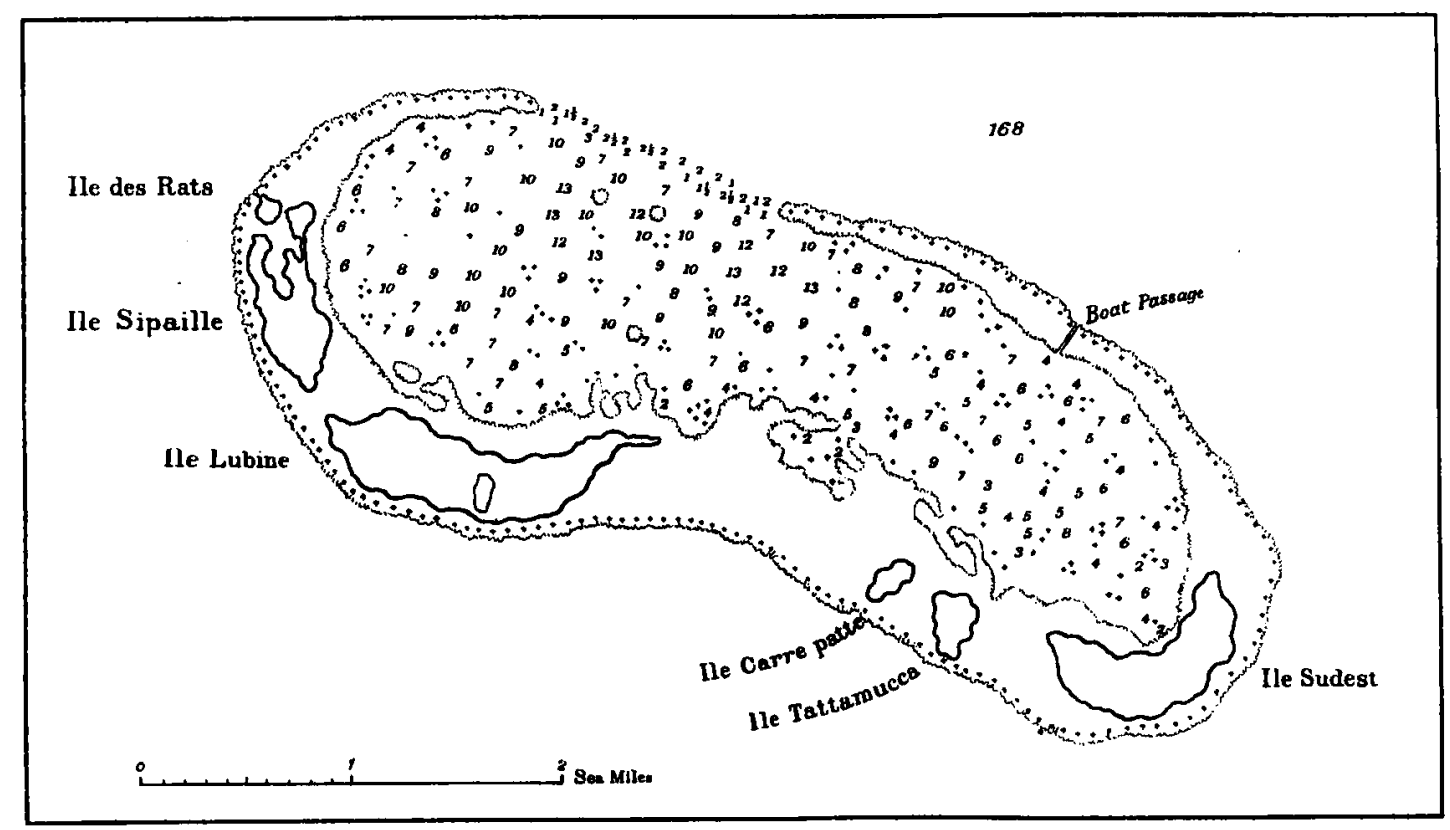

Egmont Atoll (from the Admiralty chart).

length of about a mile. The atoll is peculiar in that the reef of its southern side attains an average breadth of roughly 1000 yards, and, gradually narrowing at its ends, merges into that of its northern side, which is not more than a quarter as much across. The enclosed lagoon is four and a half miles long by a mile to a mile and a quarter broad. It varies in depth from a maximum of 14 fathoms close to the passage. Our own soundings showed that the bottom might reasonably be described as gradually rising from this depth up to the encircling reefs on all sides, the angle of the slope varying with its distance away. The sand covering the bottom becomes to a certain extent coarser as the depth decreases. The whole lagoon is studded with shoals, most of which

* Horsburgh (loc. cit. p. 134) states that the islands were seen by M. de Surville in 1756, by the 'Egmont' in 1760, by M. de Roslan in 1771, and surveyed by Capt. Blair 1786. They were then all covered with timber, three having coconuts. Moresby (loc. cit. p. 64) calls them the "Six Islands," and states that in 1837 they produced 6000 gallons of oil. He found abundance of pigs and poultry, pigeons and fat-tailed land-crabs (Birgus latro). 
reach the surface. In their slopes they, as well as the encircling reef, generally arise with perpendicular walls for the last 2 to 4 fathoms. They are far more numerous and occupy a greater area of the bottom in the shallower waters away from the passage, but at the same time the individual shoals are much larger near the passage.

Judging from the chart there appeared to be on the southern side of the lagoon a peculiarly ragged reef-edge. A series of horns extended outwards from its edge into the lagoon, bending towards each other so as to enclose areas of the latter. If, on the one hand, these were in process of growth, the area of the lagoon would have been reduced considerably in size, and if the process continues the lagoon would ultimately disappear and leave a flat reef. On the other hand, the more or less enclosed areas might represent pits or holes in the reef, velu as they are termed in the Maldives, their inner walls breaking down so as to throw them into communication with the lagoon. In this case the lagoon would obviously be increasing everywhere at the expense of its encircling reef, and it might be supposed that the whole atoll would be growing outwards as a fairy ring. While fully aware that our chart was not sufficiently accurate for us to base any comparison on a firm foundation, yet we considered the question one of sufficient importance to claim our special attention. We may now say at once that we found traces of every horn shown in the chart represented by shoals, some small and some of them large. All the narrower northern extensions shown on the reef between Iles Sudest and Lubine were seen to be cut off from the encircling reef proper by channels of at least 2 to 3 fathoms in depth, the inner edge of the reef running fairly evenly and parallel with its seaward edge. To the north of Carré Patte a small pool 50 yards long and 1 to 2 fathoms deep was enclosed within the reef-edge, but otherwise the whole reef-surface was flat with no trace of any velu.

The above observations on the lagoon all point to the conclusion that it is increasing at the expense of its encircling reefs. If this be the case it must be due to the solution of the lime by the seawater and to the removal of fine particles of coral and sand held in suspension in the water. Seventy years ago Moresby (loc. cit. p. 64) referred to this outwash of mud at Egmont:- "The current and tides sometimes washes the looses and off the reef to leeward and discolours the blue water for half-a-mile, which we took to be shoal water fit for anchorage until we found we were deceived." We ourselves noticed it in the heavy weather experienced both when we arrived at and left Egmont, as, indeed, we have observed it off many other coral-islands. Its effect also was quite clear in the passage into Egmont, in that the bottom was largely formed of bare coral-stone, living coral being relatively scarce.

Yet with all this apparent decay and removal of material from the lagoon at Egmont, we found in it a type of lagoon-shoal altogether new to us. For while the encircling reef had the same general character as that of Salomon, we were surprised to find encrusting Lithothamnia, the most important constituent of its outer edge, to be scattered everywhere except just near the islands. While some shoals were covered by corals and sand, others showed a surface formed entirely by this group of plants. They were found particularly along the north side, being most marked perhaps exactly opposite the passage. One shoal that we visited in this position was about 60 yards across, with a 
flat surface exposed for nearly a foot at low spring-tides. A second near it was similar, about 100 yards across, and slightly hollowed out in the centre, where all the organic growth was dead. Otherwise both were completely covered with every conceivable branching or columnar form of Lithothamnia, every plant being of precisely the same brilliant red-pink colour (Pl. 9). No other important building-agents were found on the surface or slopes of either. Another shoal visited on the same day, to some degree enclosed in the north-west end of the atoll, was similar to the second, being a little dead in the centre, but its surface was formed by dull orange encrusting Lithothamnia. It was obviously, however, a mere skin, its real builders being corals, of which we noted six genera, together with Millepora and Tubipora, growing on its edges. The three shoals examined overhung their bases to some slight degree, but there was no sign of any falling. All seemed so completely covered with organisms, save in their centres, that

Fig. 23 .

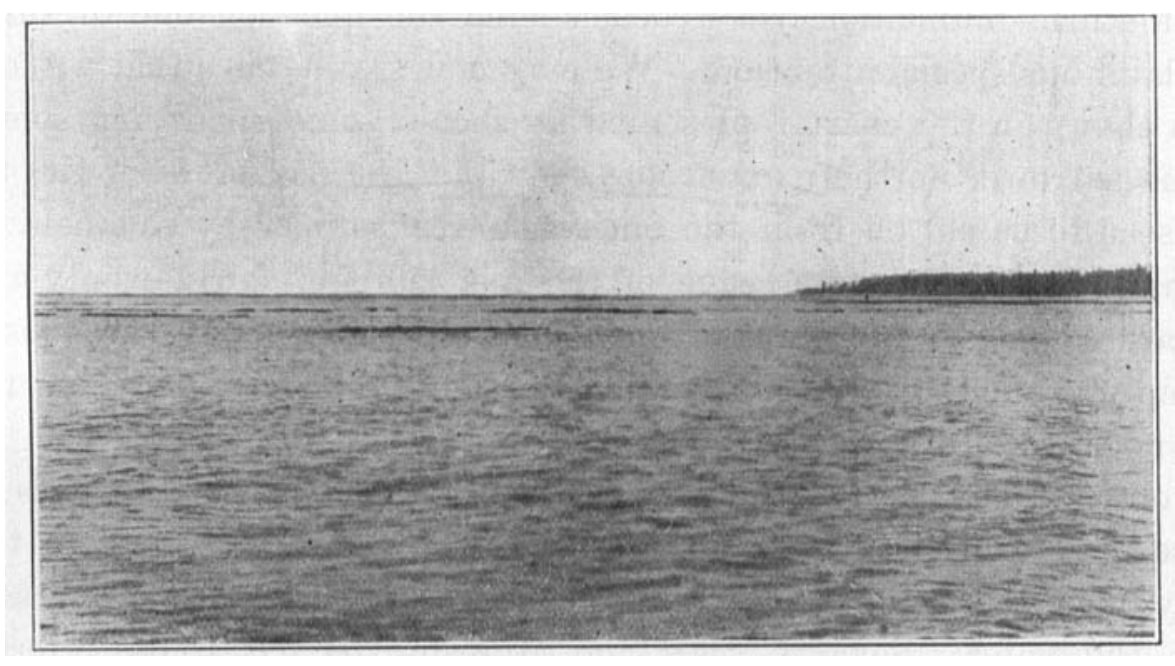

Shoals in the lagoon of Egmont Atoll at low tide.

decay did not seem possible. They forced themselves on our notice, since they would be taken to represent, according to one theory, the first stage of miniature atolls, arising, in this case, within a true atol, the lagoon of which, quite contrary to the same theory, they would be materially aiding to fill up.

The presence of these Lithothamnia shoals would naturally be taken as evidence of oceanic characters in the lagoon, in particular in its having continual change in its water, little being stationary. Theoretically this should mean that a greater varjety of animal life ought to be found than in a more enclosed lagoon. Actually the contrary was the case. The total quantity of sedentary organisms (corals and Lithothamnia) was no doubt greater, but free-living animals were decidedly scarce. The dredgings did not bring up a tithe of what was obtained at Diego Garcia, and reef-collecting was a failure, though we secured some Chitons, Haliotis, and Nudibranchs which we had not seen before. The reason would seem partly to be the absence of nooks and crevices in which animals 
could hide, and partly the fact that the strong growth of sedentary organisms by covering over the rock with organic substance prevented the entrance into it of destructive organisms, such as boring algæ, sponges, worms, and molluscs, on the products of which so many free-living animals-burrowers, sancl-feeders, and scavengers - thrive. The chief coral was a green Stylophora, which quite took the place of the Madrepora and Porites of other atoll-lagoons. Its relatively blunt, massive branches were mostly thickened at their ends with the galls of a crab, Hapalocarcinus. A colony of Madrepora or branching Porites usually yields a rich variety of crustaceans, starfishes, molluscs, and other animals when broken up, but this coral was scarcely infested by a single form beyond the delicate Melia tessellata. This little crab, so conspicuous in its purple and orange body, carries a small green palythoid anemone in each of its slender chelæ, making use of their thread-cells probably both for protection and for securing prey.

Land on an exposed reef is always to a certain degree in a condition of change. Sand is piled up at one end of an island while one wind prevails, only to be washed away and carried to the other end when it blows from the opposite quarter. The six islands now existing are probably merely the remains of an island once continuous along the whole southern side. A junction by a sand-barrier of the lagoon half of Île des Rats to hle Sipaille has been a recent change, while the outer half of the former has been made into a separate island.

The islands themselves are very like those of Salomon, with similarly situated areas of coral-rock, sand, and sand-rock (or tuffe). All have a tendency to be slightly hollowed out and marshy in their centres, though their surfaces in most places lie well above the high-tide level. In the centre of Lubine we found one such marsh covered with reeds 8 feet in height, a condition not found elsewhere on any coral-islands we have visited in the Indian Ocean (Pl. 10). It was like a Mauritian or Ceylon swamp, and presented a most refreshing feature to the eye. It is unlikely that its reed was intentionally introduced, as it is not used for house-thatching or any other purpose. In most places the soil is relatively abundant and richly impregnated with phosphate of lime from former bird-colonies. Île Sudest has a large grove in its centre of badamier (Terminalia Catappa), valuable for its almond-like nuts, while everywhere the growth of ferns and herbaceous plants is extraordinarily rich. The jungle-trees were the same as elsewhere, but there was no trace of the former existence of any gayac. Mangroves were absent, though there were many places along the shore eminently suitable for their growth. Indeed, they were not seen throughout the whole Chagos, a singular fact when we consider their extraordinary adaptability to marine transport.

As elsewhere, we devoted great attention to the land-fauna, but found it very scanty and difficult to collect. Rats and mynahs (the Indian starling) had been introduced, the latter intentionally, so that almost only those insects which hide themselves away have managed to survive. Geckos are exceedingly scarce and mosquitoes consequently are a plague everywhere. However, we found our first land-shell in the decaying trunk of a "bois blanc" (Hernandia), and some beetles, which ordinarily live in guano. Birgus is common- Ille Sipaille is called after it-and does enormous damage. Together with the rats it is responsible for the destruction of as much as a third of the coconut-crops, 
in spite of special natives being entirely employed in trapping them. Birds were as numerous as at Diego Garcia, the larger grey-headed tern breeding in the mapou trees of Île Lubine, to the tops of which all the whimbrels and curlews of the whole atoll seemed to direct their flight when disturbed, constantly tumbling off in the wind, their feet being ill-adapted to a perching-habit.

During our stay of nine days at Île Sudest we had ample opportunity of seeing the oil-establishment, which differed in no respect from that described elsewhere. The produce is about 26,000 gallons per annum, which may be increased to 40,000 when certain new plantations come into bearing. The islands belonged then to the Hon. Leopold Antelme in Mauritius, but have since been bought by the company which owns Diego and Peros. The whole had evidently been somewhat neglected, but the plantations had more the characters of cultivation, the trees being in lines, 34 feet apart, with 30 feet between the rows. The population consists of about 120, 53 adult males with a white manager, M. Gaston de Comarmond. At first the people were perhaps rather afraid of us, but ended by making great friends with the 'Xanthus' crew, for whom they got up fish-spearing excursions by torch-light and coconut-husking competitions.

On the whole, we can now look back on our stay in Egmont with considerable satisfaction. It was the period of spring-tides, and we were enabled to get out and collect upon the reefs both by day and night. The crew of the 'Xanthus,' too, were by this time thoroughly experienced in collecting, and we managed to put down about twentyfive dredgings in the lagoon. The weather had been showery and was especially suitable for land-collecting; and we had by that time got accustomed to the peculiar modes of life adopted by most forms of insects. Although we preserved a considerable number of organisms, we found very few which had not been already obtained in the Chagos. We are led therefore to hope that the collections of marine and land faunas and floras which we have brought home are sufficiently extensive to be of real value for comparison with those of the Maldives and other areas of the Indian Ocean. At a glance it is obvious that all Chagos atolls are of purely oceanic type, and we may expect that when worked out they will give a firm basis on which to estimate the possibilities of distribution to newly formed land across wide areas of the ocean.

The night of July 23 was spent at anchor in Diego Garcia lagoon, and the following day we sailed for Mauritius. Our first objectives were two submerged banks, to the south-east of the group. We anchored on them on following days, Hancock going off in the whaleboat and running lines of soundings out from the ship. It was unpleasant work, as there was a heavy swell caused by the strong south-east trade-wind, broken up into a confused sea by the shallowness of the banks. We had no time to explore either bank fully, but where we passed on and off each we saw no trace of any uprising rim. The sea was too milky to allow the bottom to be seen plainly, even in 10 to 12 fathoms, but we took 25 samples of the bottom with the snapper lead from each bank. From these and what we could see we judged that there was little coral-growth (though we picked up a fragment of Psammocora) and practically no Lithothamnia. Large areas appeared to be covered with spreading Alcyonaceans, between which was sand, almost entirely composed of the shells of pelagic species of Foraminifera. 
Our next objective was the supposed position of Owen's bank to the north-west, on which we got a depth of 2100 fathoms. We continued the same course to lat. $4^{\circ} 48^{\prime} \mathrm{S}$. and long. $67^{\circ} 22^{\prime}$ E., the latter almost halfway between the longitude of the Chagos and that of the eastern edge of the Saya de Malha bank, finding there a depth of 2173 fathoms, bottom globigerina-ooze. We then set an almost direct course to Mauritius. The voyage was devoid of incident, though we sighted a brigantine one day, evidently an oilboat bound for the Chagos, and the only ressel we saw during our six months' cruise except in port. The weather was against us the whole time, but every day we sounded, each sounding serving to give additional evidence that there is no connecting-bank of shallower water between the Chagos and the Mauritius-Seychelles line. Occasionally the ship was swung for variation, and serial temperature observations were constantly taken from the poop down to 200 fathoms during soundings. We gave up further sounding and sailed the last part of the way, our coal-consumption having been rather heavier than we had expected on account of the strong winds experienced. Our progress by no means came up to expectation, but fortunately we had enough coal in reserve to carry us into Port Louis on August 5, the thirteenth day out from Diego Garcia, the first half of our journey and work accomplished.

[Part II.-See page 111 onwards.]

\section{EXPLANATION OF THE PLATES.}

\section{Plate 1.}

Map of the Indian Ocean, on the scale of $1: 7,000,000$, or 1 inch $=110 \cdot 47$ statute miles.

Plate 2.

H.M.S. Sealark.

Plate 3.

Sounding on H.M.S. Sealark.

Fig. 1. Andrews and Wise taking a deep sounding.

Fig. 2. Webber, Andrews, Baily, Wise, and Williams : a sounding-party with the Lucas Machine.

\section{Prate 4.}

Dredging on H.M.S. Sealark.

Fig. 1. Looking forward along the starboard side during a sounding.

Fig. 2. Rectangular dredge coming in.

Fig. 3. A big haul, trawl badly bent up.

\section{Plate 5.}

Salomon A toll.

Fig. 1. View from Takamaka across lagoon.

Fig. 2. Typical dry sandstone-land on Anglaise with coconuts. 


\section{Plate 6.}

Peros Banhos Atoll.

Fig. 1. Reef looking seaward between Gabrielle and Monpatre.

Fig. 2. Coral-rock and seaward reef of Anglaise at low tide.

\section{Plate 7.}

Peros Banhos Atoll : commencing vegetation.

Plate 8.

Diego Garcia Atoll.

Fig. 1. Reef of east side at low water.

Fig. 2. Shore and inner flat looking south.

\section{Plate 9.}

Egmont Atoll: Shoal in lagoon covered with masses of Lithothamnia.

Plate 10.

Egmont Atoll : Swamp in Lubine surrounded by coconuts. 


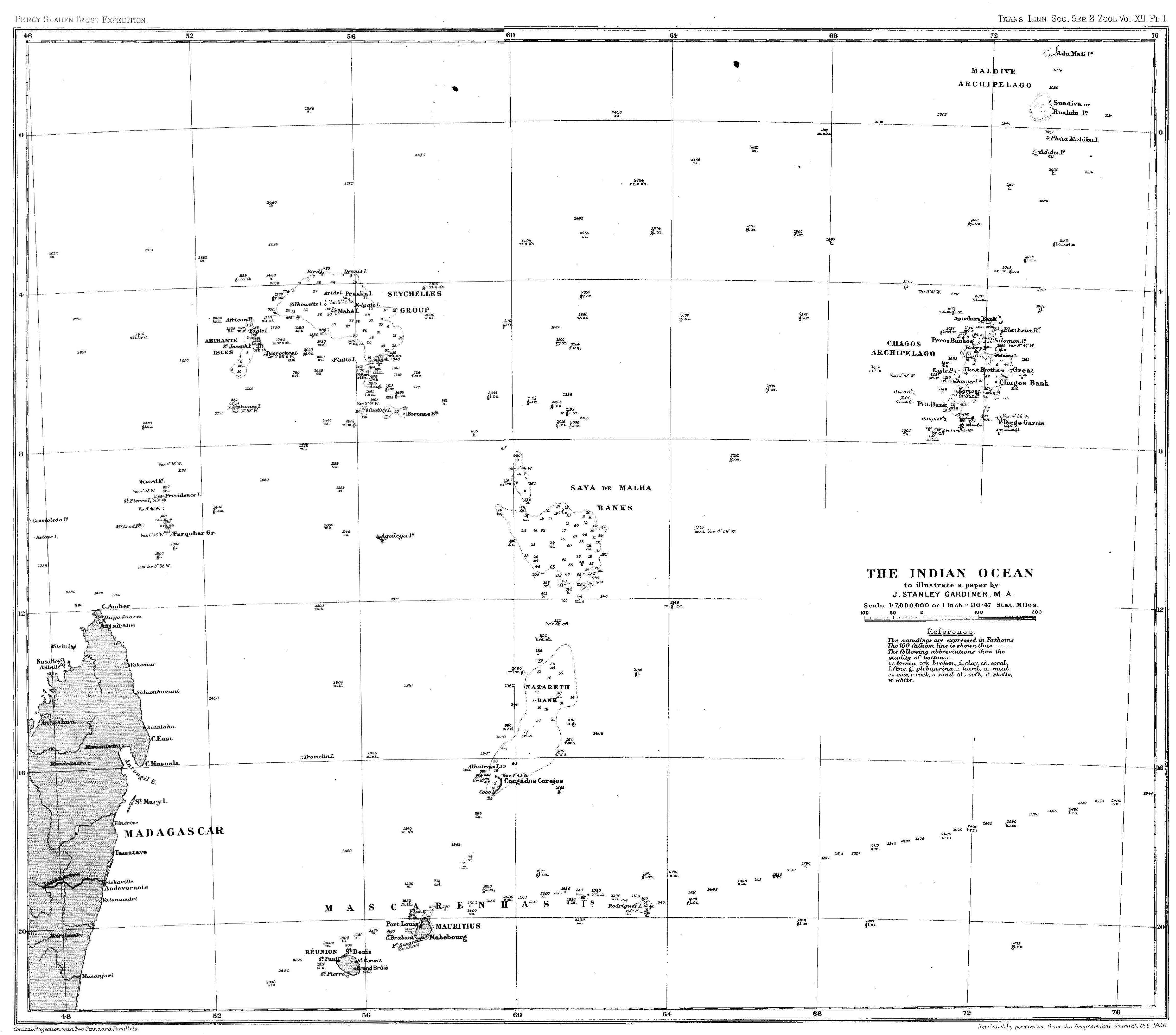


TRANS. LINN. SOC. SER. 2, ZOOL. VOL. XII. PI. 2.

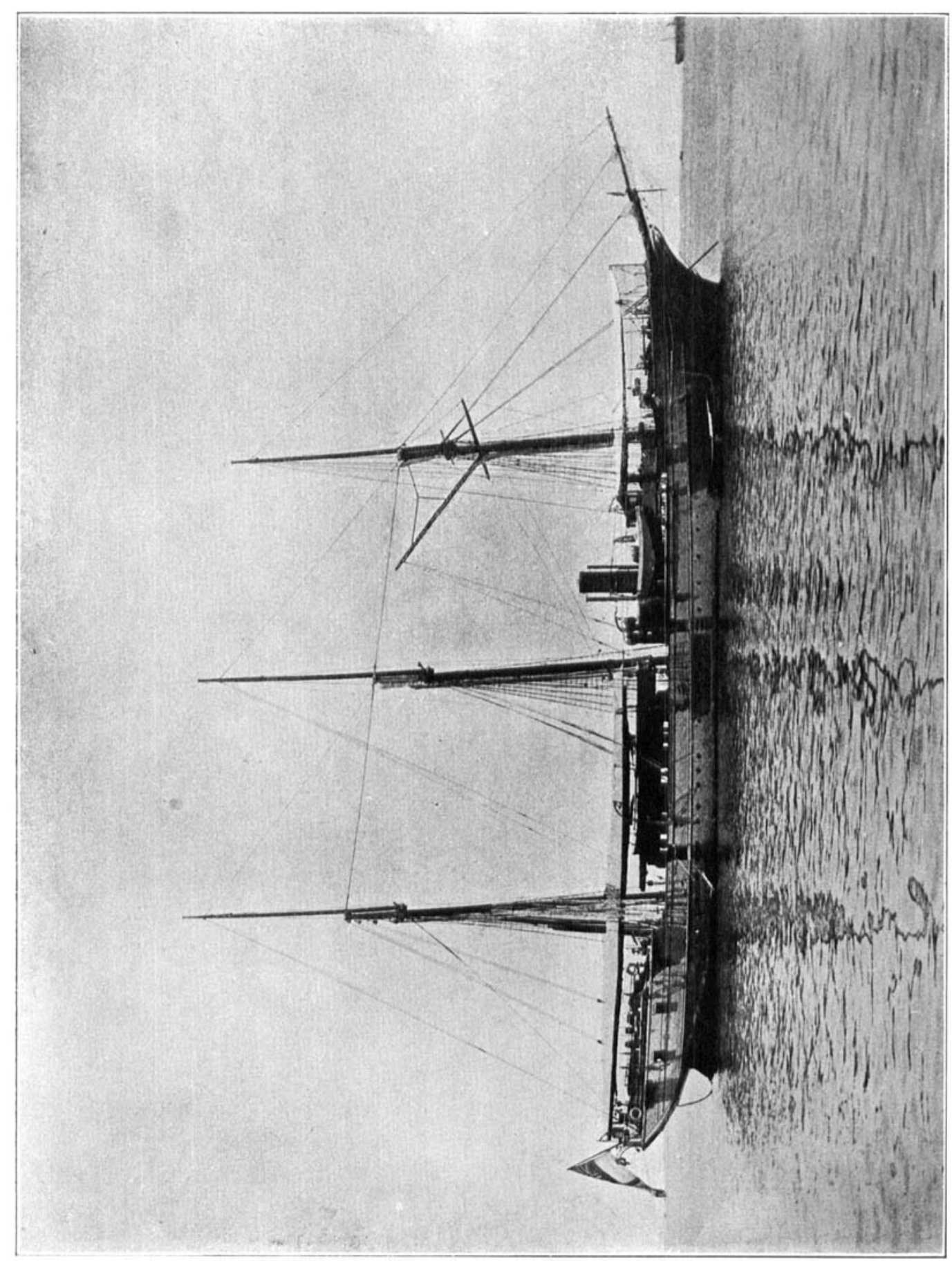

告 


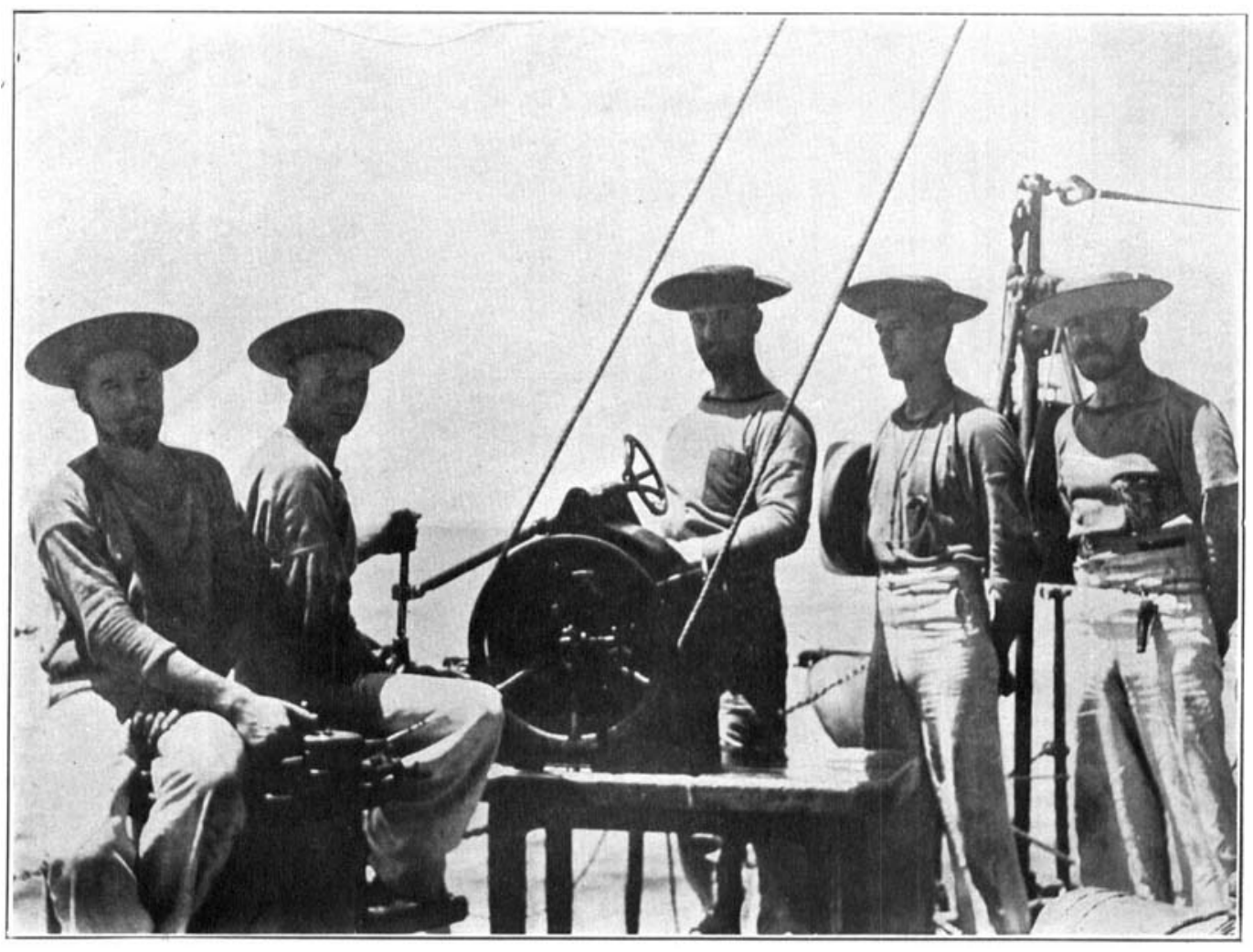

Fla. 1.-Andrews and Wise taking a deep sounding.

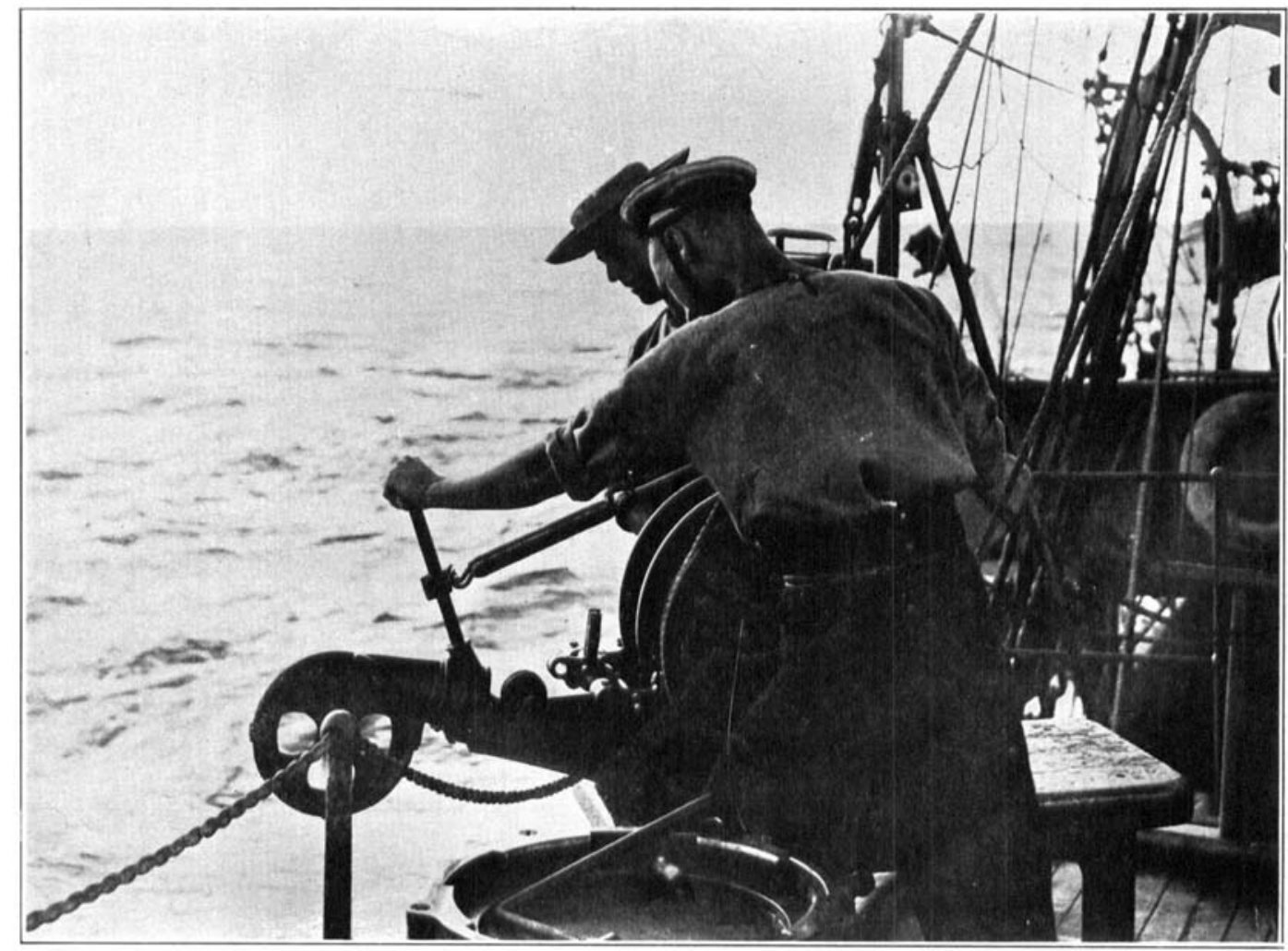

Fig. 2.-Webber, Andrews, Baily, Wise, and Williams: a soundingparty with the Lucas Machine.

SOUNDING ON H.M.S. SEALARK. 


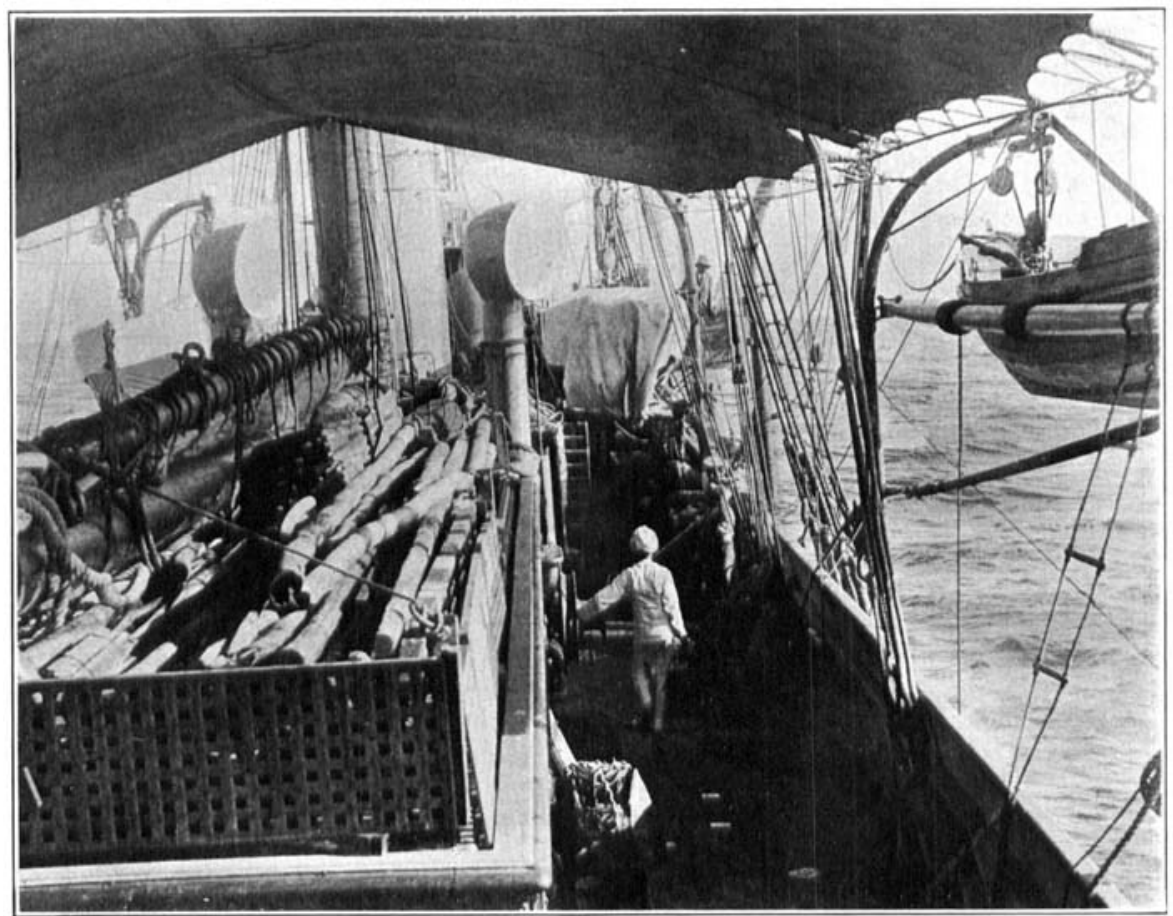

Fla. 1.-Looking forward along the starboard side during a sounding.
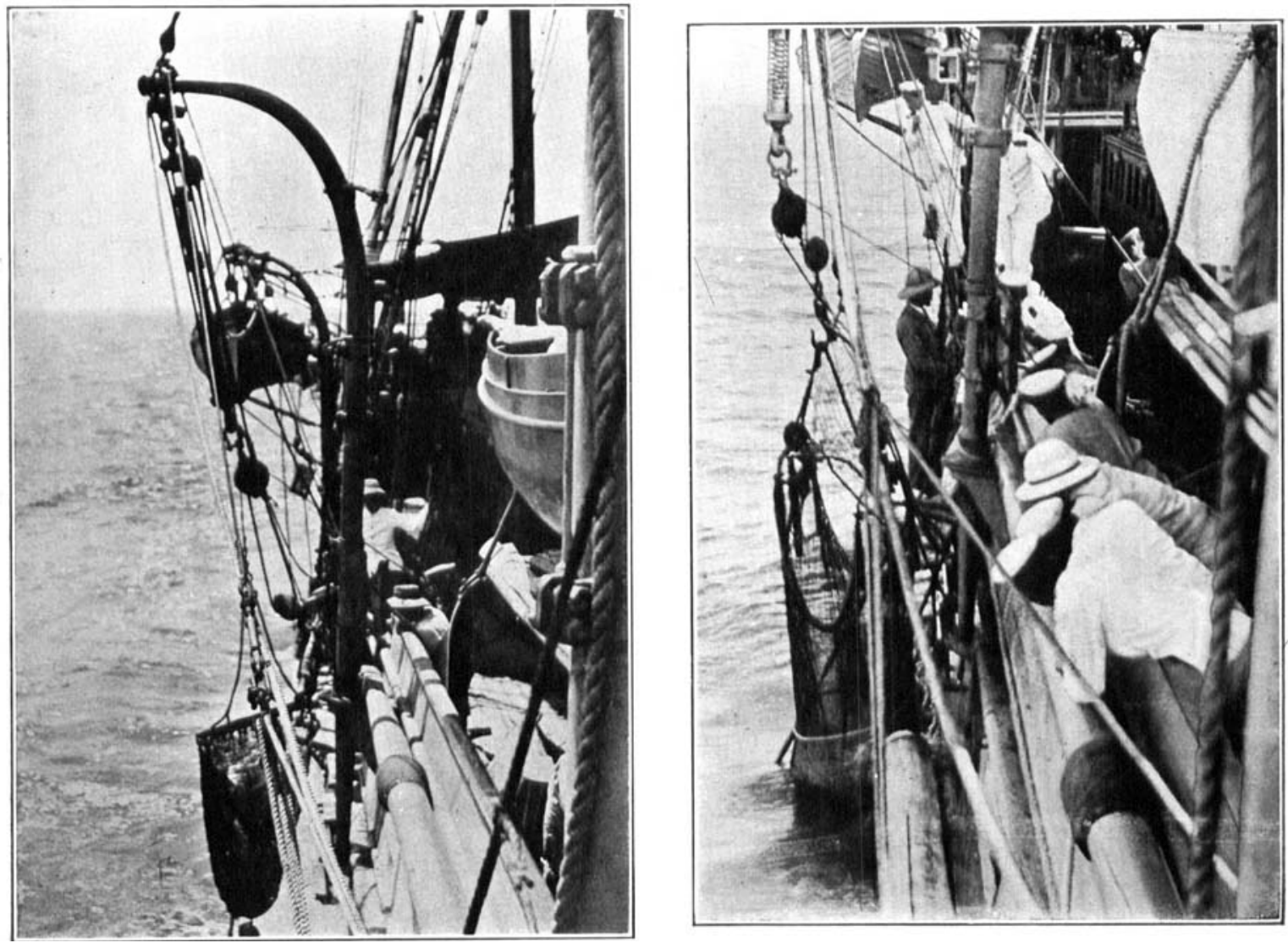

Fia. 2.-Rectangular dredge coming in. ;Fus. 3.-A big haul, trawl badly bent up. DREDGING ON H.M.S. SEALARK. 


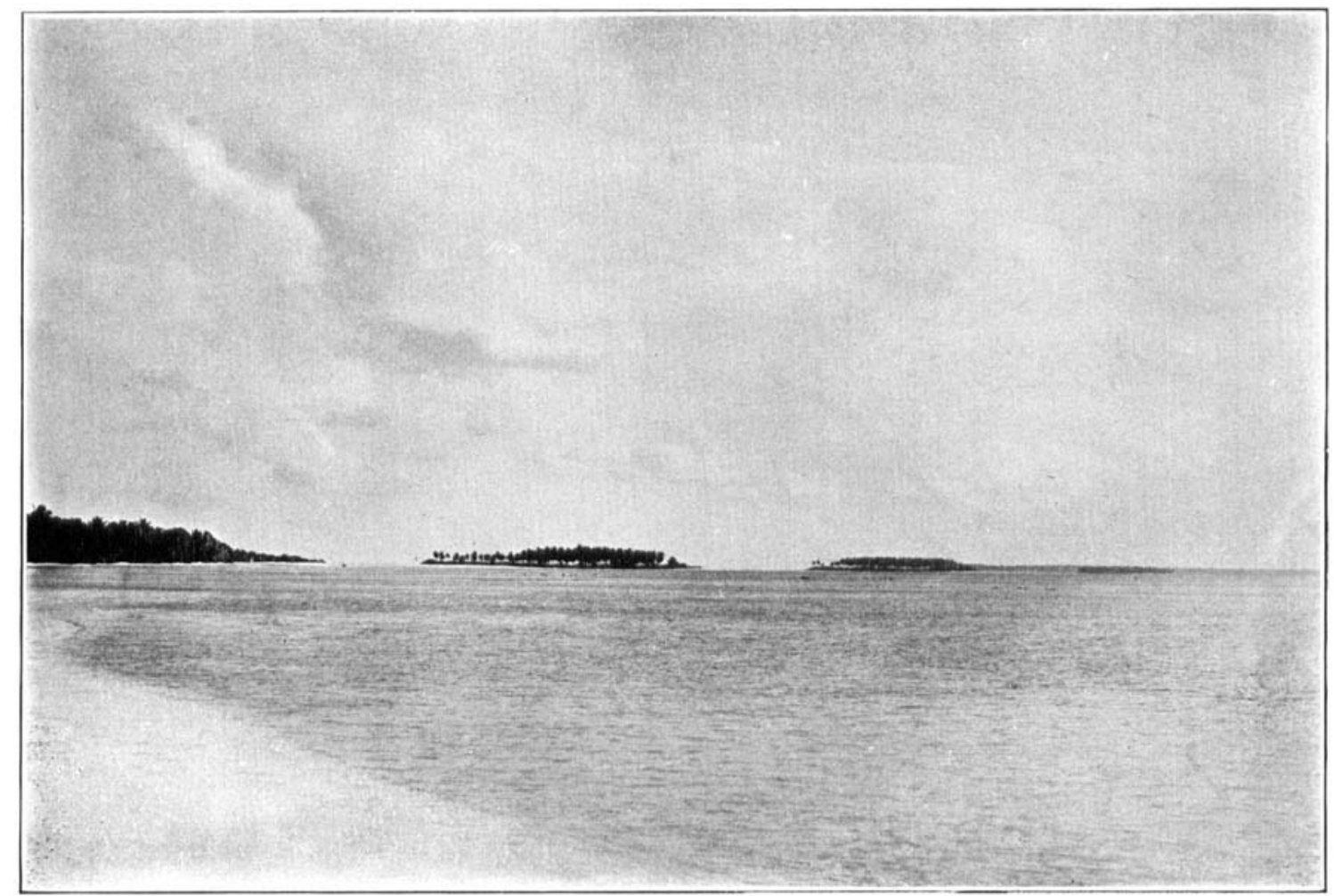

Fra. 1.-View from Takamaka across lagoon. Islands from left : Foquet, Sepulture, Iacobin, and Sel; with coral-masses exposed on lagoon. reefs at low tide.

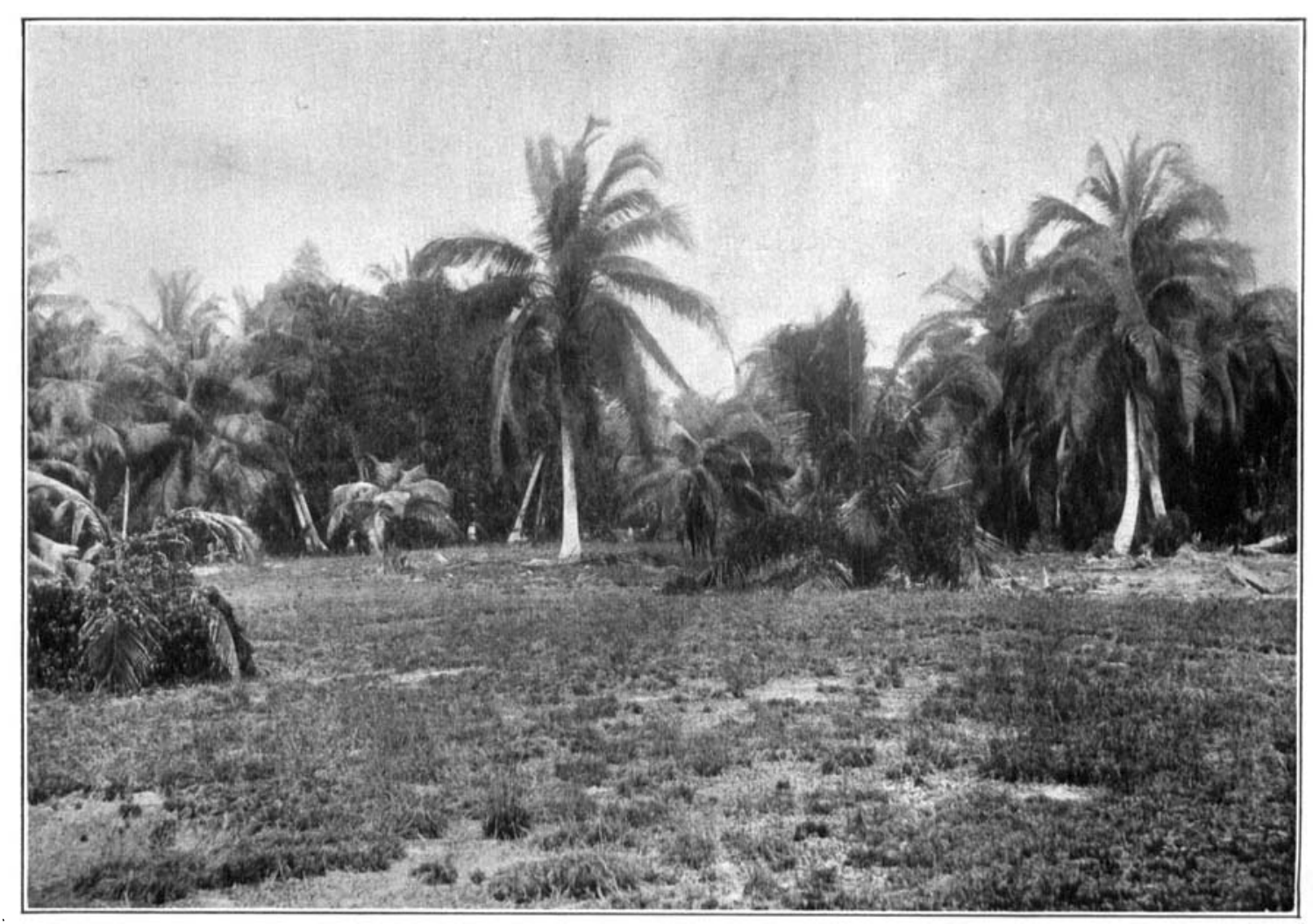

FIG. 2.-Typical dry sandstone-land on Anglaise with coconuts. 


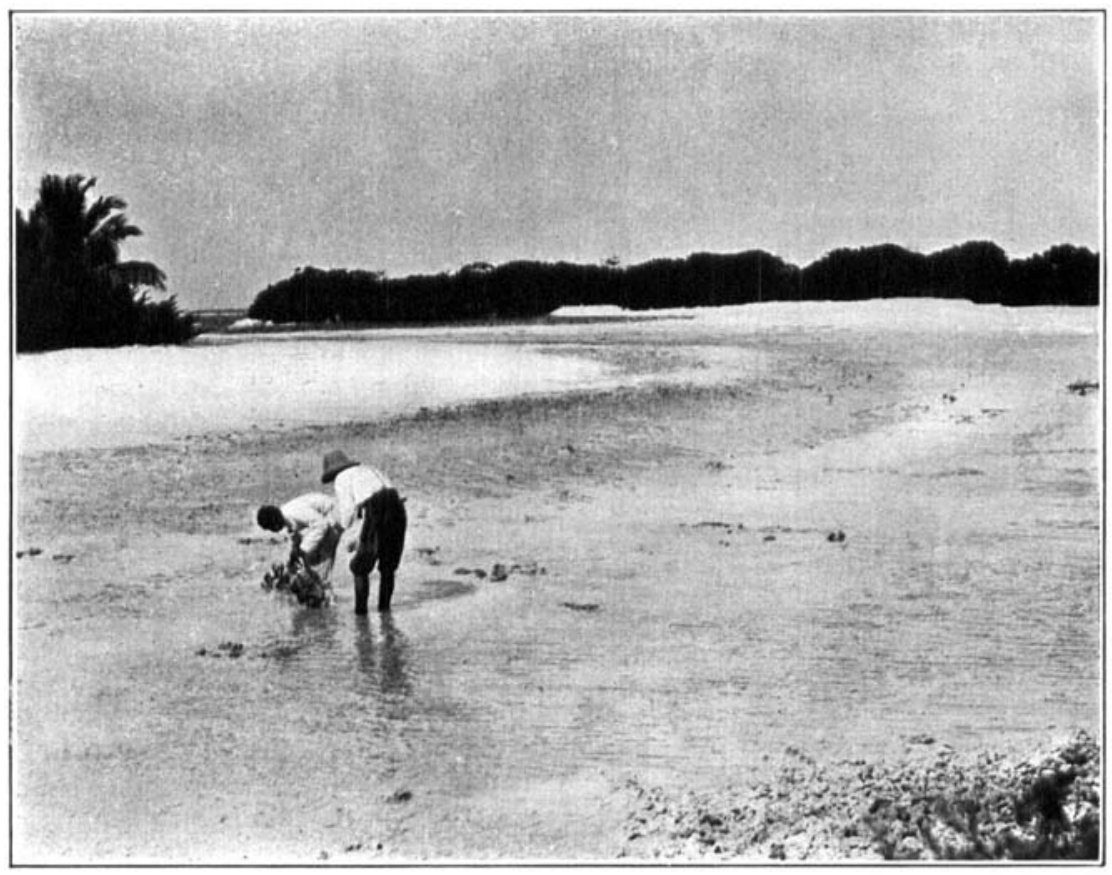

Fig. 1.-Reef looking seaward between Gabrielle (left) and Monpatre (right).

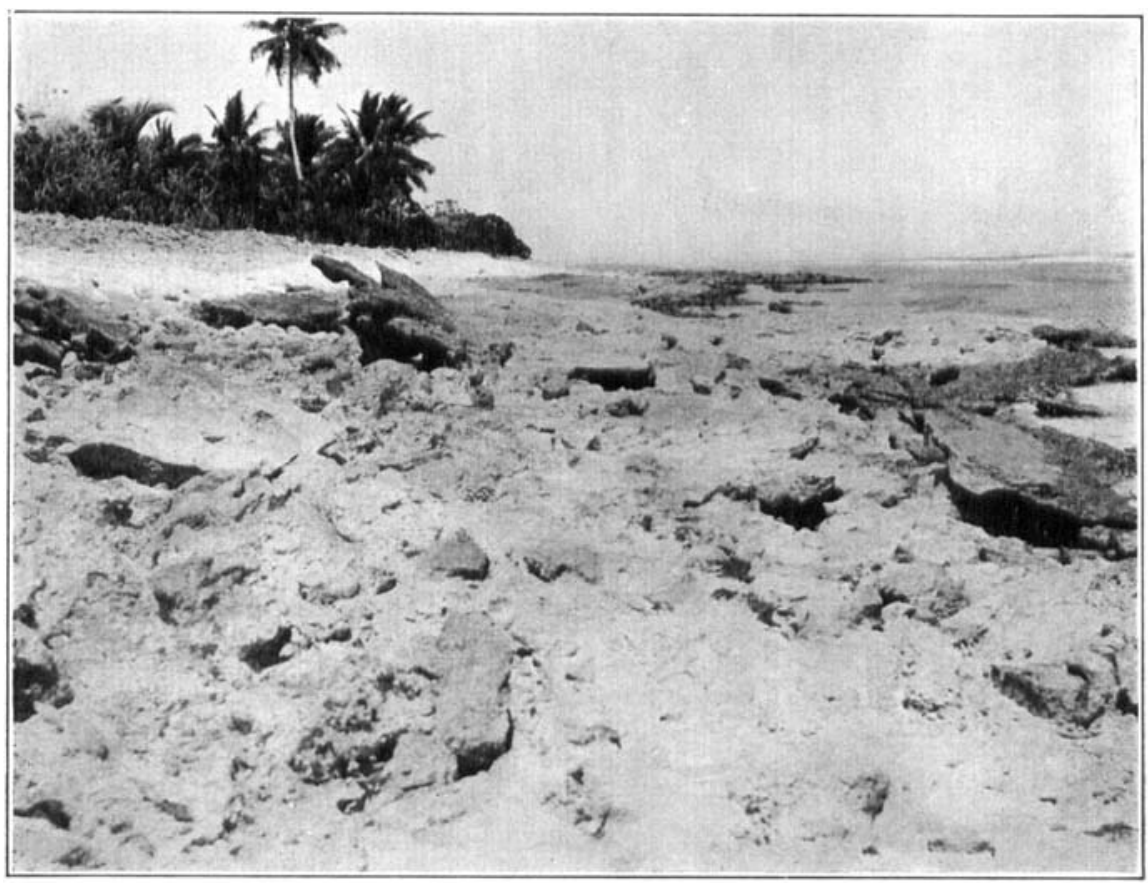

Fig. 2.-Coral-rock and seaward reef of Anglaise at low tide.

PEROS BANHOS ATOLL. 


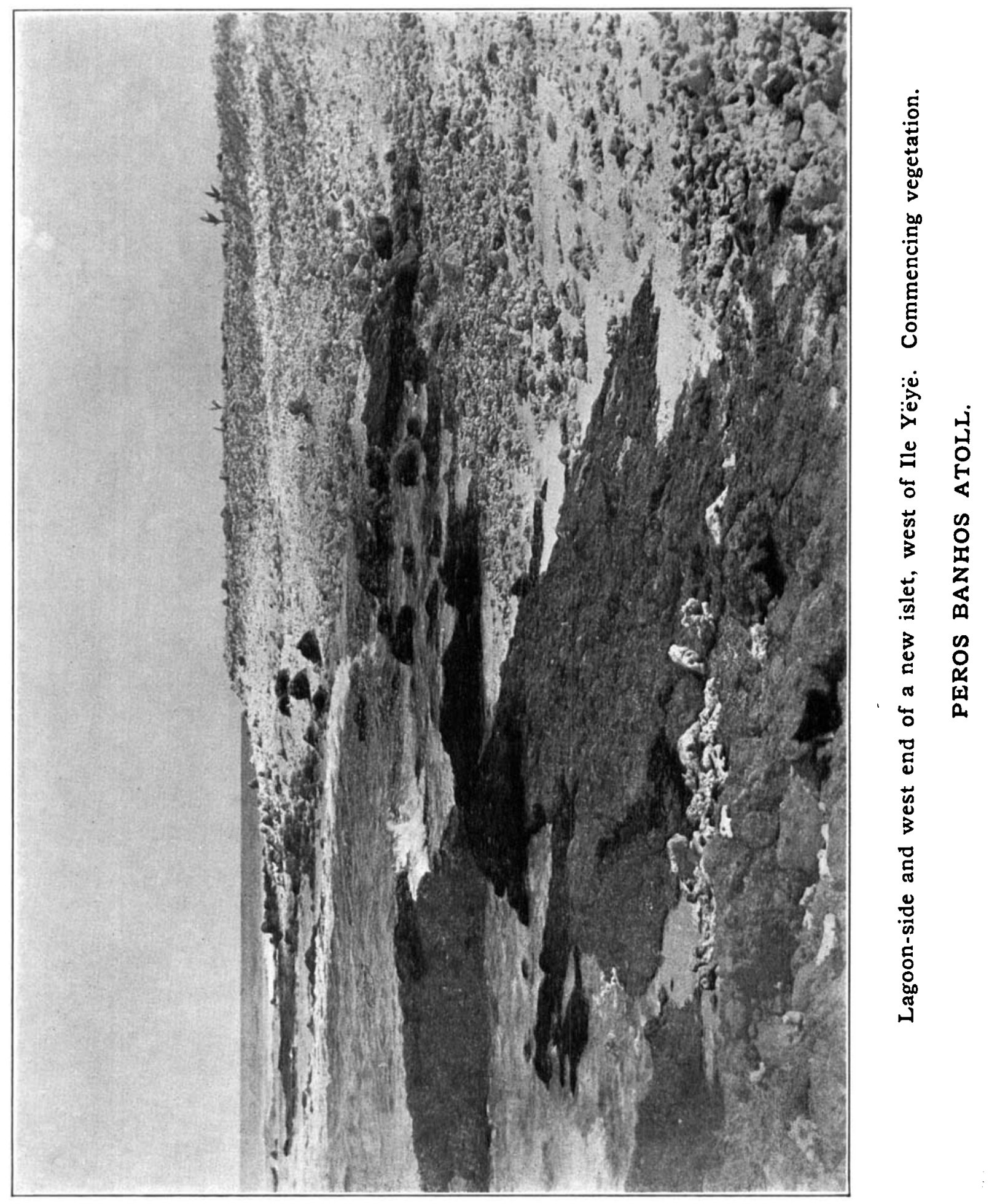




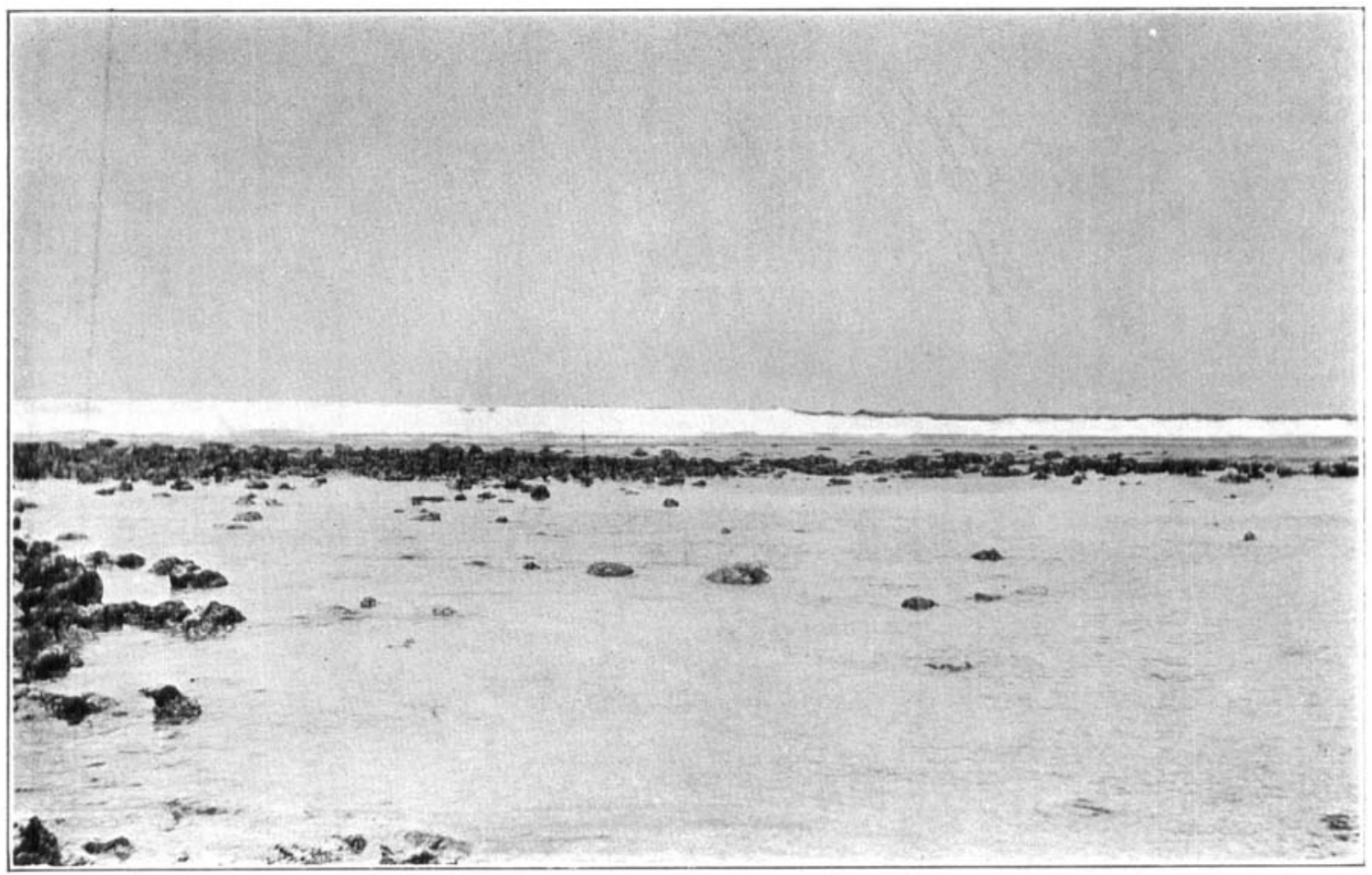

Fit. 1.-Reef of east side at low tide looking seaward. Note boulder-zone with inner and outer flats and line of breakers.

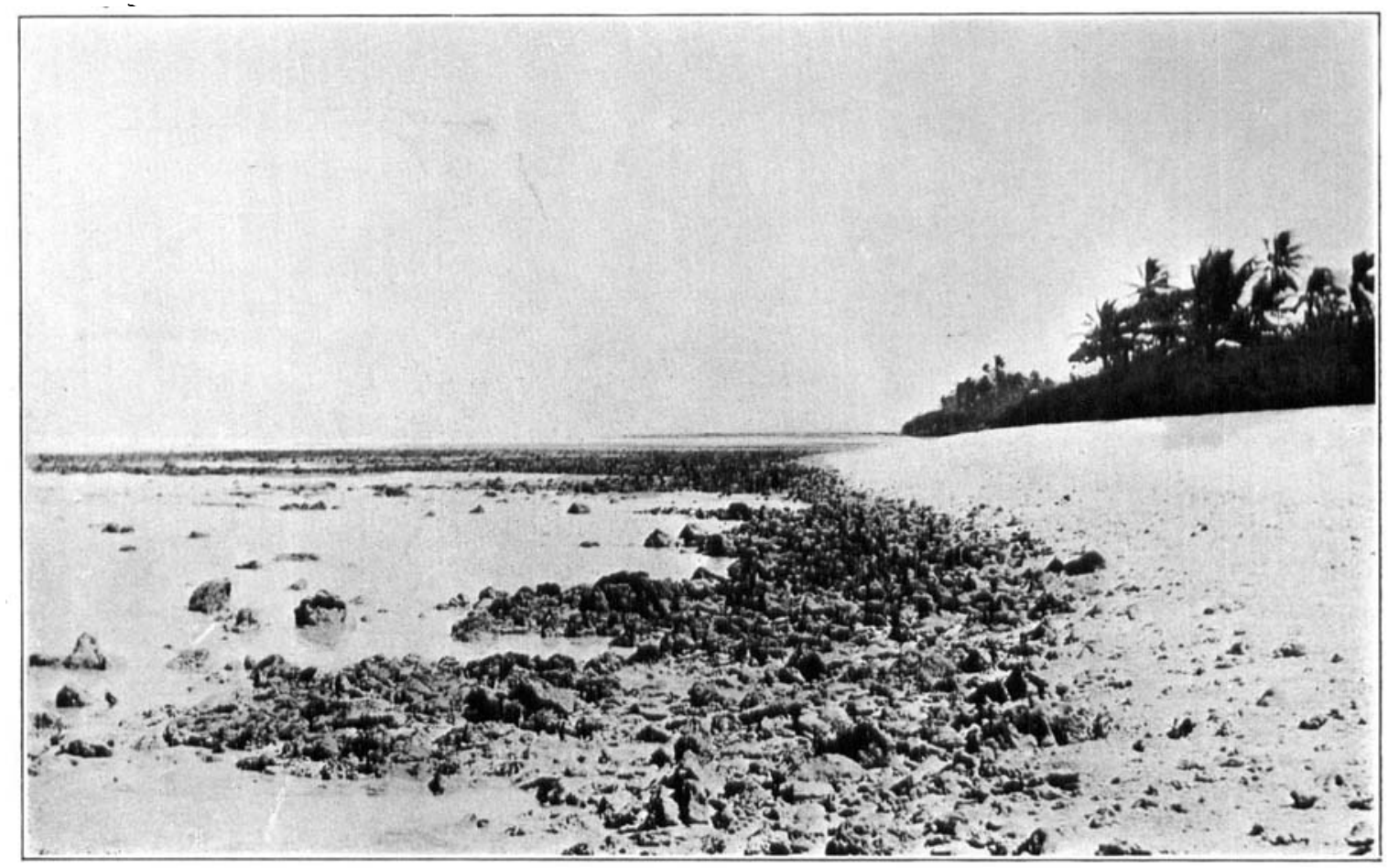

FIG. 2.-Shore and inner flat looking south (taken from same spot as Fig. 1).

DIEGO GARCIA ATOLL. 


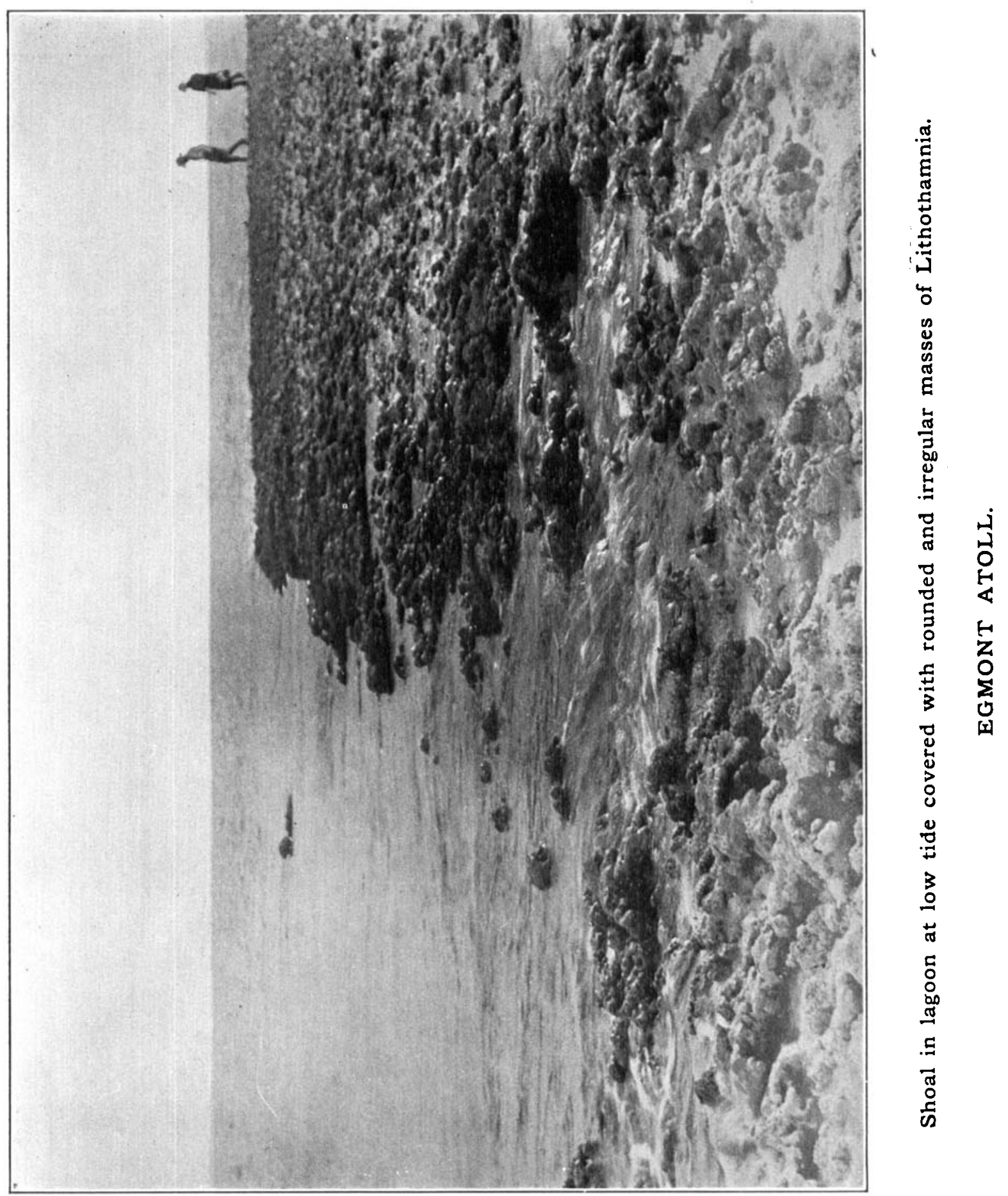




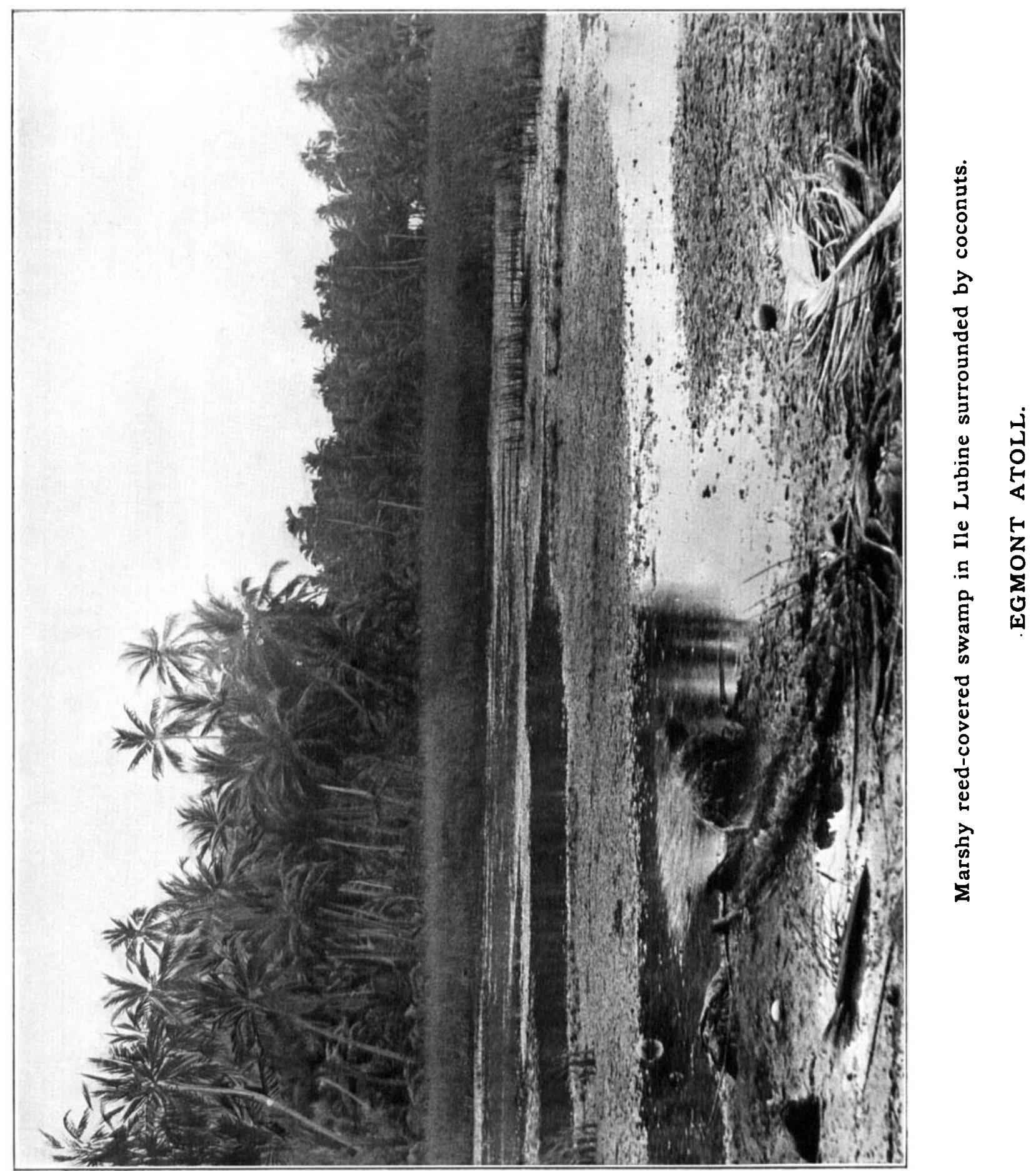

